Illinois State University

ISU ReD: Research and eData

Theses and Dissertations

$5-28-2014$

\title{
A comparative study of upper limb mechanical stress in the Pre- Colombian Tennessee River Valley
}

Deborah Lyn Neidich

Illinois State University, dlneidi@ilstu.edu

Follow this and additional works at: https://ir.library.illinoisstate.edu/etd

Part of the History of Art, Architecture, and Archaeology Commons

\section{Recommended Citation}

Neidich, Deborah Lyn, "A comparative study of upper limb mechanical stress in the Pre-Colombian Tennessee River Valley" (2014). Theses and Dissertations. 194.

https://ir.library.illinoisstate.edu/etd/194

This Thesis is brought to you for free and open access by ISU ReD: Research and eData. It has been accepted for inclusion in Theses and Dissertations by an authorized administrator of ISU ReD: Research and eData. For more information, please contact ISUReD@ilstu.edu. 


\title{
A COMPARATIVE STUDY OF MECHANICAL STRESS \\ IN THE PRE-COLUMBIAN TENNESSEE
}

\section{RIVER VALLEY}

\author{
Deborah L. Neidich
}

105 Pages

August 2014

This investigation establishes the presence of rotator cuff disease (RCD) within human skeletal samples from a prehistoric North American context and evaluates the subsistence based (hunter-gatherer an agricultural) differences of the pathological and non-pathological osseous reactive change. The skeletal sample as recovered as a part of an archaeological salvage project from the western Tennessee River Valley prior to the 1944 completion of the Kentucky Lake Dam. The sites consist of three Middle and Late Archaic (4500-1000 BCE) period hunter-gatherers and one Mississippian (1050-1450 CE) period agriculturalist sample. These sites are now submerged in the Kentucky Late Reservoir.

The bone elements of the rotator cuff which were examined were the humeral head, the lateral clavicle, and the acromion process of the scapula. Aspects of RCD evident on dry bone (enthesopathies, degenerative joint disease) and skeletal and entheseal robusticity were examined to provide an image of mechanical stress as possible behavior correlates within the region and between subsistence strategies. 
RCD was found to be ubiquitous in both the hunter-gatherer and agriculturalist samples. Examination between the subsistence strategies indicates that the Mississippian sample was subject to higher overall mechanical stress. Furthermore, the Mississippian sample had greater skeletal robusticity than the Archaic sample. Although both subsistence economies are labor intensive, there is more shoulder stressing behavior evident in the food-producers. 


\section{A COMPARATIVE STUDY OF MECHANICAL STRESS \\ IN THE PRE-COLUMBIAN TENNESSEE \\ RIVER VALLEY}

DEBORAH L. NEIDICH

A Thesis Submitted in Partial

Fulfillment of the Requirements

for the Degree of

MASTER OF SCIENCE

Department of Sociology and Anthropology

ILLINOIS STATE UNIVERSITY 
Copyright 2014 Deborah L. Neidich 


\section{A COMPARATIVE STUDY OF MECHANICAL STRESS \\ IN THE PRE-COLUMBIAN TENNESSEE \\ RIVER VALLEY}

DEBORAH L. NEIDICH

COMMITTEE MEMBERS:

Maria O. Smith, Chair

Fred H. Smith 


\section{ACKNOWLEDGMENTS}

With deepest gratitude I would like to thank all of those who helped make writing this thesis possible. I would first like to thank my advisor and thesis chair Dr. Maria O. Smith for her tireless efforts, advice, and insights, and without whom I would be huddled in a corner crying somewhere. Additionally, I would like to thank my other committee member Dr. Fred H. Smith for his unwavering support and guidance. Additionally, I owe much gratitude to Dr. Steven Juliano for helping me with my endless statistics questions.

Furthermore, I would like to thank the staff at the McClung Museum for access to their extensive osteological collections. I would also like to thank all of my peers at ISU and specifically my colleagues Elizabeth Wilk, Katherine Lacy, Sarah Caldwell and Sarah Boncal for providing an outlet for my stress and acting as a sounding board for ideas.

Finally, I would like to thank the people who are most important to me, my family. Ben, thank you for being my personal editor. And mom and dad, thank you for everything you have done for me over the past six years. Thank you for your support and love, without you none of this would have been possible.

D.L.N. 


\section{CONTENTS}

Page

ACKNOWLEDGMENTS

i.

$\begin{array}{ll}\text { CONTENTS } & \text { ii }\end{array}$

TABLES vi

FIGURES vii

CHAPTER

I. INTRODUCTION 1

Archaeological Investigation $\quad 2$

II. BACKGROUND 4

Archaeological Context 4

Shell Mound Archaic 4

The Middle Cumberland Mississippian $\quad 7$

Review of the Paleopathological and Medical Literature 9

$\begin{array}{ll}\text { The Rotator Cuff } & 11\end{array}$

Anatomy 11

The Humerus 12

The Scapula 13

$\begin{array}{ll}\text { The Clavicle } & 15\end{array}$

$\begin{array}{ll}\text { Rotator Cuff Disease } & 16\end{array}$

Entheseal Change Etiology $\quad 17$

Entheseal Change as an Indicator of Behavior $\quad 19$

Entheseal Rugosity 22

Degenerative Joint Disease Etiology 24 
Degenerative Joint Disease at the Acromioclavicular Joint

III. OSTEOLOGICAL SAMPLES

Archaic Sample

Eva (40BN12)

Cherry (40BN74)

Kays Landing (40HY13)

Mississippian Sample

Thompson Village (40HY5)

IV. METHODS

Age and Sex

Scoring Protocols

Entheseal Change

Entheseal Rugosity

Degenerative Joint Disease

Skeletal Robusticity

Statistical Methods

V. RESULTS

Site Demography

Eva

Cherry

Kays Landing

Osteological Change

Enthesopathies by Osteological Landmark

The Subscapularis

Eva

Cherry

Kays Landing 
Thompson Village $\quad 48$

Subsistence differences $\quad 48$

The Supraspinatus $\quad 49$

Eva $\quad 49$

Cherry $\quad 50$

Kays Landing $\quad 50$

Thompson Village $\quad 51$

Subsistence differences $\quad 51$

The Infraspinatus $\quad 52$

Eva $\quad 52$

Cherry $\quad 53$

Kays Landing $\quad 53$

Thompson Village $\quad 54$

Subsistence differences $\quad 54$

Teres Minor Rugosity $\quad 55$

Eva $\quad 55$

Cherry $\quad 56$

Kays Landing $\quad 57$

Thompson Village $\quad 58$

Subsistence differences $\quad 59$

Acromioclavicular Degenerative Joint Disease 60

$\begin{array}{ll}\text { The Clavicular Articular Facet } & 61\end{array}$

Eva $\quad 61$

Cherry $\quad 63$

Kays Landing $\quad 63$

Thompson Village $\quad 63$

Subsistence differences $\quad 64$

The Acromial Articular Facet of the Clavicle 65

Eva $\quad 65$

Cherry 66

Kays Landing $\quad 67$

Thompson Village $\quad 68$

Subsistence differences $\quad 68$

$\begin{array}{ll}\text { Skeletal Robusticity } & 70\end{array}$ 
Kays Landing $\quad 70$

Thompson Village $\quad 71$

$\begin{array}{ll}\text { Subsistence differences } & 72\end{array}$

$\begin{array}{lll}\text { VI. DISCUSSION } & 73\end{array}$

$\begin{array}{ll}\text { Intra-site Differences } & 74\end{array}$

$\begin{array}{ll}\text { Eva } & 74\end{array}$

Cherry $\quad 75$

Kays Landing $\quad 76$

Thompson Village $\quad 78$

Patterns of Rotator Cuff Disease $\quad 79$

Entheseal Change at the Rotator Cuff 79

Degenerative Joint Disease of the

Acromioclavicular Joint $\quad 80$

Skeletal Robusticity $\quad 81$

Subsistence- based Differences in Mechanical Stress 81

Entheseal Change at the Rotator Cuff 82

Degenerative Joint Disease of the

Acromioclavicular Joint $\quad 84$

Skeletal Robusticity $\quad 88$

$\begin{array}{llr}\text { VII. CONCLUSIONS } & 89\end{array}$

$\begin{array}{ll}\text { REFERENCES } & 91\end{array}$

APPENDIX A: Demographics for Entheseal Change by Site 101

APPENDIX B: Demographics for Entheseal Change by Period 104 


\section{TABLES}

Table

1. Criteria Assessed for Entheseal Change

2. Scoring Protocol for Teres Minor Rugosity

3. Criteria for Scoring DJD 38

4. Age Distribution of Sites 41

5. Age Cohort Demographics by Period 44

6. Total Humeri by Site with Entheseal Change 47

7. Total Humeri by Period with Entheseal Change 49

8. Humeri with Rugose Teres Minor Insertions by Site 56

9. Humeri with Rugose (I and F) Teres Minor Insertions by Period 59

10. Fishers Exact Scores Comparing Teres Minor Rugosity Presence $(\mathrm{N}$ versus $\mathrm{I}$ and $\mathrm{F}$ )

11. Fishers Exact Scores Comparing Teres Minor Rugosity Development ( $\mathrm{N}$ versus I versus $\mathrm{F}$ )

12. Clavicular Facets with DJD by Site

13. Clavicular Facets with DJD by Period

14. Acromial Facets with DJD by Site

15. Acromial Facets with DJD by Period

16. Mean Robusticity at Kays Landing 


\section{FIGURES}

Figure

Page

1. Map of the Tennessee River Valley 6

2. The Four Muscle Attachment Sites of the Rotator Cuff: Subscapularis (blue), Supraspinatus (green), Infraspinatus (red), Teres Minor (black) (Curtis et al., 2006)

3. Left Scapula with Intact Acromion Process

4. Inferior Aspect of Left and Right Clavicles

5. Entheseal Change at the Subscapularis, Supraspinatus and Infraspinatus

6. Rugose Teres Minor Insertion

7. a) Arthritic Pitting at the Glenoid of the Scapula b) Eburnation on the Distal Humerus

8. Degeneration of the Acromioclavicular Joint

a) Severe Degeneration at the Clavicular Articular Facet of the Scapula b) Severe Degeneration at the Acromial Articular

Facet of the Clavicle

9. Sample Sex Distribution by Site

10. Sex Distribution by Period 


\section{CHAPTER I}

\section{INTRODUCTION}

Over the past several decades reactive changes at muscle insertions (enthesopathies) and at joints (degenerative joint disease) have been used to estimate mechanical stresses endured by past peoples (Alves Cardoso and Henderson, 2010, 2013; Armelagos et al., 1991; Auerbach and Raxter, 2008; Bass, 1987; Blakely, 1995; Boulle, 2001; Boyd, 1996; Boyd and Boyd 1989, 1991; Bridges 1985, 1989; Bridges et al., 2000; Chamay and Tschantz, 1972; Cook, 1979; Dutour, 1986; Goodman, 199; Hawkey and Merbs, 1995; Henderson, 2012, 2013a, 2013b; Jurmain, 1999; Jurmain et al., 2012; Kackia et al., 2011; Kennedy, 1989; Knüsel, 2000; Larsen, 1995, 1997, 2000, 2002; McClain, 2013; Merbs, 1983; Milella et al., 2012; Miles, 1994, 1996, 1999, 2000; Molnar, 2006; Molnar et al., 2011; Mummert et al., 201; Myazaka and Pointek, 2011; Niimimäki 2012; Oygucu et al., 1998; Powell, 1988; Roberts et al, 2007; Rogers, 2000; Stirland, 1996; Trinkaus, 1975; Villotte et al., 2010; Villotte and Knüsel, 2012; Waldron, 2007, 2012; Weiss 2004, 2007). These markers, consisting of both traumatic and nontraumatic reactive changes to bone surfaces, are a result of continuous postures and repetitive physical movements. This study proposes a comparative investigation of various components of Rotator Cuff Disease, and its associated motions in several samples from the Shell Mound Archaic ( 4500-1000 BCE) and Middle Cumberland 
Mississippian (900-1600CE) from the Tennessee River Valley. There is archaeological consensus concerning fundamental subsistence-settlement differences between the peoples of $\mathrm{t}$ prehistoric western Tennessee (e.g. Lewis and Kneberg, 1947). It is predicted that differential muscle use between hunting and gathering peoples and agriculturalists will yield modifications to entheses as well as other signs of musculoskeletal stress including trauma, degeneration, and the skeletal robusticity. In this study the examination of the skeletal elements of the rotator cuff (humerus, clavicle, and scapula) will be used as a proxy for overall mechanical stress in both Archaic and Mississippian contexts.

\section{Archaeological Investigation}

Long term in situ cultural development in the prehistoric Tennessee River Valley suggests population stability within the region as opposed to demographic disruption (e.g. migration, emigration) (Boyd and Boyd 1989). Therefore, any skeletal morphological changes are probably less likely to be the result of population replacements, and more likely to be the consequence of activity-related changes with a shift in subsistence (Boyd and Boyd 1989). This is the focus of the present study.

The earliest investigation of mound sites in the Tennessee Valleywas carried out by Cyrus Thomas (1894). Later excavations, starting in 1933, were carried out as part of a recovery project to prevent the destruction of prehistoric cultural materials by flooding after the completion of multiple dams within the American Southeast (Lyon, 1996; Pritchard and Ahlman, 2009; Smith, 2006). The dam projects were part of the Works Progress Administration (WPA) program instituted by Franklin D. Roosevelt during the Great Depression ("The New Deal") for flood control and TVA (Tennessee Valley Authority) to electrify the southeast (Hawley and Dye, 2011; Lyon, 1996; Pritchard and 
Ahlman, 2009). The sites examined in this study from upper west-central Tennessee and were excavated between 1935 and 1942 preceding the completion of the Kentucky Lake dam. The four sites utilized generated three hunter-gatherer samples and one agriculturalist sample. The excavations in the Kentucky Lake reservoir were under the auspices of the TVA and directed by Thomas Lewis, in association with the University of Tennessee. Madeline Kneberg was in charge of lab analysis (Lyon, 1996; Pritchard and Ahlman, 2009). The remains of all of the sites utilized in this study are currently Prior osteological investigations in the region include general demographic data (Lewis and Kneberg; 1961), violent trauma (Keuman-Drews, 2000), disease (Smith, 2006), dental anomalies (Smith and Wojcinski, 2011), and robusticity (Boyd and Boyd, 1989). The hunter-gatherer samples have often been used as contrasts to late prehistoric agriculturalist samples from east Tennessee. 


\section{CHAPTER II}

\section{BACKGROUND}

\section{Archaeological Context}

\section{Shell Mound Archaic}

The three hunter-gatherer site samples used in this study, Eva (40BN12), Cherry (40BN74) and Kays Landing (40HY13) are located along the main channel of the Tennessee River in what is now the Kentucky Lake Reservoir (Figure 1). Early settlement of the region was defined by these highly mobile groups (Bowen, 1975, 1977; Lewis and Kneberg 1947, Lewis and Lewis, 1961). These sites are associated with a cultural horizon known as the Shell Mound Archaic (Anderson 2004; Brown 1985; Marquardt, 2010; Marquardt and Watson, 1983; Morse, 1969; Peacock et al., 2010; Phillips and Brown 2009; Price, 1985; Sassaman, 2004).

This way of life presumably post-dates the Early Archaic (ca. 8000-6000 BCE). The onset of the Hypsithermal Warming Event in the mid-Holocene (ca. 7000-3000 BCE) (Marquardt; 2010; Lewis and Kneberg, 1959; Peacock, 2000; Pritchard, 2009) led to the adoption of more sedentary living patterns during the Middle (ca. 6000-4500 BCE) and Late Archaic (ca. 4500-1000 BCE). It is believed that reliable and predictable resources allowed for longer settlement periods. During this period people were identified as were limnomobile settlers; meaning, they lived in large settlement during plentiful 
months (Spring through fall). But, as resources became scarcer, groups would break into small winter camps to ensure maximum survival (Bowen 1975, 1977; Bridges, 1989; Larsen et al., 2000). The limnomobile hypothesis of settlement suggests that an abundance of wetland resources during warmer months provided sufficient resources to support aggregate living. However, fluctuations in resource availability during cooler months may have caused peoples to move elsewhere (Larsen, 2000). Evidence suggests that the climate change at the onset of the Middle Archaic provided a more stable environment for longer term settlement; patterns; but with shifting resource availability by the Late Archaic (Franklin, 1994), people once again took up more mobile settlement patterns suggesting that they were not engaged in intensive agricultural practices (Lewis and Lewis, 1961; Nance, 1987).

During the Hypsithermal there was evidently intensive exploitation of riverine bivalves. Mussels and other mollusks are high in nutrients; however, they provide little meat and are a poor source of calories unless consumed in large quantities (Klippel and Morey, 1986). This, in conjunction with widespread consumption of riverine resources, allowed for mass accumulation of bivalve refuse (Bridges, 1989; Charles and Buikstra, 1983; Emerson et al., 2009; Jefferies et al., 2005; Kidder, 2006; Peacock, 2000). Which inspired the name of this period; Shell Mound Archaic. 


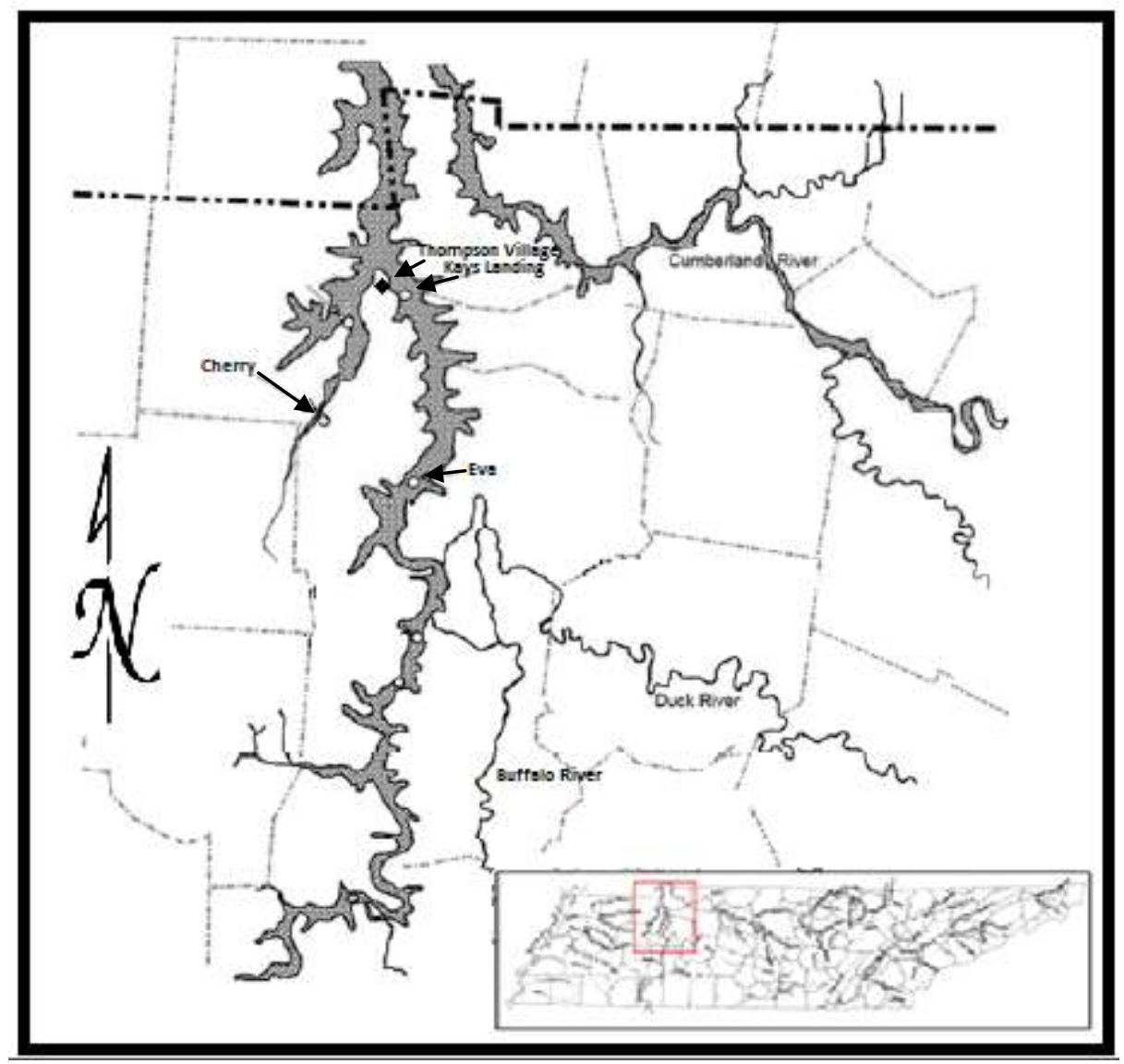

Figure 1. Map of the Tennessee River Valley

Accumulations of riverine and marine bivalves identified as mounds, circles and middens associated with Middle to Late Archaic Period ( 4500-1000 BCE) of the Southeastern United States have been assigned many meanings over the years (Emerson et al., 2009; Jefferies et al., 2005; Lewis and Kneberg 1961; Peacock, 2000). They have primarily been identified as sites of food refuse from hunting and gathering peoples, including functional uses (e.g., cooking areas, storage areas, domiciles) with secondary socio-cultural roles (e.g., mortuary) (Lewis and Kneberg, 1961; Marquardt, 2010; Peacock, 2000).

The diet in the Middle and Late Archaic was certainly not exclusively dependent on shellfish. Other riverine resources include fish and nut-centered plant foods (Boyd and 
Boyd 1989). The use of small grains and fleshy fruits are rare in Tennessee until the late Late Archaic and Early Woodland period transition at about 4500 BP (Boyd and Boyd, 1989). And by 1200 BCE some evidence suggests the early presence of Mesoamerican crops (i.e. maize) in the Tennessee River Valley (Boyd and Boyd, 1989; Nance, 1987). The Middle Cumberland Mississippian

The Mississippian site utilized in this study, is associated with the Middle Cumberland culture (Fergisun, 1972; Jolley, 1983) (1050-1450 CE) and is defined by unique mortuary, artistic and ceramic styles. An interment form, known as stone box burials are a common mortuary form observed in Tennessean Mississippian burial sites (Boyd and Boyd, 1989, 1991; Dowd, 2008; Fergisun, 1972; Jolley, 1983)These interments, are defined by a limestone stone slab formation around a corpse which is shaped to fit the body of the individual interred (Bass, 1985; Dowd, 2008).

At the onset of the Mississippian period (ca.900 CE), small semi-sedentary family groups transitioned to giant city centers like Cahokia; population and life expectancy increased while culture flourished(Emerson and Lewis, 1999; Fowler, 1997, Pauketat, 2005). Population growth coupled with the newly aggregated way of life allowed for occupational diversification which in turn led to increased cultural complexity (Bass, 1985; Cook, 1979; Eshed, 2012; Mummert et al., 2011). This shift allowed for the development of material culture as well as a dramatic change in social organization. The introduction of crop cultivation also allowed for the assumption of sexual divisions of labor that became common in most Mississippian communities (Emerson, 2012).

The Mississippian period is hallmarked by its monumental earthworks, these monuments varied in range and diversity in size, shape and use throughout the cultural 
sphere (Bass, 1985; Bense, 1994; Blakely, 1980, 1995; Boyd and Boyd, 1989; Bridges, 1989; Brown, 1985; Pauketat, 2005; Powell, 1988). Mississippian earthworks functioned variably as symbols of social stratification, cultural and religious centers, as well as burial sites (Bridges, 1989; Bridges et al., 2000; Lukacs, 2008; Powell, 1988). These mounds have become a testament to the complexity of the era, as they have not only spiritual but socio-political meaning.

Socially stratified societies, including many Mississippian chiefdoms institute differential access of goods and services which become manifest in the archaeological record. Certain burial contexts (i.e. mound internment, exotic grave goods) may reflect hierarchical political organization or social role diversity (e.g. ceremonial religious) in a stratified society (Bass, 1985; Blakely, 1980, 1995; Blakely and Beck, 1981; Powell, 1988).

There is evidence that the Eastern Agricultural Complex (cultivation of oily and starchy seeds) was in place in the Middle Cumberland Region of Tennessee by the Early Woodland suggesting that crop cultivation was common in Tennessee by the Mississippian era in which maize agriculture became a dietary staple (Boyd and Boyd, 1989; Nance, 1987). Local resources such as deer, birds and fish were exploited along with cultivated foods signifying an atypically diverse diet for the period and helped mitigate some of the negative health consequences associated with agricultural adoption (Boyd and Boyd, 1989).

Osteological, material, and ethnographic evidence indicate a sexual division of labor within Mississippian society (Bridges, 1989; Bridges et al., 2000; Lukacs, 2008; Powell, 1988). Ethnographic data, based on studies of North American peoples 
indigenous to the southeast, states that women were responsible for the majority of the agricultural duties including crop tending, and food processing (Bartram, [1791]1980: Hudson, 1976). Male roles in agriculture generally included clearing fields, planting, and harvesting (Bridges, 1989; Bridges et al., 2000; Hudson, 1976: Lukacs, 2008).

\section{Review of the Paleopathological and Medical Literature}

As noted in Wolff's Law (Wolff, [1892], 1982), bone is an extremely plastic structure; it easily reacts to both external (e.g., habitual postures) and internal forces (e.g. disease or infection), which could cause permanent or semi-permanent traces on the cortical surface (Ruff et al., 2006). Changes to bone dimensions and strength induced by compressive or tensile forces of connective tissues and neighboring bones and may be indicative of daily activity (microtrauma), disease, and acute traumatic events (AlvesCardoso and Henderson, 2010; Boulle, 2001; Bridges, 1989; Bridges et al., 2000; Crubézy et al., 2002; Eshed et al., 2004; Kannus et al., 1995; Kennedy, 1989; Lai and Lovell, 1994; Larsen,1995; Lukacs, 2008; Jurmain et al., 2012; Powell, 1988). These markers, all signs of continuous, repetitive, or traumatic stress, are seen as degenerative in nature although many of them have multifactorial etiologies.

Bioarchaeologists have long used bone reactive changes, in the form of degenerative joint disease (also labeled osteoarthritis), entheseal change (formerly musculoskeletal stress markers[MSM]), and skeletal robusticity, to estimate activity and behavior (Alves-Cardoso and Henderson, 2010; Boulle, 2001; Bridges, 1989; Bridges et al., 2000; Crubézy et al., 2002; Eshed et al., 2004; Lai and Lovell, 1992; Larsen,1995; Lukacs, 2008; Jurmain et al., 2012; Kennedy, 1989; Oygucu et al., 1998; Pearson, 2000;

Powell, 1988;Rogers et al., 1986; Rogers et al., 2004; Ruff, 2000; Ruff and Hayes, 1983; 
Ruff et al., 2006; Trinkaus, 1975). These studies have all been integral in the discussion or establishment of methodologies and interpretation of skeletal remains.

Subsistence has often been linked to community health status (e.g. Armelagos and Cohen, 1984; Armelagos et al., 1991; Eshed et al., 2010; Larsen, 1995, Larsen et al., 2002; Ruff and Hayes, 1983; Ruff et al., 2012). Isotopic analysis along with paleobotanical research has concluded that pre-agricultural people often had more diverse, nutritionally complex diets than those engaging in agriculture (Schoeninger, 2009). Archaic peoples relied on a wide variety of dietary resources including berries, nuts, mollusks, and other local wildlife; conversely, the Mississippian diet relied heavily on nutritionally poor cultigens (Mummert et al., 2001; Larsen, 1995; Larsen et al., 2002). The differences in food procurement and processing, activity, health, and diet between these two periods are expected to yield differential mechanical stress markings on the bones of the rotator cuff. By examining particular entheseal locations on these bones, another link between subsistence and subsistence behaviors may me forged.

Many of the skeletal changes on muscle insertions (enthesopathies) and joint surface (degenerative joint disease) under investigation have been bioarchaeologically observed and etiologically associated with time spent with long term repetitive behavior (Alves-Cardoso and Henderson, 2010; Crubézy et al., 2002; Davis et. al., 2012; Jurmain et al., 2012; Kannus et al., 1995; Kennedy, 1989; Lai and Lovell, 1994; Villotte et al., 2010; Weiss, 2004, 2007). Unfortunately, as cause, kind, and severity of these changes are actually multifactorial, great care must be taken in the assessment of reactive change, including determining a threshold of pathology (Crubézy et al., 2002; Nolte and Wilczak, 2013; Niinimäki, 2011; Niinimäki and Sotos, 2013; Woo and Pak, 2013). 
Age is generally considered to be a factor in all forms of osteological change. Muscle insertion footprints delineate at puberty and joint, bone and tissue degeneration are associated with old age (Alves-Cardoso and Henderson , 2010; Auerbach and Raxter, 2008; Bass, 1987; Benjamin, 2006; Benjamin and Mcgonagle, 2001; Crubézy et al., 2002; Davis et. al., 2012; Jurmain et al. 2012; Kannnus et al., 1995; Kennedy, 1989; Mall et al., 2013; Niinimäki, 2011; Niinimäki et al., 2013; Ruff et al., 2006; Schwartz, 1995; Stock and Shaw, 2007; Villotte et al., 2010; Weiss, 2004, 2007; Woo and Pak, 2013). Interestingly, clinical research has shown that skeletal changes that occur in adults are affected by the amount of mechanical stress endured prior to puberty (Kannus et al., 1995). The fact that musculoskeletal stress is continuous makes age-dependant diagnostics difficult unless well-defined age boundaries are established.

\section{The Rotator Cuff}

The rotator cuff is comprised of three bones: the humerus, scapula and clavicle as well as four muscles: the supraspinatus, the infraspinatus, teres minor, and subscapularis. The rotator cuff stabilizes the shoulder (glenohumeral) joint and the muscles are responsible for arm movement. The associated joints of the rotator cuff include the glenohumeral joint and acromioclavicular joint and the sternoclavicular joint (Culham and Peat, 1993: Curtis et al., 2006).

\section{Anatomy}

The shoulder is the most mobile joint of the body because it only connects to the thorax at a single point. The range of motion and the function as a joint stabilizer makes the structure prone to stress and injury. Comprehending the anatomy of the rotator cuff is essential to understand the physiological origins of degenerative change. 


\section{The Humerus}

The humerus is the largest long bone of the upper limb and articulates proximally with the glenoid fossa of the scapula and distally with the radius and ulna. The proximal epiphysis coalesces around five years of age and begins fusion with the shaft around the twentieth year, finishing at around the age of twenty-five years. Distal epiphyses fusion to the humeral shaft begins at around the age of seventeen (Bass, 1987; Schwartz, 1995).

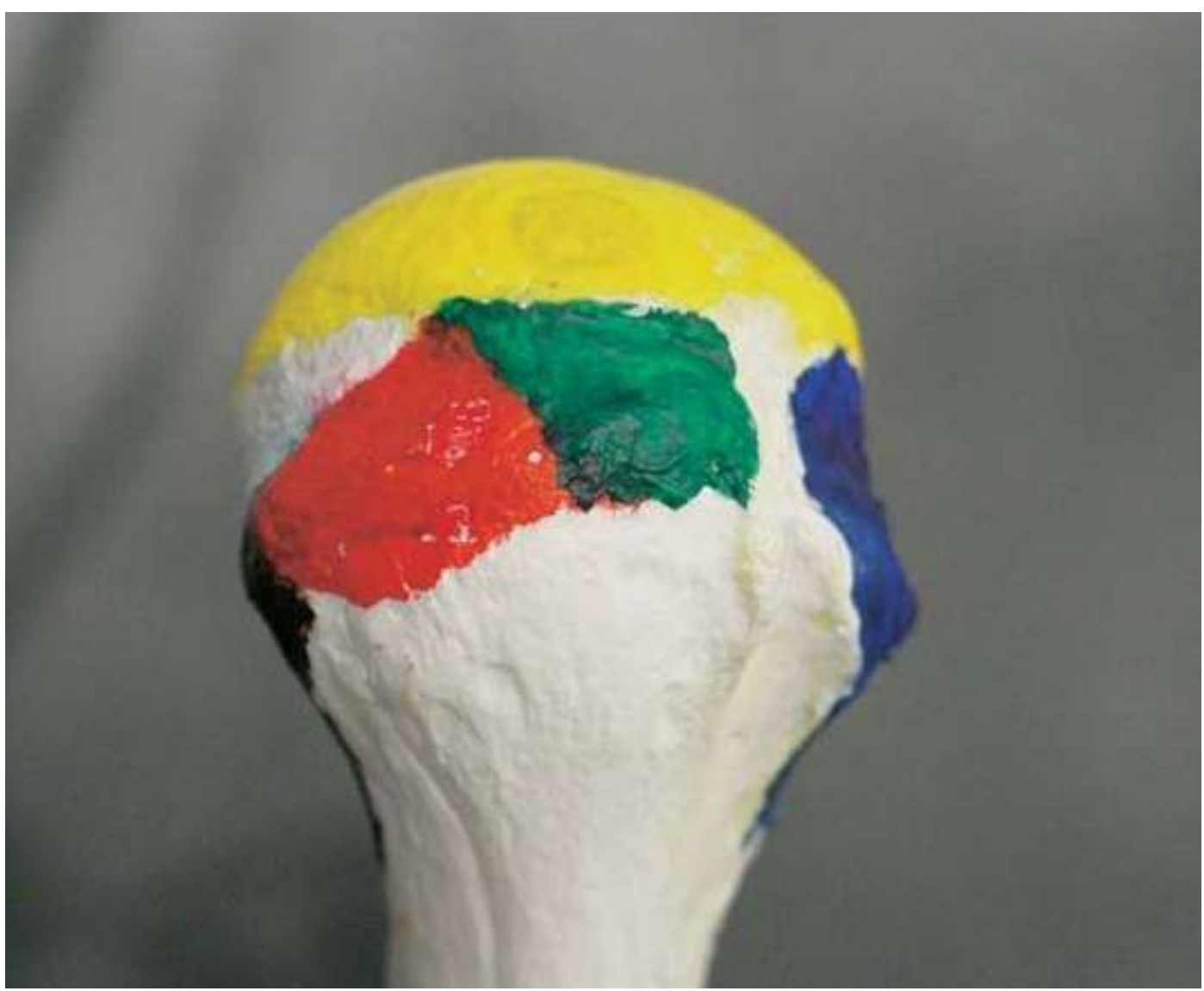

Figure 2. The Four Muscle Attachment Sites of the Rotator Cuff: Subscapularis (blue), Supraspinatus (green), Infraspinatus (red), Teres Minor (black) (Curtis et al., 2006)

The four muscles investigated in this study all attach to the proximal humerus

(Figure 2). These Muscles all leave distinct "footprints" known as entheses. Curtis et al. 
(2006) investigated the shape and boundaries of each insertion. It was found that the subscapularis, which is the largest muscle in the group; it is found on the lesser tuberosity. It is responsible for internal rotation, extension and adduction of the shoulder.

Moving posteriorly around the humeral head we see the next three muscles, the supraspinatus, infraspinatus and teres minor are on the greater tubercle of the humerus (Figure 2). The anterior most muscle of the greater tubercle is the supraspinatus. The second smallest muscle in the rotator cuff, it is located within the sulcus between the biceps groove and the adjacent area at the top of the greater tubercle. The supraspinatus' primary function is arm abduction (lateral lifting).

Next is the infraspinatus (Figure 2), the second largest of the muscles of the rotator cuff, is situated on the superior aspect of the greater tubercle. Fibers from this muscle group wrap around the supraspinatus (Curtis et al., 2006). That being said, the infraspinatus traditionally works in tandem with the teres minor (Figure 2), the smallest muscle in the rotator cuff. It is found inferior to the infraspinatus on the lateral aspect of the greater tubercle. Both the infraspinatus and teres minor are responsible for external rotation, extension and horizontal extension of the arm.

\section{The Scapula}

The humeral head articulates with the glenoid fossa of the scapula. The scapula is a flat, triangular bone that rests on the dorsal lateral aspect of the thorax over the second through seventh ribs (Bass, 1987; Culham and Peat, 1993).

The junction of the humerus and scapula is known as the glenohumeral joint. It is a synovial ball-and-socket joint that is surrounded by a well-vascularized capsule, which receives its blood supply from the tendons inserted in the proximal humerus. 
Hypovascualrity of the region makes the rotator cuff prone to injury (rotator cuff disease) (Andary and Petersen, 2002; Culham and Peat, 1993).

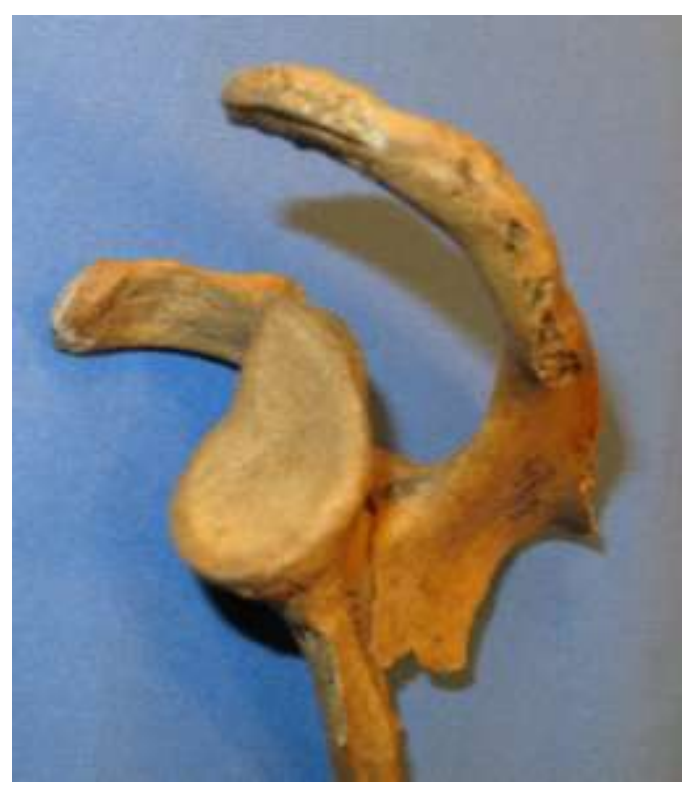

Figure 3. Left Scapula with Intact Acromion Process

There are two projections off of the scapula. The first of these is the corocoid process, which connects to the scapular spine, and the second, off the lateral aspect of the scapula, is the acromion process (Figure 3 ). The acromion articulates with the clavicle; this junction, known as the acromioclavicular (AC) joint connects the upper limb to the axial skeleton (Auerbach and Raxter, 2008; Bass, 19987; Culham and Peat, 1993). The acromion has four ossification centers that fuse between the age of 16 and 22. It is sensitive to compression and trauma meaning that is the acromion is exposed to excessive stress; it could lead to non-fusion of epiphyses (Bass, 1987; Miles, 1994).

The acromioclavicular (AC) joint is a synovial joint, which limits the movement of the scapula as it primarily functions as a stabilizer for the glenohumeral cavity. The $\mathrm{AC}$ joint responds to compressive and tensile stress although overloading of the joint may 
result in the subduction of the acromion beneath the clavicle (Auerbach and Raxter, 2008; Culham and Peat, 1993). The joint is lined by a capsule that, in turn, stabilizes the AC joint, held by the superior and inferior acromioclavicular ligaments.

\section{The Clavicle}

The clavicle (collar bone) is a long bone situated on the anterior of the thorax, located directly above the first rib (Figure 4). The lateral end of the clavicle articulates with the acromion of the scapula and the sternum, and anchors the upper limb to the axial skeleton. The clavicles are among the earliest bones to ossify, beginning at around the fifth week after birth, and is one of the longest bones to finish fusing at around twenty-six years of age. Thus, the clavicles have a long period in which they may be sensitive to lateralized behavior, potentially many more years after the cessation of primary growth (Auerbach and Raxter, 2008; Bass, 1987; Mall et al., 2013).

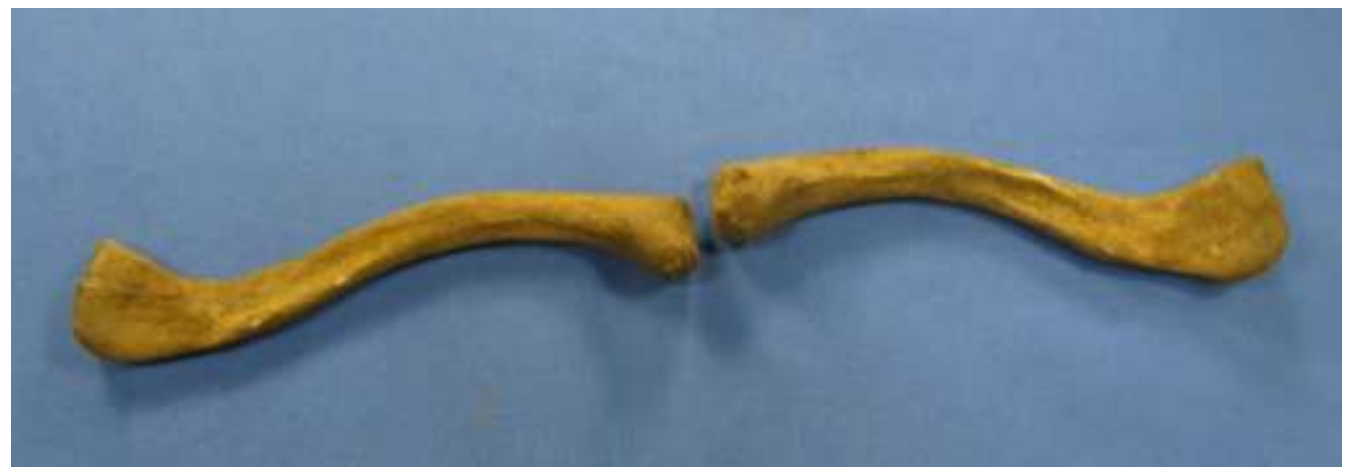

Figure 4. Inferior Aspect of Left and Right Clavicles

Much of the mobility in the rotator cuff is dependent on how the shoulder complex attaches to the axial skeleton. As it is the one connection between the upper limb and torso, the clavicle and the $\mathrm{AC}$ joint are subject to various stresses including torsion and shear stress. The joint itself is not very mobile; however it is flexible enough to 
respond to the movements of the shoulder. Excessive compression or loading to the clavicular surface may induce damage to both the bone and its associated joint (Auerbach and Raxter, 2008; Bass, 1987; Costic et al., 2003; Culham and Peat, 1993; Stenlund et al., 1992).

\section{Rotator Cuff Disease}

Rotator cuff disease (RCD), as noted in modern clinical contexts, is the most common pathology associated with the shoulder (Bunker, 2002; Roberts et al. 2007; Via et al. 2013). In reality, RCD is not a singular condition but describes a suite of pathologies within the shoulder complex (Benson et al., 2010; Northover et al., 2007; Roberts et al. 2007). The interconnectivity of the rotator cuff often means that injury to one aspect of the region may trigger further injury. The multifactorial etiology of RCD is often linked to various degenerative changes over time associated with external stressors. (Benson et al., 2010; Bunker, 2002). The most common pathology associated with RCD is subacromial (anterosuperior) impingement syndrome. However, additional injuries include enthesopathies and degenerative changes to the surrounding bones and tissues (Bunker, 2002). Several archaeological studies conducted by Miles have identified this

disease paleopathologically $(1996,1999,2000)$. While no evidence of severe subacromial impingement has yet been identified in the study sample (where pathology manifests osteologically), it does not rule out other facets of RCD. Although skeletal manifestations of subacromial impingement were not observed on the humeral head, the pathology is closely associated with the presence of rotator cuff tears (enthesopathies; particularly that of the supraspinatus) and reactive change to the acromioclavicular joint which will be 
investigated in this study (Bigliani and Levine, 1997; Frost and Anderson; 1999; Mall et al., 2013; Roberts et al., 2007).

As mentioned, continuous stress over time contributes to the development of the degenerative changes that are hallmarked by RCD. Many of these changes are linked to damage or injury at muscle insertion sites, which, in this investigation will be identified as enthesopathies. Additionally, RCD is often a causative precursor to degenerative joint disease (DJD). Therefore this investigation will focus on these two aspects of RCD to quantify degenerative and injurious osteological change in relation to stress.

As the degenerative changes associated with RCD are not contributory to death, it is safe to assume that they reflect prevalence within a living population (Woo and Pak, 2013; Waldron, 1994).

Entheseal Change Etiology

The locations where tendons and ligaments insert into bone are clinically known as entheses or insertions. Tendons and ligaments distribute muscular loads transferred to and from the skeleton. Stress concentration at the site of insertion makes these insertions vulnerable to injuries.

Long term stress (microtrauma) or acute trauma to the entheses can manifest in several ways (pitting, bone formation, etc.), known as enthesopathies. Sensitivity to damage may be exacerbated by the integration of disease, hormonal levels, and/or genetic predisposition (Benjamin, 2008; Benjamin et al., 2006; Benjamin and McGonigal, 2001; Benson et al., 2010; Milella et al., 2012; Niinimäki 2011; Niinimäki and Sotos; 2013; Wilczak, 1998; Woo and Pak, 2013). 
Entheseal sites are categorized by their locations on bone. Fibrocartilagenous attachments are found on epiphyses while diaphyseal entheses are known as fibrous attachments (Benjamin et al., 2006). The attachments of the rotator cuff, all located on the proximal humerus, are the former and will be the primary concern of this study. The manner of transition in zones of fibrocartilagenous entheses from bone to soft tissue makes it difficult to pinpoint the where the enthesis begins and ends (Benjamin et al., 2006).

Recent research has endeavored to map the footprint of the fibrocartilagenous entheses on the proximal humerus (Curtis et al., 2006; Jurmain et al., 2012). Fibrocartilagenous attachments are smaller that fibrous attachments, and thus allow associated tissues a greater range of motion. This is evident in the attachments of the rotator cuff. The freedom of the shoulder complex requires high levels of joint stability. Closely packed muscle, tendon, and joint groupings help diffuse stress and tension. However, this comes at a price because damage to one muscle or tendon grouping may compromise those nearby (Alves-Cardoso and Henderson, 2010; Benjamin, 2006; Benjamin and Mcgonagle, 2001).

Change to fibrocartilagenous entheses function as an excellent means for assessing mechanical stress osteologically. In healthy entheses, attachment sites are avascular; this suggests a poor healing response leaving permanent indications of degenerative or destructive change. These modifications can manifest in two varieties, bone formation or bone destruction (Figure 5) (Jurmain et al., 2012; Milella, 2012). In either case, bioarchaeologists can use these changes as a proxy for quantifying stress. 


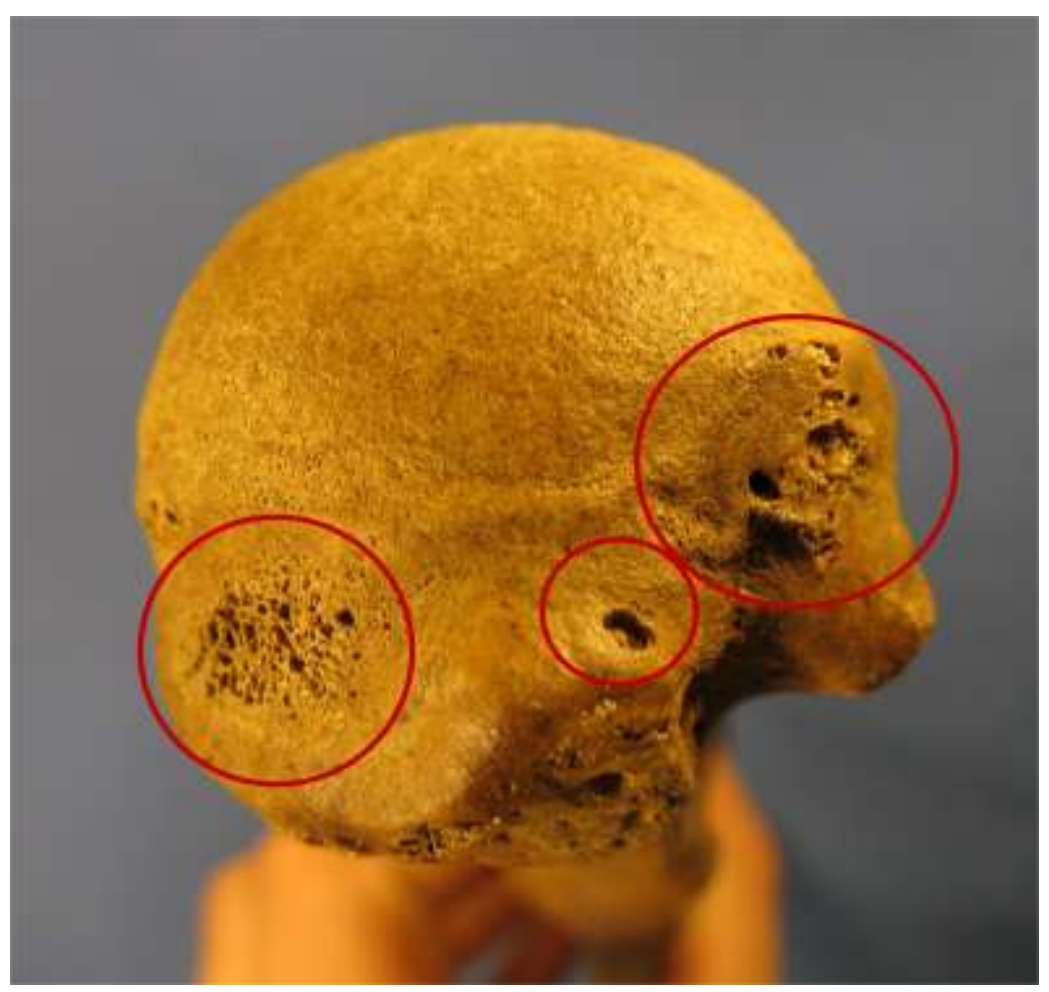

Figure 5. Entheseal Change at the Subscapularis, Supraspinatus and Infraspinatus.

\section{Entheseal Change as an Indicator of Behavior}

There has been a great transformation in how the archaeological community has examined entheseal change over time. Ken Kennedy (1989) posited that entheseal changes, then called musculoskeletal stress markers (MSM), could be attributed to specific actions. From this, much of the following research on entheseal change has been in relation to the reconstruction of specific mechanical stresses (Eshed et al. 2004; Hawkey and Merbs 1995; Lie and Lovell, 1994; Lieverse et al. 2009; Molnar 2006).

The primary issue that arises when associating skeletal markers to specific behaviors, since people engage in several activities on a daily basis, is that it is often difficult to differentiate occupations from skeletal material. Several behaviors may contribute to a particular entheseal change, or one behavior may contribute to many entheseal modifications (Alves-Cardoso and Henderson 2010; Jurmain 1999; Jurmain et 
al., 2012; Milella et al., 2012; Niinimäki 2011; Roberts 2007; Villotte et al. 2010; Villotte and Knüsel). It is for this reason that it is difficult to ascribe specific occupations or behaviors to entheseal change; instead scholars look specifically at causative actions (i.e., lifting the arm above the head, pulling something towards the body, etc.) and postures to determine what triggered a specific change. Additionally, changes in terminology from MSM to EC were made to accommodate the multifactorial origin of change (Jurmain and Villotte, 2010; Milella et al. 2012).

The degree of entheseal change is more likely the product of age, sex and body size in tandem with culture, occupation, and subsistence strategies (Alves-Cardoso and Henderson 2010; Jurmain 1999; Jurmain et al., 2012; Kennedy, 1989: Lieverse et al. 2009; Milella, 2012; Weiss 2004). It is because of this that larger individuals have more pronounced entheseal changes than smaller individuals, males have more than females, and older individuals have more than younger individuals (Eshed et al. 2004; Hawkey and Merbs 1995; Kennedy, 1989; Milella et al., 2012). This variability must be taken into account when examining behavioral stress and can explain much of the differentiation between individuals of differing cohorts.

Early research of entheseal change (EC), often utilized a technique proposed by Hawkey and Merbs (1995). This method involved scoring three aspects of osteological change: robusticity markers, stress lesions, and ossification exostoses. Recently, this method has been reevaluated and found to be too general in its descriptions of osteological change (Davis, 2012). Revised methodologies have been proposed.

Studying entheseal change is still useful in evaluating behavioral trends in past populations. However, instead of using it as a tool to determine specific occupational 
stress, it better serves as a means for comparison. This includes the examination of temporal change in activity at a single site or even stress related to common activities over a spatial distance.

As mentioned previously, new methods proposed by Mariotti et al. $(2004,2007)$ were created for a more thorough scoring system of entheseal change and robusticity. Later, these techniques were built upon to establish a yet more detailed methodology at a conference held at the University of Coimbra (thus termed the Coimbra Method). These methods include the division of entheseal margins and insertional surfaces when assessing degenerative change. Many studies have created a foundation of basic assessments on which to support this new methodology (Alves-Cardoso and Henderson 2010, 2012; Henderson, 2012, 2013; Henderson et al., 2010; Henderson et al., 2013; Milella et al. 2012; Villotte et al., 2010; Villotte and Knüsel).

Temporal research on entheseal change has been conducted, using the Coimbra Method, on Moundville and its surrounding communities between the Late Woodland (500-900 CE) and the Mississippian (1000-1500 CE) which indicated increased upper limb stress during the later period. Differences in changes also appeared between the sexes, age and settlement location. It was found that status had the greatest impact on entheseal change (Jurmain et al., 2012; Schuler et al 2012). Evidence suggests that not all Mississippian communities were stratified to the same extent; therefore it would be interesting to see if status impacted entheseal change in other urban Mississippian communities. 


\section{Entheseal Rugosity}

Entheseal changes are not the only way in which archaeologists have evaluated musculoskeletal stress in past populations. Research has been conducted to determine status related stress by measuring cortical thickness in long bones, examining growth arrest lines, dietary differences, age at death, and dental pathologies (Ambrose et al., 2003; Goodman and Armelagos, 1988; Hatch et al., 1983; Hatch and Geidel, 1983;

Hedman, 2006; Wilson, 1997). These methods used concurrently with entheseal data can be used to evaluate activity related stress to nutritional and health related stress, to create a comprehensive understanding of living conditions in past populations.

Robusticity is the normal osseous markings at the site of attachment of a muscle or ligament that was stimulated by high levels of muscle loading (Figure 6). Rugosity of muscle insertions, also identified as robusticity, indicates exuberant bone growth at the area adjacent to the attachment and they reflect the stress of muscular pull, require a substantial attachment area to prevent rupture (Hawkey and Merbs, 1995; Kannnus et al., 1995; Niinimäki, 2011; Niinimäki et al., 2013; Ruff et al., 2006; Stock and Shaw, 2007).

Early in development, fibrocartilagenous muscle insertions are presented as a well articulated facet, continuous use beyond puberty can result in damage, but normal wear is also evident at insertion sites; rugosity is counted among the latter (Niinimäki, 2011; Niinimäki et al., 2013; Ruff et al., 2006; Stock and Shaw, 2007; Villotte and Knüsel ). Bone needs to accommodate increased muscle mass. Rugosity is apparent when the bone surrounding the facet thickens around attachment sites, mechanical loading induces bone remodeling. The type and the magnitude of the response can vary depending on several factors (e.g. genetic predisposition, health, etc.). Robusticity markers are always 
observable, although with variable degrees of expression, while enthesopathies can be absent or present (Hawkey and Merbs, 1995; Kannnus et al., 1995; Mariotti et al., 2004, 2007; Niinimäki, 2011; Niinimäki et al., 2013; Ruff et al., 2006; Stock and Shaw, 2007; Villotte and Knüsel).

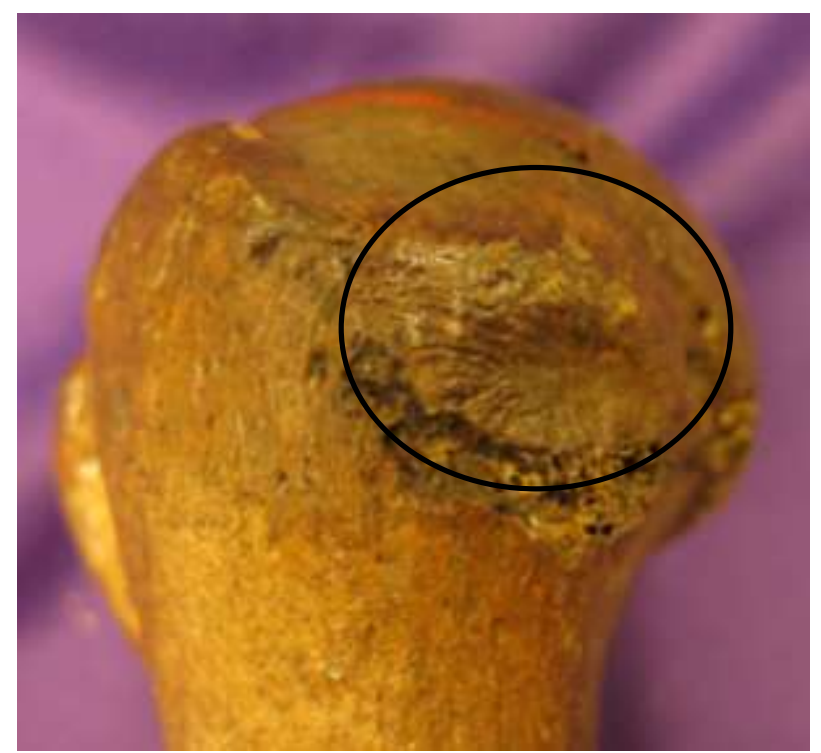

Figure 6. Rugose Teres Minor Insertion

As seem above with EC, Mariotti and colleagues $(2004,2007)$ proposed a standardized method for scoring robusticity of entheses and the possible presence and degree of development of enthesopathies. This method not only specifies normal change to pathological change, but develops a standardized scoring protocol that is accompanied with corresponding imagery. Although this method has been gaining supporters over the years, detractors argue that this method does not account for the variation in change to entheses. 


\section{Degenerative Joint Disease Etiology}

Degenerative joint disease (DJD), also identified as osteoarthritis (OA), is the most common of all joint disease found in skeletal remains. I here use the term DJD as opposed to OA to fully differentiate it from other types of inflammatory diseases also known as arthritis (e.g. rheumatoid arthritis). DJD is a multifactorial degenerative condition that may be the result of long-term use, over-use or acute trauma to a joint (Bridges, 1992; Eshed et al,. 2004; Eshed et al,. 2010; Jurmain, 1999; Mall et al., 2013; Waldron, 2012; Weiss and Jurmain; 2007). Its prevalence increases with age (Bridges, 1992; Waldron, 2012). Over time, articular cartilage surfaces that make up synovial joints deteriorate, thus resulting in the formation of osteophytes at the joint margins and areas of porosity (pitting) on denuded bone (Figure 7a). Many bioarchaeologists require the presence of eburnation in (Figure 7b) the identification of Osteoarthritis. However, as a diagnostic standard, the presence of marginal osteophytes is usually sufficient in its diagnosis (Rogers 2000; Waldron, 2012).

Early studies of DJD focused on its association with aging with special attention paid to spinal deformation (Chapman, 1962; Jurmain et al., 2012). By the 1980s, DJD was used as an indicator of occupational (behavioral) stress beginning with Merbs' (1983) investigation of activity induced pathologies of an Inuit population (Jurmain et al., 2012; Merbs, 1983). Inquiries of this nature took off after this investigation and introduced a new line of stress related change although many of these studies warn against using DJD as a specific behavior indicator (Bridges, 1992; Crubézy et al., 2002; Hawkey and Merbs 1995; Jurmain and Kilgore, 1995; Waldron, 1991, 1995; Woo and Pak, 2013) 
Reactive change results from the deterioration of articular cartilage of synovial joints. Traditional indicators of DJD include peripheral osteophytic growth, porosity at the joint surface (Figure 7a), and eburnation (Figure 7b) (Bridges, 1992; Waldron, 2012). Recent studies have suggested that these criteria are too narrow and should be expanded to include these changes at both joint surfaces and margins (Bridges, 1992; Crubézy et al., 2002; Jurmain et al., 2012).
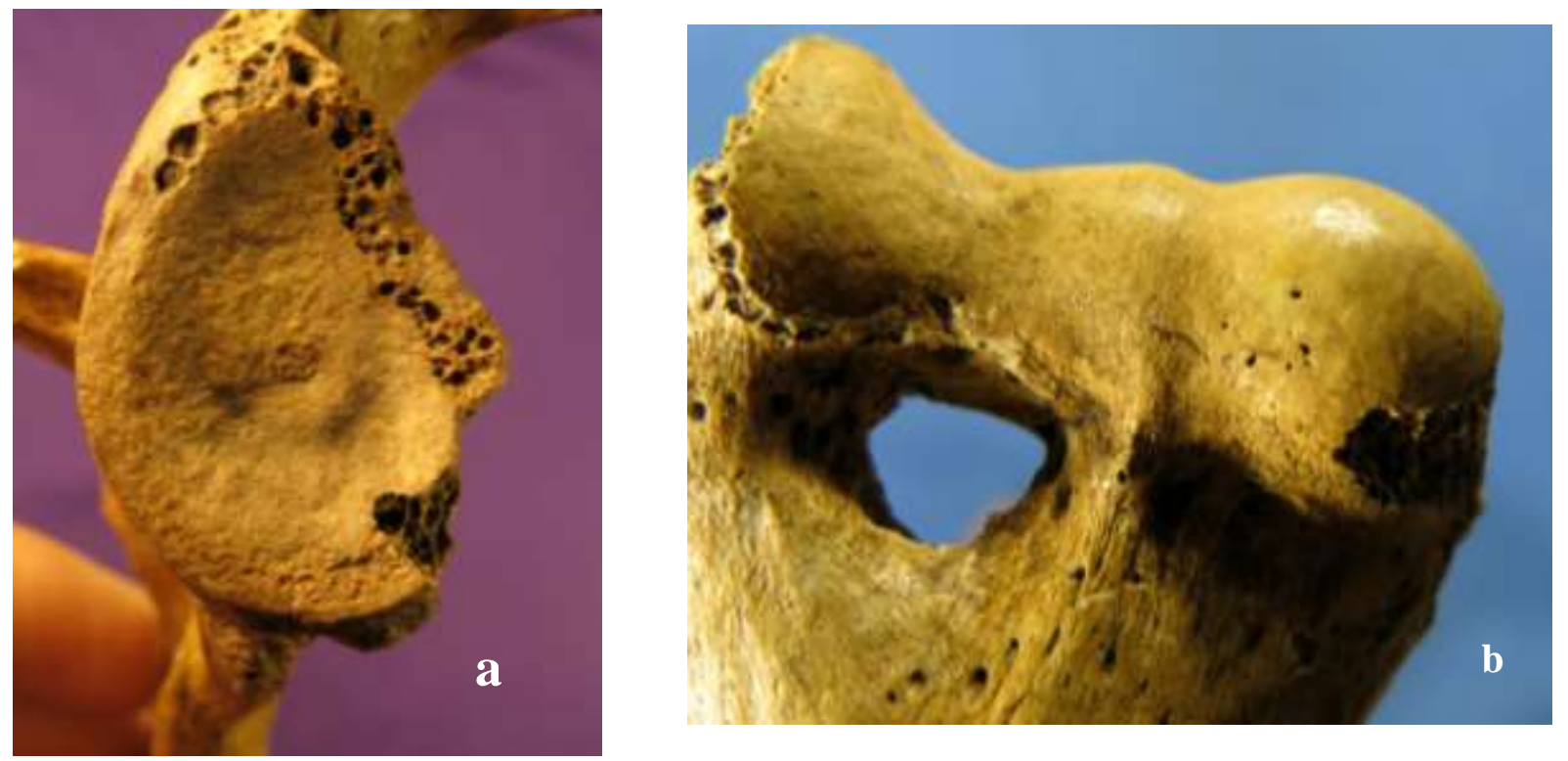

Figure 7. a) Arthritic Pitting at the Glenoid of the Scapula b) Eburnation on the Distal Humerus

Additionally, many studies have been conducted on DJD, which indicate that physical stress increases with the introduction of agriculture. However, it is not a universal observance (Bridges 2000; Eshed et al. 2010; Larson 1995). It has been suggested that the prevalence and severity of behaviors is what causes the degree of DJD in a population. In hunting and gathering societies, meat that was obtained in a hunt was probably a primary source of protein. Success in hunting requires accuracy and strength. It would be a year round activity one which could not be put off for childbirth (meaning 
that men probably did more hunting than women). Therefore, individuals who hunted regularly (males) would indicate greater presence of degenerative change than those who did not (females). This, along with greater overall size of males would be expected to result in higher levels of activity related pathology in males (Rogers 2000).

As DJD and entheseal change are identified as indicators of stress both have been used in tandem to examine mechanical stress in several studies of note (Lai and Lovell, 1994; Molnar, 2011; Woo and Pak, 2013). An investigation by Lie and Lovell (1994) used the two stress indicators to illustrate the harsh working environments experienced by Canadian fur traders. Degenerative damage to the spine, correlated with entheseal data indicating that men engaged in the fur trade were subject to heavy burden bearing activities. Additional examinations of the lower limb show changes associated with kneeling and canoe paddling.

In 2013, a study by Woo and Pak investigated the association of these two mechanical stress indicators in a skeletal population from a Joseon Dynasty cemetery in Seoul, Korea. They found that there is an association between DJD and EC in specific joints including the elbow and hip. They agreed that both DJD and EC increased in severity with age and they conclude that both of these stress indicators have the same pathogenesis and are both sensitive to genetic and external factors.

Degenerative Joint Disease at the Acromioclavicular Joint

This investigation focuses on DJD of the acromioclavicular joint. Heavy mechanical use, typically cross body and over-head movements during manual labor, associated with burden bearing is coupled with the degeneration of the fibrocartilagenous disc that sits between the clavicle and acromion process of the scapula. Many of the 
studies of degenerative change to the region have been clinical radiographic investigations (Mall et al., 2013; Stenlund et al., 1992). Although helpful in understanding the pathology, these radiographs do not provide the insight necessary for osteological investigation as they focus on soft tissue damage.

Of the few paleopathological investigations of the degeneration of the acromioclavicular joint, little has been noted about both facets connecting the tissues of the joint (Figure $8 \mathrm{a}$ and $\mathrm{b}$ ). Most of these studies have used either one attachment site or the other (Waldron and Rogers, 1991), combined data from the region or both joint facets (Rogers et al., 2004; Waldron, 1995) or it was not mentioned what was examined to determine change to the acromioclavicular joint (Crubézy et al., 2002; Waldron, 1991)

A study by Roberts et al. (2007) indicates similar rates of DJD in both the clavicular facet of the acromion process and the acromial facet of the medial clavicle. They documented high rates of degeneration, but data for both facets were pooled in this investigation. Although there were high rates of reactive change at the acromioclavicular joint surfaces, it was not associated with an increase in degeneration at other joints and surfaces of the rotator cuff in their sample.

Additional studies have also found high rates of DJD in the acromioclavicular joint from the Neolithic through to the Georgian and Early Victorian periods in England (Crubézy et al., 2002; Waldron, 1991). In these investigations, reactive change usually expressed bilaterally although there was no differentiation between which facet site was examined in either study. When it did not express bilaterally, there was a right side bias. Small sample size was small so the likelihood. No resource has suggested a difference in 
the cause, if any between the expressions of reactive change at the clavicular facet versus the acromial facet of the AC joint.

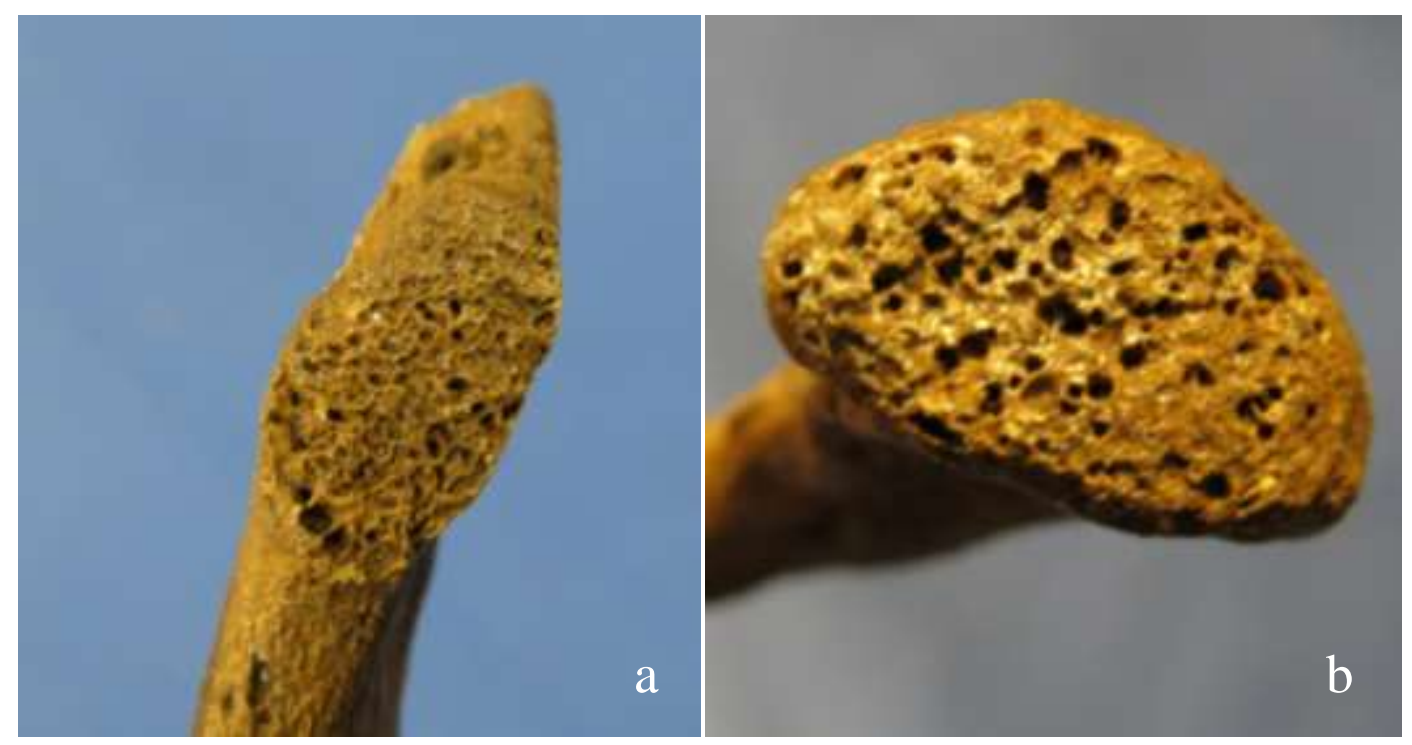

Figure 8. Degeneration of the Acromioclavicular Joint a) Severe Degeneration at the Clavicular Articular Facet of the Scapula b) Severe Degeneration at the Acromial Articular Facet of the Clavicle

\section{Skeletal Robusticity}

Robusticity is a probably the most important factor in interpreting signs of stress induced skeletal change. Skeletal size has been positively correlated with the development of stress indicators (e.g. EC) (Cohen and Armelagos, 1984; Boyd and Boyd, 1989; Jurmain et al., 2012; Mummert et al., 2011; Niinimäki and Sotos, 2013; Nolte and Wilczak, 2013; Pearson, 2000; Ruff and Hayes, 1983; Ruff et al., 2012; Stock, 2006). Skeletal morphology is influenced by many of the same factors that produce/influence stress related skeletal change (diet, genetics, disease, etc.) therefore it is not a far leap that the two are associated (Godde and Taylor, 2010; Konigsberg et al., 1998; Mummert et al., 2011; Pearson, 2000; Ruff and Hayes, 1983; Ruff et al., 2012; Stock, 2006). 
The most well documented association between skeletal stress and robusticity is the quantification of EC and body size. Fundamentally, the footprints of entheses are fixed during development. Muscle growth, however, can continue long beyond skeletal growth ceases. When an enthesis is too small to accommodate surrounding musculature, it becomes more prone to injury (Hawkey and Merbs, 1995; Jurmain et al., 2012; Nolte and Wilczak, 2013). Additional research has suggested that imprint formation is also linked to body size (Godde and Taylor, 2010; Trinkaus, 1975).

Environmental and cultural factors are also considered indicators for skeletal robusticity. The chief factor linked to changes in stature and robusticity are associated with distinct cultural change, which often manifests as transitions in subsistence strategies (Boyd and Boyd; 1989; Bridges et al., 2000; Goodman et al., 1992; Larsen et al., 2002), although these findings are not universal (Mummert et al. 2011). Dietary and health consequences of subsistence change are thought to influence skeletal change. Decreases in nutritional diversity and increased disease exposure coupled with greater mechanical demands may affect skeletal robusticity within populations, specifically those transitioning to sedentary agriculturalism (Boyd and Boyd, 1989; Goodman, 1993; Mummert et al., 2011).

Past research has indicated that disparities in between populations' robusticity are generally linked to activity level (Boyd and Boyd, 1989; Bridges, 1989; Pearson; 2000; Ruff and Hayes, 1983; Ruff et al., 2012). One of these investigations carried out by Boyd and Boyd (1989) examined femoral robusticity between Archaic hunter-gatherers and Mississippian agriculturalist sites from Tennessee. Their study indicates that the Mississippian samples did not display reduction in robusticity thought to be linked to 
nutritional stress brought on by maize intensive diets. They concluded that the Mississippians in the region most likely supplemented their maize consumption with a wide variety of other local resources.

Further investigations, like that by Godde and Taylor (2010), suggest that body mass index (BMI) combined with skeletal robusticity could be a major factor in the development of degenerative changes to the skeleton. As with muscular robusticity, the entheses did not develop to cope with the burden of extra weight (body fat). The increased weight (strain) at attachment sites makes the skeletal system more prone to injury especially at the joints. Obesity and its related skeletal alterations are not very apparent in pre-agricultural sites; however, obesity and related illness are visible in agricultural societies.

It must be noted that lower skeletal robusticity may be indicative of frailty or vulnerability. Individuals with low robusticity scores may be ill and die at a young age (Goodman, 1993). So samples with low skeletal robusticity may indicate high rates of health issues. This is why investigations of skeletal robusticity must be multifactorial in nature. 


\section{CHAPTER III \\ OSTEOLOGICAL SAMPLES}

The four collections used in this study, (three Archaic and one Mississippian) are housed at the McClung Museum in Knoxville, Tennessee. The sites were selected for their proximity in location in upper west-central Tennessee along the Tennessee River, and for the contrasting subsistence pattern (mobile hunter-gatherers versus sedentary food producers).

\section{Archaic Sample}

Eva (40BN12)

The Eva site is located in Benton County, Tennessee. It lies along a former elevation of the Tennessee River bank between the river and one of its branches, Cyprus Creek (Bass, 1985; Magennis, 1977; Lewis and Lewis, 1961). Eva is a multi component site with distinctions of three Archaic cultures, Eva Phase in the Middle Archaic (5200BCE) Strata IV-V), Three Mile (4000-2000 BCE) (II-III) for the Late-Middle Archaic, and Big Sandy which was late Late Archaic with contact with Woodland ((2000-1000 BCE) Strata I and Plowzone) cultures.

A total of 179 burials were excavated from Eva. The component being investigated in this study is the Late Archaic, and some Middle Late Archaic from strata 
II and III, which correspond with the Three Mile Phase (Lewis and Lewis, 1961). Onehundred and two burials correspond with this phase.

Cherry (40BN74)

Also in Benton county, the Cherry site is located between two former tributary streams of the Tennessee River, specifically, the Big Sandy confluence (Magennis, 1977). It is considered to be one of the most remote of the western Tennessee valley Archaic sites (Lewis and Kneberg, 1959; Magennis, 1977). That being said, it is geographically located in close proximity to the Eva site when compared to Kays Landing.

Excavations, contemporary to the Three Mile phase (Eva III) at the Eva site (Middle and Late Archaic) were recovered. This was the only deposit identified at the site and 69 burials were recovered from it.

Kays Landing (40HY13)

The Kays Landing site is located in Henry County along the main branch of the Tennessee River. No formal site report has been compiled, although it has been mentioned in articles and unpublished master's theses (Boyd and Boyd, 1991; Lewis and Kneberg, 1947, 1959; Wojicinski, 2011). It is the northernmost Archaic site in this study. Excavation of the site yielded three components to the site all within the range of the Archaic period although the sample is dated slightly later than both Eva and Cherry (Lewis and Kneberg 1959). 


\section{Mississippian Sample}

It was not possible to find a comparable number of Mississippian sites from the region; however, the sample utilized in this study, Thompson Village (40HY5), fit the geographic requirement, and yielded a higher number of burials making the sample size of this single site more complete than those found in the Archaic. The two other Mississippian samples under consideration for this study, Link Farm (40HS6) and Slayden (40HS1) (suggested to be the settlement of a single site across the river), and Indian Bluff (40SW20) were rejected from the study due to poor preservation.

\section{Thompson Village (4OHY5)}

Thompson Village is located in Henry County, just north of the Kays Landing site, at the confluence of the Big Sandy and Tennessee Rivers. No radio-carbon dates have been established for this site, ceramic and carbon dates of the region has placed settlement at 1050-1450 CE within the geographic confines of and preceding the temporal period known as the Vacant Quarter (Beaham, 2013;Cobb and Butler, 2002; McClain, 2013) The site, briefly visited by C.B. Moore, was excavated under the direction of George Lidberg for the University of Tennessee with the majority of the work was done by WPA (Works Projects Administration) field Crews (Bass, 1985). The site resided on an alluvial plain that proved to be ideal for agricultural activities (Bass, 1985).

The site itself was a habitation site found in loose association with the Gray Farm mound center (40SW1) (as opposed to the site containing a mound center). This suggests that Thompson Village was a satellite settlement, and thus not a major center for 
social, religious or economic activity (Bass, 1985). Two cemeteries were identified at the site from which 187 burials were recovered.

The primary cemetery at Thompson Village was found at the point of highest elevation at the site. Only two burials were in limestone slab boxes, probably due to a lack of raw materials (Bass, 1985). Many of the burials were found in kin groups with several interment forms (e.g. bundle burials, isolated skulls, and the inclusion of a few infants) (Bass, 1985). 


\section{CHAPTER IV}

\section{METHODS}

Cortical changes of the three bones of the rotator cuff (humerus, clavicle and scapula) will be examined for this study. Only adult (skeletally aged 18 or older) individuals with at least one mostly preserved skeletal element of the shoulder will be subject to study. Each skeletal element will be examined for entheseal change or osteoarthritis and, in the case of humerus, robusticity. Males, females, and individuals of undetermined sex from both subsistence strategies, as well as those of the three adult age groups will be counted and assessed by each skeletal element. Frequencies will be calculated for comparison between temporal periods, sex and age. Further Statistical analysis will determine whether the hypothesis that Mississippian women sustained the greatest amount of bone change with older individuals having more severe changes than younger individuals is accepted.

\section{Age and Sex}

Age and sex determination are based on previous osteological analysis as appears on inventory lists at the McClung Museum. The adult age was determined by the occlusion of at least one third molar. All individuals will be grouped into three age cohorts, "Advanced" (50+), "Middle Aged" (25-50) and "Young"(18-25) based on previously set aging system. As the age cohorts are overly broad, age-based analysis will 
not be the primary focus of this study. In fact, age will only be taken into account when sampling bias is evaluated.

\section{Scoring protocols}

Rotator cuff disease, as previously mentioned is the primary clinical term for stress related injury to the shoulder. In this study, entheseal change was chosen as a proxy for RCD. It was selected because it is indicative of soft tissue damage that is often clinically recognized as RCD. Further investigation of entheseal wear includes an examination of teres minor robusticity which is indicative of heavy muscle use.

Additionally, RCD is often a precursor to degenerative joint disease as the body is subject to similar wear-and-tear to elicit both pathologies.

\section{Entheseal change}

Entheseal change will be quantified through a modified comparative scoring system in accordance with the Coimbra Method (Alves-Cardoso and Henderson 2010, 2012; Henderson, 2012, 2013; Henderson et al., 2010; Henderson et al., 2013; Milella et al. 2012; Villotte et al., 2010; Villotte and Knüsel). Seven criteria were established for types of change at the margin and attachment surface of the muscle attachment (Table 1). The number of present changes was counted for each enthesis. An adaptation of Hawkey and Merbs (1995), Mariotti et al. (2007), and Alves-Cardoso and Henderson (2010) scoring methods was used to quantify EC. Two scoring groups, indicating nonpathological (0 and 1) and pathological (2+) change were measured. For an enthesis to qualify for examination two-thirds of the entheseal footprint must be present for analysis. Due to limited sample size, further analysis on severity was not undertaken. 
Table 1. Criteria Assessed for Entheseal Change

\begin{tabular}{ll}
\hline Margin of attachment site & Attachment surface \\
\hline Bone Formation (BFZ1) & Bone Formation (BFZ2) \\
Erosion (ERZ1) & Erosion (ERZ2) \\
& Fine Porosity $</=1 \mathrm{~mm}$ (FPO) \\
& Macro porosity $>/=1 \mathrm{~mm}(\mathrm{MPO})$ \\
& Cavitations (CA) \\
\hline
\end{tabular}

\section{Entheseal Rugosity}

The teres minor entheseal insertion was the only one assessed on rugosity alone. The muscle attachments were scored for ruggedness following standards set by Mariotti et al., (2004, 2007). However, instead of using a five degree scale, this study used only three measured on a scale from none to incipient to full (Table 2). This change was implemented to differentiate no rugosity from what could be considered normal and abnormal (high) entheseal buttressing. Scoring protocol is as follows:

Table 2. Scoring Protocol for Teres Minor Rugosity

\begin{tabular}{|c|c|c|}
\hline \multirow{2}{*}{$\begin{array}{l}\text { No Rugosity } \\
\text { None (N) }\end{array}$} & \multicolumn{2}{|c|}{ Rugosity } \\
\hline & Incipient (I) & Full (F) \\
\hline $\begin{array}{l}\text { The impression is } \\
\text { practically absent; } \\
\text { The surface of the } \\
\text { attachment site is } \\
\text { smooth }\end{array}$ & $\begin{array}{l}\text { The attachment area } \\
\text { is well delimited } \\
\text { although the edges } \\
\text { are discontinuous }\end{array}$ & $\begin{array}{l}\text { The impression is } \\
\text { delimited by well- } \\
\text { defined margins } \\
\text { with an irregular or } \\
\text { rugose surface }\end{array}$ \\
\hline
\end{tabular}

Many of the research questions employed involved the further condensation of the data set to presence/absence. In this case, scores of zero were compared to combined scores of one and two.

Degenerative Joint Disease

Degenerative Joint Disease, was scored on a four point scale, but analyzed in two categories divided non-pathological (scores of 0 and 1) and pathological (scores of 2 and 
3) based on scoring criteria seen in Table 3. For the purposes of this study, the clavicular imprint on the acromion process of the scapula, and the acromial facet on the lateral clavicle will be analyzed. For a joint surface to be analyzed, two-thirds of the surface and/or margin had to be present.

Table 3. Criteria for Scoring DJD

\begin{tabular}{clll}
\hline & Non-Pathological & \multicolumn{2}{c}{ Pathological } \\
\hline Nothing & \multicolumn{1}{c}{ 1 } & \multicolumn{1}{c}{2} & \multicolumn{1}{c}{3} \\
& Up to 1 criteria in & Has to have 2 of each & Has to have 2+ of each \\
& each category & in at least 1 category & in both categories \\
and/or eburnation & and/or eburnation \\
& Margin & Margin & Margin \\
& Osteophytes & Osteophytes & Osteophytes \\
New bone & New Bone & New Bone \\
& Pitting & Pitting & Pitting \\
& Joint surface & Joint Surface & Joint surface \\
Bone formation & Bone formation & Bone formation \\
& Pitting & Pitting & Pitting \\
Deformation & Deformation & Deformation \\
\hline
\end{tabular}

\section{Skeletal Robusticity}

Skeletal robusticity has been found to have a positive correlation with insertional rugosity as well as other signs of stress (Knüsel, 2000; Konigsberg et al., 1998; Mummer et al., 2011; Pearson, 2000; Ruff, 2000; Ruff and Hayes, 1983; Ruff et al., 2012; Stock and Shaw, 2007; Trinkaus, 1975), for this reason, I chose to examine the effects of robusticity as well.

A robusticity index utilizing osteometiric data from the humerus, as noted by Pearson (2000) was utilized for this study. Measurements were taken for both the minimum and maximum mid-shaft diameters using hand calipers as well as a 
measurement for maximum length taken on an osteometric board. The index was formed utilizing the equation

$$
\left[\frac{(M D M+m D M)}{M L} \times 100\right] \quad(\text { Pearson, 2000). }
$$

Skeletal robusticity studies work best when examining genetically and geographically distinct populations to themselves (Pearson, 2008). As the samples in this study represent continuous use of the region by the same peoples over time, inter site analysis would be deemed feasible.

Robusticity data was only gathered from the Kays Landing site, and partially from Thompson Village. It is for this limited sample that only a cursory investigation of skeletal robusticity will be conducted.

\section{Statistical Methods}

All comparative analyses will be done using Fisher's Exact tests with a significance level of 0.05 . Additionally, a threshold of 0.1 (90 percent confidence level) was used to assign a statistical significance to prevalence which trended to, but did not achieve the 95 percent confidence interval. These were labeled "not quite statistically significant." The Fisher's Exact test is presented as an alternative to the chi-square test for small sample size. One-tailed tests were used because expression of skeletal change can only be judged on a positive scale. The null hypothesis is that of no difference between samples. The test is useful for categorical data, $2 \mathrm{X} 2$ tests utilize this data when split into two categories (McDonald, 2009; O'Rourke et al., 2005). This test is used unless otherwise specified. Two-tailed tests were employed only when data contained more than presence/absence data. 


\section{CHAPTER V}

\section{RESULTS}

This chapter contains several components including site sample demographics, data on skeletal change and comparative analyses of settlement and subsistence strategies. examination of stress related change by physiological location, and temporal differences between the Late Archaic and the Mississippian all indicate that skeletal stress was more prevalent within the Mississippian period.

\section{Site Demography}

There is an uneven sample size distribution of the skeletal material recovered from each site. A total of 161 adult burials for the Middle and Late Archaic sample and 132 burials were recovered for the Mississippian sample were originally recovered. A generally poor preservation of the shoulder girdle (primarily the posterior proximal humerus, acromion process of the scapula, and the distal clavicles) resulted in incomplete data sets for many individual burials.

Within the Middle and Late Archaic, 114 burials from all three sites that fit the minimum criteria for use in this investigation. The Mississippian sample yielded 82 usable burials. However, issues with preservation led to substantially smaller sample sizes for each tested variable. 
Eva. Sixty-five individuals were examined from Eva, 40 of which have usable data. Of these, 9 (22.5 percent) were sexed as male and 24 (60 percent) as female, 7 (17.5 percent) were not sexable. The proportion of females to males indicates a female bias within the sample (Figure 9). The age data suggests that there is also a bias towards young individuals in the total sample.

The young age cohort comprises 62.5 percent (25/40 individuals) of the sample. Young individuals composed 66.7 (6/9) of the male sample, and is the only discernible age cohort represented in males. The young age cohort represents 70.8 percent (17/24) of female burials. The middle age cohort is 10 percent (4/40) of the total sample but is only present in female burials where it represents 11.8 percent $(2 / 17)$ of the age sample. There are no advanced age burials identified. Eleven individuals were not ageable.

Table 4. Age Distribution of Sites

\begin{tabular}{lllllll}
\hline Site & Young & \multicolumn{5}{c}{ Middle } \\
& $\mathrm{N}$ & $\%$ & $\mathrm{~N}$ & $\%$ & $\mathrm{~N}$ & $\%$ \\
\hline Eva & $25 / 40$ & 62.5 & $4 / 40$ & 10.0 & 0.40 & 0 \\
Cherry & $15 / 34$ & 44.12 & $7 / 34$ & 20.59 & $0 / 34$ & 0 \\
Kays Landing & $8 / 40$ & 20.0 & $24 / 40$ & 60.0 & $3 / 40$ & 7.5 \\
Thompson & $13 / 82$ & 15.85 & $34 / 82$ & 41.46 & $6 / 82$ & 7.32 \\
Village & & & & & & \\
\hline
\end{tabular}




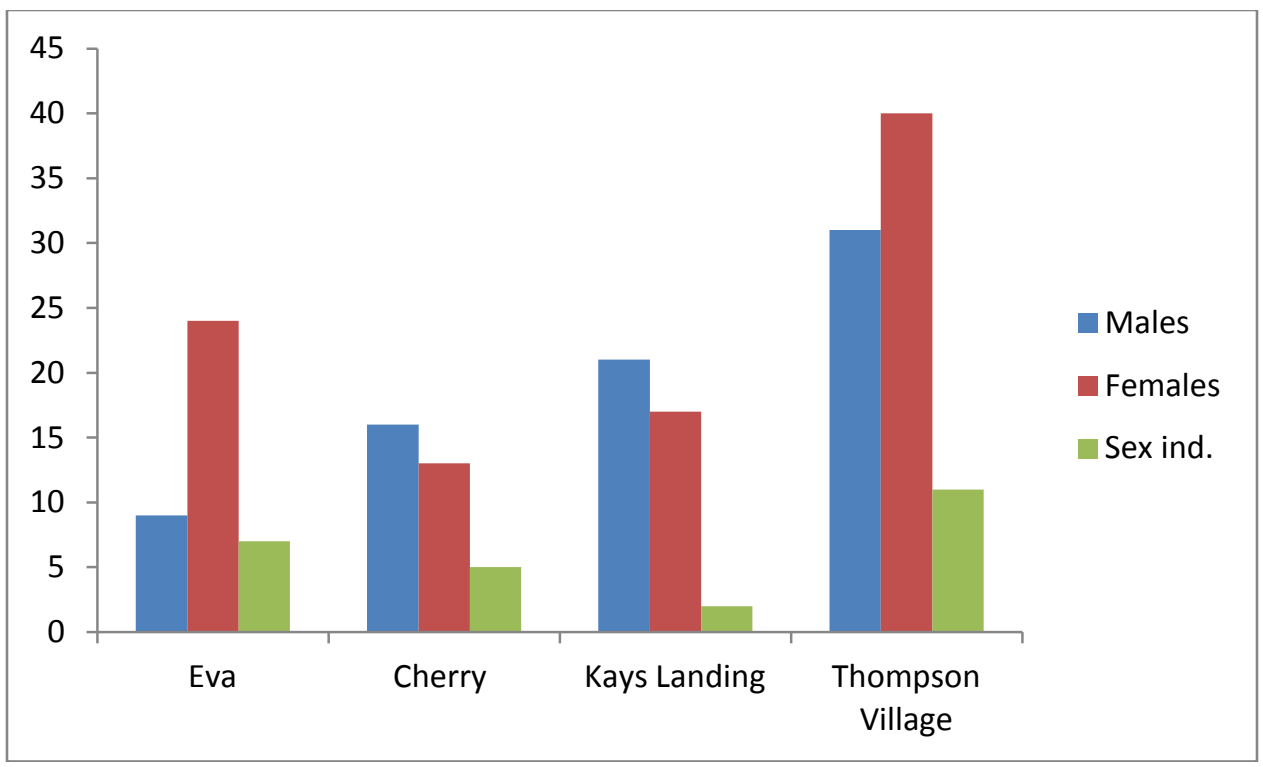

Figure 9. Sample Sex Distribution by Site

Cherry.The smallest Archaic sample, 52 individuals are examined with 34 yielding usable skeletal elements. Sixteen of the total individuals (47.1 percent) which in the sample are male, 13 (38.2 percent) are female, and 5 (14.7 percent) are sex indeterminate. The total young age cohort comprises 44.1 percent (15/25) of all aged data. Of these, 50 percent (8/16) are males and 38.5 percent (5/13) are females. The middle age cohort comprises 20.6 percent (7/34) of the Cherry Sample. Twenty-five percent (4/16) of the male sample and 23.1 percent (3/13) of the female sample fall into this age cohort (Table 4). Twelve burials could not be aged. Similar to Eva, Cherry has a higher proportion of younger individuals in the sample than other age groups and no burials from the advanced age cohort (Table 4).

Kays Landing. The best preserved sample, 40 out of the original 45 burials generated from Kays Landing have usable data. The sample is comprised of 21 (52.5 percent) males, 17 (42.5 percent) females, and 2 (5 percent) unsexable individuals. All three age cohorts are represented in the Kays Landing sample (Table 4). The young age cohort 
composes 20 percent (8/4) of the total sample. Fourteen-point-three percent (3/21) of the males and 29.4 percent $(5 / 15)$ of the females fall within this age group. The middle age group represents the majority of the sample at 60 percent $(24 / 40)$. This cohort represents 61.9 percent $(13 / 21)$ of the total male sample and 64.7 percent $(11 / 17)$ of all females. The advanced age cohort represents 7.5 percent (3/40) of the total sample. All of these individuals are sexed as male and thus represent $14 / 3$ percent $(3 / 21)$ of the total male sample. There are no advanced age female burials (Table 4) .

Thompson Village. The only Mississippian site had 132 individuals, 82 of which have any usable data for this study. Thirty-one (37.8 percent) burials are sexed as male, 40 (48.8 percent) are female, and 11 (13.4 percent) are sex indeterminate. All three age cohorts are represented in the Thompson Village sample. The young age cohort represents only 15.85 percent (13/82) of the total sample. The male component is comprised of 19.4 percent (6/31) of young individuals and 12.5 percent $(5 / 40)$ of the female sample. The middle age cohort is the largest group represented in the sample at 41.5 percent $(34 / 82)$ of the usable burials. Of the males, 45.2 percent (14/31) are in the middle age group while 45 percent (18/40) of the females fall into this cohort. The advanced age group comprises 7.3 percent (6/82) of the total sample and is represented by both sexes. One (3.23 percent) advanced age male (out of 31 ) is present as is 10 percent (4/40) of the female sample. Nineteen individuals could not be aged (Table 4). Subsistence differences. When the Archaic sites were collapsed into a single temporal unit, it became evident that the sex distribution from both time periods is similar for both sexes suggesting little, if any, sex bias in temporal data (Figure 10). 
Interestingly, there is a difference in age demographic of the individuals interred Between subsistence strategies. Demographic data indicate that the Archaic period has a higher occurrence of young burials (40.7 percent) in the sample than the Mississippian (15.9 percent). The Mississippian sample conversely has more middle and advanced age individuals than the Archaic. While the presence of advanced individuals is rare, it is more so in the Archaic than the Mississippian (Table 5).

Table 5. Age Cohort Demographics by Period

\begin{tabular}{lccccc}
\hline & \multicolumn{2}{c}{ Late Archaic } & \multicolumn{2}{c}{ Mississippian } & p-Value \\
& $\mathrm{N}$ & $\%$ & $\mathrm{~N}$ & $\%$ & \\
\hline Young & $48 / 114$ & 40.7 & $13 / 82$ & 15.9 & \\
Middle & $35 / 114$ & 30.7 & $34 / 82$ & 41.5 & \\
Advanced & $3 / 114$ & 2.6 & $6 / 82$ & 7.3 & \\
\hline
\end{tabular}

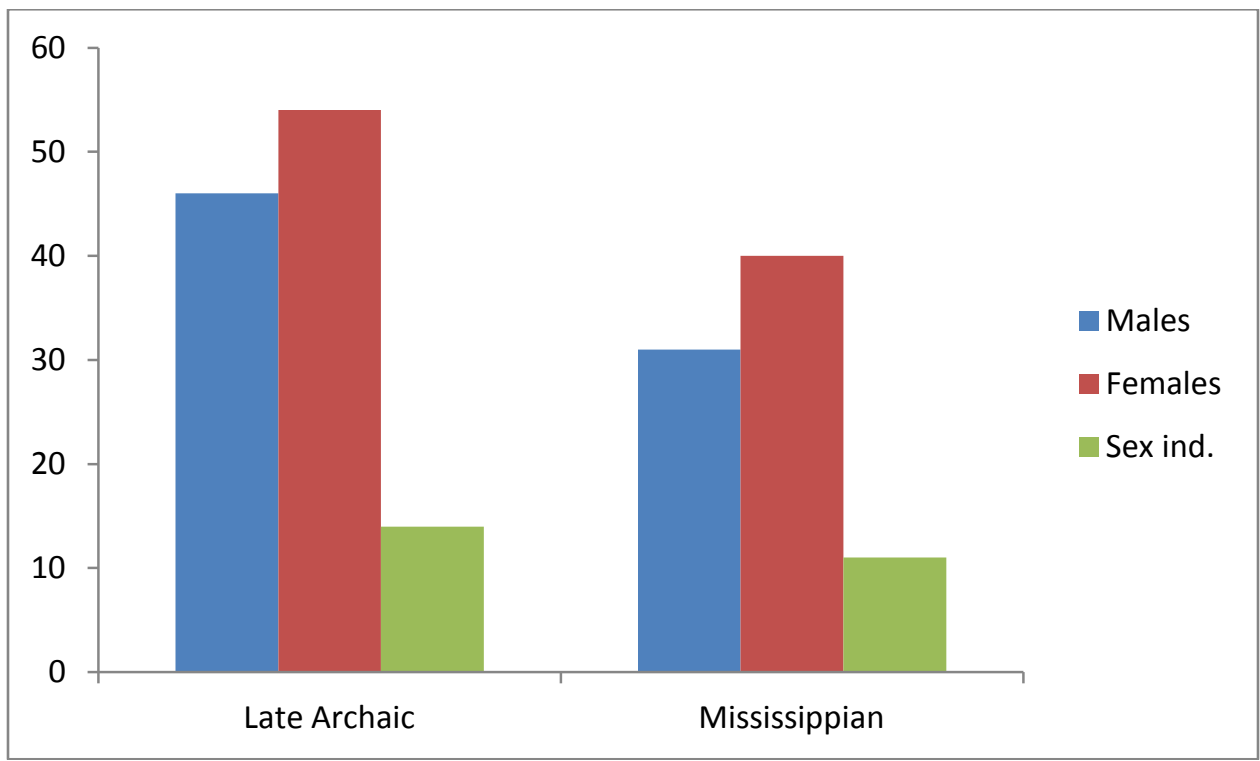

Figure 10. Sex Distribution by Period 


\section{Osteological Change}

The results here indicate the presence of osteological change throughout the Tennessee River Valley. Here, temporal trends appear that that are not necessarily reflected by individual sites.

\section{Enthesopathies by Osteological Landmark}

Temporal differences in the expression of entheseal change are apparent between the Middle and Late Archaic and Mississippian samples. Although entheseal differences were not universally observed at every insertion site, however, patterns emerge when data is collapsed by subsistence strategy.

\section{The Subscapularis}

Eva. The Eva site has 24 individuals with a preserved subscapularis footprint (7 males, 16 females, 1 sex indeterminate). Eighteen left humeri and fifteen right humeri are preserved. Of the left insertions, 33.3 percent (6/18) had pathological changes. The surviving right subscapularis entheses have a slightly higher rate of pathological destruction at 46.7 percent (7/15) of insertions. A one-tailed Fisher's Exact test, determined that enthesopathies are expressed bilaterally $(\mathrm{p}=0.3360)$ (Table 6).

The majority of the left male entheses display normal wear leaving one individual out of six (16.7 percent) with injury to the insertion. Half of the right male humeri (2/4) have pathological damage. In contrast, females have a higher proportion of left-side enthesopathies (5/12, 41.7 percent). Forty percent of the female right humeri (4/10) have enthesopathies. Although side asymmetry may not be present between the sexes, the male sample size is too small to support any hypotheses. Pooled data indicates no sex differences in pathological change to the subscapularis are found in this sample $(\mathrm{p}=0.4273)$ (Appendix A, Table 6). 
Cherry. The Cherry site has 23 individuals with at least one preserved subscapularis insertion (12 males, 9 females, 2 sex indeterminate). Of the twenty-one preserved left arms, 28.57 percent $(6 / 21)$ show pathological changes. In the sixteen preserved right subscapularis footprints, 12.5 percent (2/16) have comparable damage. Statistical analysis suggests that there is no side bias ( $\mathrm{p}=0.2221)$ (Table 6).

Sex based data indicates that 27.3 percent (3/11) of left male humeri and 18.2 percent (2/11) of right male entheses have pathological damage. In comparison, 22.2 percent (2/9) of left female humeri display pathological changes to the subscapularis insertion. All of the surviving right female humeri ( $0 / 4$ enthesopathies) display normal wear. As there is little difference between arms, all usable humeri were pooled by sex and indicate that there is no dimorphism in the sample $(\mathrm{p}=0.4751)$. However, all results for this site should be considered tentative as the sample, particularly segregated by sex, is very small (Appendix A, Figure 6). 
Table 6. Total Humeri by Site with Entheseal Change. P-values Derived from One-tailed Fisher's Exact Tests. * Unsexable Individuals Included

\begin{tabular}{|c|c|c|c|c|c|}
\hline Insertion & Site & $\begin{array}{c}\text { Total } \\
\text { Humeri* } \\
\mathbf{N} \\
\end{array}$ & $\%$ & $\begin{array}{c}\text { Bilateral } \\
\text { differences } \\
\text { P-value } \\
\end{array}$ & $\begin{array}{c}\text { Sex } \\
\text { differences } \\
\text { P-value } \\
\end{array}$ \\
\hline \multirow[t]{4}{*}{ Subscapularis } & Eva & $13 / 33$ & 39.39 & 0.3360 & 0.4273 \\
\hline & Cherry & $8 / 37$ & 21.62 & 0.2221 & 0.4751 \\
\hline & Kays & $14 / 33$ & 42.42 & 0.4201 & 0.1216 \\
\hline & Thompson & $8 / 65$ & 12.31 & 0.5544 & 0.0720 \\
\hline \multirow[t]{4}{*}{ Supraspinatus } & Eva & $5 / 29$ & 17.24 & 0.6038 & 0.4520 \\
\hline & Cherry & $5 / 41$ & 12.20 & 0.2221 & 0.2979 \\
\hline & Kays & $2 / 29$ & 6.90 & 0.1921 & 0.1355 \\
\hline & Thompson & $8 / 65$ & 12.31 & 0.5544 & 0.0583 \\
\hline \multirow[t]{4}{*}{ Infraspinatus } & Eva & $20 / 34$ & 58.82 & 0.6178 & 0.2886 \\
\hline & Cherry & $16 / 41$ & 39.02 & 0.2793 & 0.6042 \\
\hline & Kays & $10 / 32$ & 31.25 & 0.1827 & 0.0029 \\
\hline & Thompson & $21 / 67$ & 31.34 & 0.1659 & 0.2664 \\
\hline
\end{tabular}

Kays Landing. The Kays Landing sample has a total of 21 separate individuals with at least one preserved subscapularis footprint (13 male, 8 female, 0 sex indeterminate). Of the sixteen preserved left arms, 37.5 percent (6/16) display pathological changes. From the seventeen preserved right arms 47.1 percent (8/17) have enthesopathies. No side based differences are present in the sample $(\mathrm{p}=0.4201)$ (Table 6).

Nine of the left humeri belong to males, 44.4 percent (4/9) of whom have enthesopathies of the subscapularis. Only 28.6 percent (2/7) of left female humeri display pathology. A majority (58.3 percent, 7/12) of right male subscapularis insertions has pathological changes; this is not the case for female entheses, 20 percent (1/5) have enthesopathies. Pooled sex data suggests that there are no sex biases in the Kays Landing sample ( $\mathrm{p}=0.1216$ ). As with the Cherry sample, the results should be considered tentative as the samples of males and females are very small (Appendix A, Table 6). 
Thompson Village. At this Mississippian site, 54 separate individuals have a preserved subscapularis footprint (17 males, 31 females, 6 sex indeterminate). Of the thirty-eight left arms, 34.21 percent (25/38) have enthesopathies. Fifty percent (19/38) of the preserved right humeri have pathological changes to the subscapularis insertion. Total side data suggests that there is no evidence of side bias $(\mathrm{p}=0.1226)$ (Table 6).

Five left male humeri out of 13(38.5 percent) show evidence of enthesopathic change. The prevalence among females is slightly lower at 28.6 percent (6/21). Males exhibited a higher rate of entheseal damage in the right arm than in the left at 77.8 percent (7/9). Female rates were closer to those observed in the left arm at 36 percent (9/25). Pooled sex data using a one-tailed Fisher's Exact test suggests that there were nearly statistically significant sex differences $(\mathrm{p}=0.0720)$. Again, due to sampling error, these statistical results are considered tentative. Further investigation of this data will be undertaken in the analysis between temporal periods (Appendix A, Table 6).

Subsistence differences. The collapsed Archaic sample yielded a total of 103 humeri, 35 of which (34 percent) have pathological changes (Table 7). As seen with the individual site data there are no differences between left and right $(\mathrm{p}=0.4680)$ nor are there differences between the sexes $(\mathrm{p}=0.3341)$.

The Mississippian sample had a total of 76 humeri. Of these, 32 (42.1 percent) have enthesopathies. The sample data is exclusively from Thompson Village. Although no side difference are found for the sample, when the sides are separated a different image appears. Left arm data does not indicate sex differences $(\mathrm{p}=0.4086)$. However, the right arm displays statistical significance $(\mathrm{p}=0.0380)$ suggesting that there may be a side- 
based sex bias. In this case, males have higher rates of subscapularis enthesopathies in their right arms than females do.

Comparisons between the Archaic and Mississippian samples indicate that there is no difference between the time period in the prevalence of pathological EC at the subscapularis $(\mathrm{p}=0.1700)$. Additionally, no temporal differences appear between the sexes (male $\mathrm{p}=0.1079$, female $\mathrm{p}=0.4721$ ) $($ Table 7 , Appendix B).

Table 7. Total Humeri by Period with Entheseal Change. P-values Derived from One-tailed Fisher's Exact Tests * Unsexable Individuals Included

\begin{tabular}{lllccc}
\hline Insertion & Period & $\begin{array}{c}\text { Total Humeri } \\
\text { N }\end{array}$ & \multicolumn{2}{c}{$\begin{array}{c}\text { Bilateral } \\
\text { differences } \\
\text { P-value }\end{array}$} & $\begin{array}{c}\text { Sex differences } \\
\text { P-value }\end{array}$ \\
\hline Subscapularis & Archaic & $35 / 103$ & 33.98 & 0.4680 & 0.3341 \\
& Mississippian & $32 / 76$ & 42.11 & 0.5544 & 0.0720 \\
Supraspinatus & Archaic & $12 / 99$ & 12,12 & 0.4237 & 0.1832 \\
& Mississippian & $8 / 65$ & 12.31 & 0.5544 & 0.0583 \\
Infraspinatus & Archaic & $46 / 107$ & 42.99 & 0.5520 & 0.1226 \\
& Mississippian & $21 / 67$ & 31.34 & 0.1659 & 0.2664 \\
\hline
\end{tabular}

\section{The Supraspinatus}

Eva. The Eva site has 21 individuals with at least one preserved supraspinatus footprint (7 male, 13 female, 1 sex indeterminate). Sixteen insertions were preserved from the left side with 18.75 percent (3/16) of them showing pathological changes. Of the 13 surviving right supraspinatus footprints 15.38 percent (2/13) display pathological change. It was determined that there were no statistical differences between side $(\mathrm{p}=0.6038)$.

None of the male left arm entheses (0/8) display abnormal change. Forty percent, (2/5) of the female left insertions have pathological changes on the entheseal surface (Appendix A). For the right supraspinatus insertions, males again, have no pathological damage (0/10) and in this case, neither did females (Table 6). Pooled sex data suggests there are no sex-based differences $(\mathrm{p}=0.4520)$. 
Cherry. There are 26 burials from the Cherry site that had at least one humerus with preserved supraspinatus entheses (13 male, 10 female, 3 sex indeterminate). Twenty-two left humeri have preserved footprints; 9.1 percent (2/22) of these show enthesopathies. Of the nineteen right humeri, 15.79 percent (3/19) have pathological changes. It was determined that there are no statistically significant side differences $(\mathrm{p}=0.2221)$ (Table 6).

As seen in Eva, none of the male left humeri had pathological EC (0/11). Of the female left humeri, 22.2 percent (2/9) have pathological changes to the supraspinatus. From both sexes, 16.7 percent (2/12 males, $1 / 6$ of females) have abnormal changes to the entheses (Table 6, Appendix A). Pooled sex data determined that there are no differences between the sexes $(\mathrm{p}=0.2979)$ (Table 6).

Kays Landing. The Kays Landing sample has 19 individuals with at least one preserved supraspinatus footprint (11 Male, 8 female, 0 sex indeterminate). Thirteen individuals preserved left insertions, 15.4 percent (2/13) of these individuals had pathological changes to the surface and margins. Right humus data indicate 17 remaining entheses, 8 of which have pathological EC (47.1 percent). As with the other two Middle and Late Archaic sites, there are no differences between left and right arms $(\mathrm{p}=0.1921)$ (Table 6).

Both instances of pathological change in the left supraspinatus insertions are in females (40 percent, 2/5). None of the males (0/8) are affected by damage to the insertion. Of the 16 preserved right footprints, there are no (0/16, 0/10 males, $0 / 6$ females) pathological changes found. There are no discernible differences between the sexes found with EC at the supraspinatus (Table 6, Appendix A). 
Thompson Village. At the Mississippian site, Thompson Village, 45 burials have at least one preserved humerus with a supraspinatus footprint (12 male, 27 female, 6 sex indeterminate). A total of 30 left footprints were preserved, 13.3 percent (4/30) of which have enthesopathies. Similar to what is observed with left insertions, 11.4 percent $(4 / 35)$ of the right arms are found to have severe damage. Statistical analysis indicates bilateral expression of the insertion $(\mathrm{p}=0.5544)$ (Table 6).

Thirty percent (3/10) of the left male insertions have pathological changes. None of the left female humeri have any change (0/17). One male (out of 7$)$ (14.3 percent) has an enthesopathy of the right supraspinatus. Right female humeri display 8.7 percent (2/23) severe changes. Statistical analysis suggests a near statistically significant bias between the sexes $(\mathrm{p}=0.0583)$ which is similar to what was observed in the Thompson Village sample for the subscapularis data. Again, this data may reflect sampling bias or it could be an indication of sexually dimorphic behaviors related to subsistence strategies (Table 6, Appendix A).

Subsistence differences. When the site data are collapsed, differences between some of the individual sites disappear. Of the 99 total humeri recovered from the Archaic sample, 12.1 percent (12/99) have supraspinatus enthesopathies. A total of 13.7 percent $(7 / 51)$ of left supraspinatus insertions from the Middle and Late Archaic period sample have pathological changes. Analogous damage could be found in 10.42 percent $(5 / 48)$ of the right entheses. The Archaic sample did not have any statistically significant differences between the right and left arms $(\mathrm{p}=0.4237)$ (Table 7).

Although at individual sites females were observed to have higher rates of pathological EC than males, when the data are collapsed, males in the Archaic were 
deemed to have similar rates of EC to females. In males, 32.1 percent (9/28) of left arms and 26.3 percent of right $(5 / 19)$ have enthesopathies. Female data indicate that 30.8 percent (8/26) of left arms and 35.8 percent (11/27) of right arms have similar pathological change. Pooled sex data also indicate no sex-based differences within the temporal frame despite the fact that females have a higher rate of entheseal change $(\mathrm{p}=0.1832)($ Table 7, Appendix B).

The Mississippian dataset is identical to that of Thompson Village. Pooled data comparisons suggest no distinction between enthesopathies of the supraspinatus between the Archaic and Mississippian $(\mathrm{p}=0.5773)$. Pooled sex data between the sites shows no difference between the males $(p=0.1002)$ or the females $(p=0.1024)$ in either sample. (Table 7).

\section{The Infraspinatus}

Eva. Eva has 23 burials were at least one infraspinatus footprint is found (7 male, 15 female, 1 sex indeterminate). Of the 20 preserved left arms, 30 percent $(6 / 20)$ have pathological change. Four out of the fourteen observed right humeri (28.57 percent) display comparable damage. Further analyses of these data suggest that entheseal damage is bilateral $(\mathrm{p}=0.6178)$ (Table 6).

Seven left male entheses were preserved. From these, only one (14.3 percent) exhibit enthesopathies. This is a lower rate than that observed in the females which is 33.3 percent (4/12). Right arm data from the same sample suggests similar rates of enthesopathies to that observed in the left. From these humeri, a quarter of the male sample (1/4) and 30 percent (3/10) of the female sample have pathological damage to the infraspinatus insertion (Appendix A). The lack of side differences allowed me to pool the 
sex data and analyze it based on total humeri. These data suggest that there are no sex differences $(\mathrm{p}=0.2886)$.

Cherry. The Cherry site has 26 individuals with at least one preserved infraspinatus footprint (13 male, 10 female, 3 sex indeterminate). Of the preserved left entheses, 45.5 percent (10/22) yield pathological changes. Right infraspinatus insertions indicate slightly lower rates of enthesopathies at 31.6 percent (6/19). Statistical analysis proposes that there are no differences in pathological change between the left and right side $(\mathrm{p}=$ 0.2793 ) (Table 6).

Eleven left entheses were preserved in males, four of whom (36.4 percent) have enthesopathies. Right side data for males indicates analogous damage at 33.3 percent (4/12). Female data show that 44.4 percent (4/9) of left $s$ and 16.7 percent (1.16) of the right insertions has enthesopathies (Appendix A). No sex-based differences are observed on infraspinatus footprints in the Cherry sample $(\mathrm{p}=0.6042)$ (Table 6).

Kays Landing. Kays Landing yields 21 burials that have at least one preserved infraspinatus footprint (12 male, 9 female, 0 sex indeterminate). Of the preserved left footprints 20 percent (3/15) have pathological reactive change. Seventeen right humeri preserved from the sample. Of these, 41.2 percent (7/17) have pathological changes to the infraspinatus insertion. There is no statistical indication of there being a side bias $(\mathrm{p}=0.1827)$.

Nine of the intact left infraspinatus insertions were male; 33.3 percent (3/9) have pathological changes. Conversely, a majority of the right male humeri (63.6 percent, 4/11) have enthesopathies (Appendix A). None of the 6 left or 6 right female humeri, have entheseal damage (Appendix A). Statistical analysis of the data suggests that there is 
a sex-based difference $(\mathrm{p}=0.0029)$ (Table 6). Only males exhibit enthesopathies. This is different than what was observed in the other two Middle and Late Archaic samples. Thompson Village. The Mississippian sample, Thompson Village has 48 surviving infraspinatus footprints (12 male, 30 female, 6 sex indeterminate). Insertional data for the preserved left entheses indicates that 24.24 percent (8/33) have pathologies. Likewise, 38.2 percent (13/34) of the right infraspinatus insertions from the Thompson Village sample have enthesopathies. No side bias was observed $(\mathrm{p}=0.1659)$ (Table 6).

Few of males with intact left entheses exhibit enthesopathies at 9.1 percent $(1 / 11)$ of the sample. Six of nineteen females (31.6 percent) with left insertions exhibit similar injuries. Infraspinatus insertional data for the right arm states that, 66.7 percent (4/6) of males and 33.3 percent (8/24) of females exhibit pathological change (Appendix A). Despite the trend toward right-sided pathologies in the males, statistical analysis indicates no sex bias in the sample $(\mathrm{p}=0.2664)$ (Table 6).

Subsistence differences. Here is must be noted that variation between the Archaic sites disappears when the sample is collapsed. The Middle and Late Archaic sample yielded 46 out of 107 (42.9 percent) total humeri with pathological changes to the infraspinatus insertion. Left humeri from this sample had similar rates of pathology; 33.3 percent (19/57) and 34 percent (17/50) respectively. No side differences are observed in the Archaic sample $(\mathrm{p}=0.5520)$ (Table 7).

Archaic males express similar rates of enthesopathies to females. In males, 29.6 percent (8/27) of left infraspinatus insertions have EC where as 44.4 percent (12/27) of right entheses have the same. Left humeri in the Archaic females have identical entheseal data as their male counter parts. It is the right arm data which is substantially lower than 
that observed in either sample where only 18.2 percent (4/22) of infraspinatus insertions have pathological changes. Using pooled data, no statistical sex differences are observed either $(\mathrm{p}=0.1226)$ (Table 7, Appendix B).

As with the other entheseal points, the Mississippian period data comprises only of the data gathered for Thompson Village. Infraspinatus enthesopathies are observed bilaterally to occur at similar rates $(\mathrm{p}=0.1659)$. There are no observable sex differences in the Mississippian sample ( $\mathrm{p}=0.2664)$ (Table 7, Appendix B).

Middle and Late Archaic and the Mississippian data indicate that there are no differences in pathological changes at the infraspinatus between subsistence strategies $(\mathrm{p}=0.4426)$ (Table7). Additionally, no temporal differences between enthesopathies in males $(\mathrm{p}=0.3945)$ nor are there in females $(\mathrm{p}=0.2656)$.

\section{Teres Minor Rugosity}

As no surface or marginal alterations (porosity, porosities, erosion, cavitations, etc.) to the teres minor enthesis were observed, different procedures were taken to measure stress at the insertion. The teres minor is observed as having differing levels of rugosity (robusticity) (scores of $\mathrm{N}$ [none], I [incipient], and $\mathrm{F}$ [full] with respect to the distinct shape changes of the insertion platform.

Eva. Nineteen individuals have at least one teres minor insertion preserved (4 male, 14 female, 1 sex indeterminate). Fifteen left arms are preserved, eleven of which (73.3 percent) of which were rugose. Eleven total right humeri with preserved teres minor insertions were recovered in the Eva sample. No side-based differences are apparent $(p=0.1504)$. 
All of the males from this sample (3/3) have rugose attachment sites, although only one individual have heavily altered margins. Left female insertions are more varied. Although a majority of females have well delineated insertional margins (72.7 percent, 8/11), only half of those are particularly rugged (i.e. scores of F) (Table 8). Only 2 male teres minor footprints preserved, both of which have well defined margins. One of these is highly rugose (score F). Three out of the nine female teres minor entheses have identifiable platforms, none of which are heavily modeled (score I). Differential sexual expression was nearly statistically significant $(\mathrm{p}=0.0822)$ (Table 8$)$. This may be the result of dimorphic behaviors or sampling size error, which, with a small sample of males is a reasonable explanation.

Table 8. Humeri with Rugose Teres Minor Insertions by Site * Unsexable Individuals Included

\begin{tabular}{ccccc}
\hline & $\begin{array}{c}\text { Total humeri } \\
\text { with rugose } \\
\text { insertions* } \\
\text { N }\end{array}$ & $\%$ & $\begin{array}{c}\text { Bilateral } \\
\text { differences } \\
\text { P-value }\end{array}$ & $\begin{array}{c}\text { Sex } \\
\text { differences } \\
\text { P-value }\end{array}$ \\
\hline Eva & $16 / 26$ & 61.54 & 0.1504 & 0.0822 \\
Cherry & $19 / 34$ & 57.89 & 0.4841 & 0.5527 \\
Kays Landing & $19 / 23$ & 82.61 & 0.2609 & 0.6482 \\
$\begin{array}{c}\text { Thompson } \\
\text { Village }\end{array}$ & $42 / 47$ & 89.36 & 0.1605 & 0.2706 \\
\hline
\end{tabular}

Cherry. The Cherry sample yielded 24 separate burials with at least one preserved teres minor enthesis (13 male, 9 female, 2 sex indeterminate). Half of the left arms $(9 / 18)$ have delineated margins. Right arm data indicate state that 10 individuals out of 16 preserved 
teres minor entheses (62.5 percent) had robust margins. Like Eva, the Cherry sample indicates bilateral rugosity $(\mathrm{p}=4841)$ (Table 8).

Of the left teres minor entheses, four males, out of nine ( 44.4 percent) have marked margins (i.e. incipient) none of which have particularly heavy bone growth (i.e. full). Half of the females in left sample (4/8) have defined margins (I) with one individual with rugose $(\mathrm{F})$ insertional margins. In males, 70 percent of individual right insertions (7/10) have defined margins (incipient and full). Sixty percent of females (3/5) with teres minor insertions exhibit rugose entheses. One individual from each sexes has high scoring (i.e. F) insertions. Pooled sex data indicates that there are no differences in the exhibition of rugose teres minor insertions (either I or F) between males and females $(\mathrm{p}=0.5527)$ (Table 8).

Kays Landing. The smallest sample, Kays Landing yields only 15 separate individuals (10 males, 5 females, 0 sex indeterminate) with teres minor insertions. The sample has the highest number of bilateral preservation with 8 individuals. Eleven left humeri were preserved, 8 of which (72.5 percent) have defined entheseal margins (scores of I or F). A majority, 91.67 percent, of right teres minor entheses (11/12) from the Kays landing sample have rugose alterations (either I or F) to their entheseal surfaces. This is a much higher rate than observed at the other Archaic samples. As with the other sites, there are no statistically significant differences between left and right arm rugosity $(\mathrm{p}=0.2609)$ (Table 8).

Five out of eight males with left teres minor insertions (62.5 percent) have rugose margins with two individuals as fully developed $(\mathrm{F})$ rugose entheseal surfaces. All of the females in the left hand sample (3/3) display rugged insertional margins. Only one of 
these women has an F score. All of the right male humeri (8/8) have rugged insertional growth (I or F). One of these males has F level remodeling to the margin. Seventy-five percent of females (3/4) have similar marginal buttressing. None of the women have the highest level of bone growth. Similar to the other two Archaic sites, no side or sex differences are found using statistical analysis $(\mathrm{p}=0.6482)$ (Table 8).

Thompson Village. The largest of the samples, the Mississippian site, Thompson village, yields 37 burials with at least one preserved teres minor insertion ( 9 males, 22 females, 4 sex indeterminate). All male humeri in the Thompson Village sample have rugose muscle insertions (I or F). Twenty-three total left arms were recovered for the Thompson village sample, nineteen of which (83.61 percent) have rugged insertional growth. This is a higher rate than that observed at any of the Archaic sites. The right teres minor entheses that were preserved are found at a similar rate to those observed at Kays Landing. In 95.8 percent of humeri (23/24), rugosity is observable. Statistical analysis indicates the presence of bilateral rugosity $(\mathrm{p}=0.1605)$ (Table 8$)$.

All of the males in the left side sample (7/7) have defined insertional margins (I or F level). Two of these men preserved heavily altered (F score) footprints. Ten out of the thirteen females (76.9 percent) have visible entheses. Five of these women have F level insertional footprints. Every male with a preserved right humerus have a rugose enthesis (Table 8). A majority of females in the sample, 94.1 percent, exhibit defined margins (I or F); half of those women exhibit exuberant $\mathrm{F}$ level marginal buttressing (Table 8). The analysis, using pooled sex data, indicates that there are no sex based differences in the sample $(\mathrm{p}=0.2706)$. 
Subsistence differences. Teres minor insertional rugosity is relatively common in the Middle and Late Archaic sample. Over half ( 54 / 83) of the total teres minor insertions have either a partially (I) or fully formed (F) margins (65.1 percent). Bilateral expression of insertional growth was apparent in the Archaic $(\mathrm{p}=0.3518)$. Sex based differences are also not apparent in the Archaic $(\mathrm{p}=0.1722)$ (Table 9).

The Mississippian sample has a higher rate of well defined entheseal margins of either partially (I) or fully formed (F) margins at 89.4 percent of all humeri (42/47). Side and sex data is identical to that observed in the Thompson Village sample (Table 9).

Severity based investigations of teres minor rugosity (I versus F) by subsistence strategy was undertaken. Statistical analysis suggests and overall difference between time periods in the presence of rugose teres minor insertions $(\mathrm{p}=0.0017)$ (Table 10). Two tailed 2X3 Fisher's exact tests show even more significant temporal differences when severity was taken into account ( $\mathrm{p}=0.0004)$. Similar patterns were observed between all male and all female humeri (Table 10; Table 11).

Table 9. Humeri with Rugose (I and F) Teres Minor Insertions by Period. * Unsexable Individuals Included

\begin{tabular}{lcccc}
\hline & $\begin{array}{c}\text { Total humeri } \\
\text { with rugose } \\
\text { insertions* } \\
\text { N }\end{array}$ & $\%$ & $\begin{array}{c}\text { Bilateral } \\
\text { differences } \\
\text { P-value }\end{array}$ & $\begin{array}{c}\text { Sex } \\
\text { differences } \\
\text { P-value }\end{array}$ \\
\hline Archaic & $54 / 83$ & $65.06 \%$ & 0.3518 & 0.1722 \\
Mississippian & $42 / 47$ & 89.36 & 0.1605 & 0.2706 \\
\hline
\end{tabular}

When the data are separated by side, a different picture emerges. None of the lefthand data indicated statistical significant differences between subsistence patterns in either comparison between rugosity presence absence and when comparing levels of 
rugosity (I versus F)(Table 10, Table 11). Analysis of the right side indicates a statistical difference between temporal periods. Sex based inquiry, however, shows differences in stress between temporal periods. No statistical difference is observed between males of either temporal data, but a distinct temporal difference in teres minor ruggedness in females (both in rugosity absence/presence and in rugosity levels [N versus I versus $\mathrm{F}]$ ) between the Middle and Late Archaic and the Mississippian in Table 10and Table 11.

Table 10. Fishers Exact Scores Comparing Teres Minor Rugosity Presence (N versus I and F)

\begin{tabular}{llll}
\hline & Left & Right & L+R \\
\hline Male & 0.0567 & 0.5632 & 0.0485 \\
Female & 0.4403 & 0.0047 & 0.0132 \\
Total & 0.0897 & 0.0056 & 0.0017 \\
\hline
\end{tabular}

Table 11. Fishers Exact Scores Comparing Teres Minor Rugosity Development (N versus I versus F)

\begin{tabular}{llll}
\hline & Left & Right & L+R \\
\hline Male & 0.0879 & 0.2377 & 0.0394 \\
Female & 0.8255 & 0.0028 & 0.0185 \\
Total & 0.2374 & 0.0005 & 0.0004 \\
\hline
\end{tabular}

\section{Acromioclavicular Degenerative Joint Disease}

This is an investigation of reactive change at two opposing joint surfaces, the clavicular articular facet (clavicular facet) of the scapula and the acromial articular facet 
of the clavicle which comprise the acromioclavicular joint. At both facets a combination of reactive change comprising pitting, osteophytic bone growth, deformation at both the joint surface and margins were used to determine the presence or absence of pathological joint degeneration.

Deterioration at the $\mathrm{AC}$ joint has been closely associated with subacromial impingement, the primary pathology clinically identified in rotator cuff disease (Bigliani and Levine, 1997; Frost and Anderson, 1997; Mall et al., 2013; Roberts et al., 2007). Reactive change at the acromioclavicular joint may be the result of continuous abduction or cross-body movement of the arm, especially in heavy load-bearing conditions. Additionally (micro) trauma to the juncture of the upper limb to the axial skeleton or directly to the clavicle may also result in degenerative changes to the joint surfaces. The Clavicular Articular Facet

Reactive change at the clavicular articular facet was scored as present when at least two-thirds of the joint surface was present. Joint surfaces were scored in accordance with the DJD scoring methods in Chapter IV.

Eva. Twenty-four separate individuals preserved their acromion processes ( 7 males, 16 females, 1 sex indeterminate). From the 24 burials, 28 total acromia were preserved. From these, 39.3 percent (11/28) of the clavicular facets have reactive change to the joint surface. A total of 15 left clavicular facets were preserved, a third of which have reactive change (5/15). Six right clavicular facets from the Eva sample from the 13 recovered (46.15 percent, 6/13) display reactive change. Statistical analysis suggests bilateral expression of reactive change $(\mathrm{p}=0.3800)$ (Table 12). 
Five of the fifteen surviving left acromia belonged to males. Two of these individuals (40 percent) have degenerative change to the clavicular facet. Four male acromia survived from the right side sample, half of which $(2 / 4)$ have reactive changes to the joint surface. Females comprise 10 of the surviving left clavicular facets. Thirty percent of the acromia (3/10) have reactive change. Eight of the preserved right acromia are female. Half of these facets (4/8) have degenerative changes. Statistical analysis of sex differences indicates no sex bias $(\mathrm{p}=0.5512)$.

Although age was not investigated closely in this analysis, it is imperative to note that none of the individuals in this sample are from the oldest age cohort indicating that degenerative change occurred among mostly young individuals in the Eva sample. DJD is seen as a progressive pathology with skeletal change beginning around middle age and fully expressing at advanced age. The high rate of DJD in the young cohort indicates heavy stress at a young age.

Table 12. Clavicular Facets with DJD by site. * Unsexable Individuals Included

\begin{tabular}{ccccc}
\hline & $\begin{array}{c}\text { Total clavicular } \\
\text { facets* } \\
\mathbf{N}\end{array}$ & $\%$ & $\begin{array}{c}\text { Bilateral } \\
\text { differences } \\
\text { P-value }\end{array}$ & $\begin{array}{c}\text { Sex } \\
\text { differences } \\
\text { P-value }\end{array}$ \\
\hline Eva & $11 / 28$ & 39.29 & 0.3800 & 0.5512 \\
Cherry & $0 / 32$ & 0.0 & 1.0000 & 1.0000 \\
Kays Landing & $6 / 21$ & 28.57 & 0.3673 & 0.3673 \\
$\begin{array}{c}\text { Thompson } \\
\text { Village }\end{array}$ & $12 / 30$ & 40 & 0.2452 & 0.3909 \\
\hline
\end{tabular}


Cherry. The Cherry sample yields 26 burials with at least one preserved acromion process (12 male, 8 female, 1 sex indeterminate). No degenerative change is documented in any of the 32 acromion processes in this sample (Table 12). This suggests that males and females did not engage in strenuous enough activity to affect the clavicular facet of the acromion process (Table 12).

Kays Landing. Fifteen individuals preserved at least one acromion ( 8 male, 7 female, 1 sex indeterminate). Although the sample is small, 21 total acromion processes with clavicular facets were recovered. Six of these 21 joint surfaces (28.6 percent) express erosion. Twenty percent (2/10) of left and 36.4 percent (4/11) of right clavicular facets have degenerative changes. Further analysis indicates bilateral expression of reactive changes $(\mathrm{p}=0.3673)$.

Two out of five ( 40 percent) of the male left scapulae have reactive modifications to the clavicular facets. Similarly, 33.3 percent of right male acromia exhibit degenerative change. None of the female left clavicular facets (0/5) have damage. Right clavicle data is similar to that observed in the rest of the sample where 40 percent of the clavicles (2/5) display reactive modifications. Statistical analysis of the sex data indicates no difference in degenerative change between males and females $(\mathrm{p}=0.3673)$ (Table 12).

Thompson village. The Mississippian sample has twenty-four separate burials with at least one preserved clavicular facet ( 9 males, 13 females, 2 sex indeterminate). Thirty total acromia were recovered from the sample. Forty percent of the clavicular facets have joint erosion (12/30) Nineteen intact left acromia were excavated, 47.4 percent (9/19) of them have degenerative modifications. Three out of the eleven (27.3 percent) right humeri have similar skeletal changes. No side differences are found $(\mathrm{p}=0.2452)$. 
Males comprised 8 out of the 19 left acromia. Of these, 5 (62.5 percent) have degenerative changes to the clavicular articular facet. Only four of the right acromia are male, individual has joint damage. In females, forty percent of the left and one-third (2/6) of the right-hand acromial sample have degeneration. Analysis of pooled sex data indicates no difference in the expression of reactive changes $(\mathrm{p}=0.3909)$ (Table 12). Subsistence differences. Thirty percent of the Middle and Late Archaic sample (17/81 of the total preserved acromia) have degenerative change to the clavicular facet have DJD. Seven, out of the 43 available left clavicular facets (16.3 percent) have reactive damage. Similar changes were observed in the right side data, where 26.3 percent $(10 / 38)$ of the facets. Bilateral expressions of reactive change was present within the Archaic $(\mathrm{p}=0.2022)$. Additional analysis indicates similar appearance of degenerative change between the sexes within the Archaic ( $\mathrm{p}=0.2452)$ (Table 13).

Total acromial data from the Mississippian sample indicates a higher rate of reactive change to the clavicular facet ( 40 percent) than that observed in the Middle and Late Archaic. No side $(\mathrm{p}=0.2452)$ or sex $(\mathrm{p}=0.3909)$ bias are observed within the sample (Table 13).

When total acromial data was pooled and compared, a significant difference becomes apparent in the presence/ absence of reactive changes to the clavicular facet between the Archaic and Mississippian ( $\mathrm{p}=0.0397)$ with the agricultural group displaying higher rates of DJD than the hunter-gatherers. This is similar to what is observed in the rates of teres minor rugosity between samples. When compared, the total left side data indicates a statistically significant difference between the Archaic and the Mississippian 
sample ( $\mathrm{p}=0.0132)$. This difference is not observed in the collective right side acromial data $(\mathrm{p}=0.4839)$.

There is a very nearly statistically significant difference in the expression of degenerative change in males between temporal samples $(\mathrm{p}=0.0604)$. Further analysis of the male sample indicates a difference in degenerative change of the left acromia between temporal period $(\mathrm{p}=0.0374)$. No differences are observed in the right acromia between subsistence strategies (0.6959). Data suggests that there is a higher rate of DJD in the Mississippian. This may be because the Mississippian sample was so small. There are no statistical differences between the females in either subsistence strategy $(p=0.1925)$. No differences are observed in the expression of reactive change in either side (left $\mathrm{p}=0.1148$, right $\mathrm{p}=0.6506)$.

Table 13. Clavicular Facets with DJD by Period. * Unsexable Individuals Included

\begin{tabular}{lcccc}
\hline & $\begin{array}{c}\text { Total Clavicular } \\
\text { facets* } \\
\mathbf{N}\end{array}$ & $\%$ & $\begin{array}{c}\text { Bilateral } \\
\text { differences } \\
\text { P-value }\end{array}$ & $\begin{array}{c}\text { Sex differences } \\
\text { P-value }\end{array}$ \\
\hline Archaic & $17 / 81$ & 20.99 & 0.2022 & 0.5707 \\
Mississippian & $12 / 30$ & 40 & 0.2452 & 0.3909 \\
\hline
\end{tabular}

\section{The Acromial Articular Facet of the Clavicle}

Reactive change at the acromial articular facet was scored as present when at least two-thirds of the joint surface was present. They were scored in accordance with the DJD scoring methods in Chapter IV.

Eva. Twenty-seven unique burials were recovered with at least one clavicle with a preserved acromial articular facet (acromial facet) from Eva (7 male, 17 female, 3 sex indeterminate). Thirty-eight total clavicles were recovered from the site. Thirteen of these 
clavicles (34.2 percent) display degenerative erosion. Twenty left clavicles were preserved, 8 of which (40 percent) have quantifiable change to the joint surface. Conversely, 5 out of the 18 preserved right clavicles ( 27.8 percent) display degenerative change (Table 14). No bilateral bias is observed within the sample $(\mathrm{p}=0.3273)$ (Table 14).

Males preserved seven left acromial facets, three of which (42.9 percent) display reactive changes. In addition, they preserved 5 right clavicles two of which have degeneration (40 percent). Females exhibit slightly lower rates of joint erosion with four out of eleven left acromial facets( 36.4 percent) and three out of eleven right clavicles (27.3 percent) demonstrating reactive change (Table 14). No sex differences are apparent within the sample $(\mathrm{p}=0.4173)$ (Table 14).

Table 14. Acromial Facets with DJD by Site . * Unsexable Individuals Included

\begin{tabular}{ccccc}
\hline & $\begin{array}{c}\text { Total clavicular } \\
\text { facets* } \\
\mathbf{N}\end{array}$ & $\mathbf{\%}$ & $\begin{array}{c}\text { Bilateral } \\
\text { differences } \\
\text { P-value }\end{array}$ & $\begin{array}{c}\text { Sex } \\
\text { differences } \\
\text { P-value }\end{array}$ \\
\hline Eva & $13 / 38$ & 34.21 & 0.3273 & 0.4173 \\
Cherry & $15 / 36$ & 41.67 & 0.1957 & 0.5602 \\
Kays Landing & $20 / 32$ & 62.5 & 0.6072 & 0.2500 \\
$\begin{array}{c}\text { Thompson } \\
\text { Village }\end{array}$ & $27 / 52$ & 51.92 & 0.0805 & 0.5000 \\
\hline
\end{tabular}

Cherry. The sample yielded 24 individuals that preserved at least one clavicle with an intact acromial articular facet ( 12 male, 10 female, 2 sex indeterminate). The sample is comprised of 36 humeri, 41.7 percent of the total sample (15/36) has joint erosion. A total of 21 left clavicles were recovered in the Cherry sample. One-third of the sample (7/21) has the scoreable reactive changes to the acromial facet. Eight out of the surviving 15 
right clavicles (53.3 percent) have similar change (Table 14). Although it seems that the right side have substantially more degenerative change, statistical analysis indicates there is no side bias $(\mathrm{p}=0.5602)$ (Table 14).

From the 21 total left arms recovered from Cherry, 10 belonged to males. Thirty percent (3/10) of the left male clavicles have reactive changes. Nine of the remaining left clavicles are noted to belong to female burials. Similar to the males 33.3 percent (3/9) of the acromial facets have reactive changes. Right clavicle data displays slightly higher rates of degeneration in both sex samples. Of the right male acromial facets, 62.5 percent (5/8) have joint modification. Female data from the right side, 42.3 percent (33/7) of clavicles have comparable alterations. No sex bias is observed within the sample $(\mathrm{p}=0.5602)$.

Kays Landing. Twenty-three individuals with at least one acromial facet of the clavicle preserved were recovered from the Kays Landing sample (14 male, 8 female, 1 sex indeterminate). The 23 burials yielded a total of 32 clavicles, 62.5 percent (20/32) of which have joint degeneration (Table 14). Nineteen left clavicles with acromial facets were excavated from the sample. Twelve individuals, of the nineteen (63.2 percent), exhibit reactive joint changes. Similarly, 8 out of the thirteen right clavicles $(61.5$ percent) display similar erosion. No side bias is observed in the sample $(\mathrm{p}=0.6072)$ (Table 14).

Left clavicle data, when examined by sex, indicated that 66.7 percent of both male and female samples (8/12 and 4/6 respectively) have degenerative changes. Right side data is a bit more varied. Seventy-five percent of the male right clavicles (6/8) and a quarter of female clavicles (1/4) have this level of change to the acromial joint surface 
Analysis of pooled sex data indicated there are no differences in DJD expression between the sexes $(\mathrm{p}=0.2500)($ Table 14$)$.

Thompson Village. The Mississippian sample yielded 34 burials with at least one preserved acromial facets (13 male, 19 female, 2 sex indeterminate). Fifty-two total clavicles were recovered from Thompson Village. Twenty-seven of these clavicles (51.9 percent) display reactive change (Table 14). Sixty-four percent of the left clavicles $(16 / 25)$ have this change to the joint surface. Total right-hand data indicates 40.7 percent of the sample (11.27) has similar modifications. A near statistically significant side bias is observed in the sample $(\mathrm{p}=0.0805)$ with a higher rate of reactive change in the left clavicle (Table 14).

Eleven of the left clavicles preserved in the sample were sexed as male. Six of these clavicles (54.6 percent) have degenerative changes. Only 40 percent (4/10) of the left male clavicles have comparable damage. Female data suggests a high rate of damage for the left hand data at 71.4 percent of clavicles (10/14). In contrast, only one-third (5/13) of the right female clavicles have reactive change to the acromial facet. Despite these differences, no sex bias is observed within the Thompson Village sample $(\mathrm{p}=0.5000)$

Subsistence differences. One-hundred and six clavicles, from 74 individuals were recovered from the Middle and Late Archaic sample. Forty-eight acromial facets (45.3 percent) have reactive degeneration. Forty-five percent of the left clavicles (27/60) and 45.7 percent of the right clavicles (21/46) exhibit joint erosion (Table 15). Again, no side bias in presence is observed $(\mathrm{p}=0.5513)($ Table15). 
Additional analysis of the Archaic data indicates a 90 percent confidence level statistically significant difference between the sexes $(\mathrm{p}=0.0753)$ (Table 15). Looking into this further, left-hand data indicates no statistical bias between the sexes $(p=0.4318)$, however, a bias was observed in the right clavicular data $(\mathrm{p}=0.0468)$. Males and females displayed similar rates of degeneration in the left clavicle. However, right acromial facet data indicates males have a higher rate of erosion (Table 15).

Mississippian data is identical to that gathered for Thompson Village. The sample yields a slightly higher rate of joint reactive change to the total acromial facets (Table 15). The near statistically significant side bias in the sample $(\mathrm{p}=0.0805)$ warrants further analysis. To do this, side differences are examined within sex cohorts. No side bias is observed within the male sample $(\mathrm{p}=0.4100)$, yet, is noticeable within the female sample $(\mathrm{p}=0.0457)$. The female data indicate higher rates of degeneration in the left clavicle (Table 15).

Pooled acromial data indicates no difference in reactive change of the acromial articular facet between subsistence strategies $(\mathrm{p}=0.2689)$. When compared by sex, males do not show any statistical difference between periods $(\mathrm{p}=0.4841)$ nor are there temporal difference between females $(\mathrm{p}=0.1624)$.

Table 15. Acromial Facets with DJD by Period. * Unsexable Individuals Included

\begin{tabular}{lcccc}
\hline & $\begin{array}{c}\text { Total } \\
\text { Acromial } \\
\text { facets* } \\
\mathbf{N}\end{array}$ & $\%$ & $\begin{array}{c}\text { Bilateral } \\
\text { differences } \\
\text { P-value }\end{array}$ & $\begin{array}{c}\text { Sex } \\
\text { differences } \\
\text { P-value }\end{array}$ \\
\hline Archaic & $48 / 106$ & 45.28 & 0.5513 & 0.0753 \\
Mississippian & $27 / 52$ & 51.92 & 0.0805 & 0.5000 \\
\hline
\end{tabular}




\section{Skeletal Robusticity}

This limited investigation of skeletal robusticity provides a precursory look at the possible changes observed between the Middle and Late Archaic and the Mississippian periods. The data samples are only represented by two sites, Kays Landing and Thompson Village.

Kays Landing. Previous data has suggests that Kays Landing may be a bit of an outlier in terms of mechanical stress within the Archaic. In many cases the skeletal change observed in this sample were more similar to that of the Mississippian site than to the other Archaic site within the sample. Yet, Kays Landing still represents a hunter-gatherer life style. Fourteen unique individuals preserved at least one measurable humerus within the sample ( 8 male, 6 female and 0 sex indeterminate).

The entire sample yielded a total of 18 measurable humeri. The mean robusticity of the total Kays Landing sample was 11.47. The data suggest that right and left robusticity is relatively symmetrical with right arms being slightly larger than the left (Table 16).

When divided by sex, males are observed to have higher skeletal robusticity than females. There is, however, no great indication of sexual dimorphism in overall robusticity. The sample may be biased because only two measurable left humeri were observed in the female sample. This may also be an indication of side bias, but as neither of these individuals possesses corresponding right humeri it is difficult to tell.

Of note, the smallest robusticity score in the sample was the right humerus of a young female (9.97), Burial 57. No health data is known about her other than the fact that 
she did not display any degenerative changes to her enthesis. It is known that she engaged in some heavy manual labor because rugose buildup was observed at the corresponding teres minor insertion.

In the three males where both right and left humeri were measurable, there does not seem to be a significant side bias; further corroborating the overall data.

\section{Table 16. Mean Robusticity at Kays Landing}

\begin{tabular}{cccc}
\hline & Left & Right & Total \\
\hline Male & 11.99 & 11.72 & 11.86 \\
Female & 10.39 & 11.63 & 11.01 \\
Total & 11.23 & 11.71 & 11.47 \\
\hline
\end{tabular}

Thompson Village. Robusticity data was gathered for 15 individuals in the sample (7 male, 6 female, 2 sex indeterminate). Measurements were not taken for all eligible humeri. Nineteen total humeri were measured for this assessment. The average robusticity for the humeri of Thompson Village is 12.4. A side bias is apparent within the sample where right humeri are generally more robust than the left (Table 17).

Sex data suggest that unlike the Archaic, Mississippian females have slightly more robust humeri than males. There is a possibility that this difference is related to sampling error as there were only two right humeri preserved by males. This may also indicate that females were placed under higher physical stressors proportionally to males during development. The measurement data for females may also be skewed by a single, particularly robust individual. The left arm of that woman, Burial 36, was at the high end of robusticity measurements (13.71) and her right arm has the highest robusticity score (14.61) expressed for the right-hand data. 
Table 17. Mean Robusticity at Thompson Village

\begin{tabular}{cccc}
\hline & Left & Right & Total \\
\hline Male & 12.56 & 12.89 & 12.72 \\
Female & 12.74 & 13.06 & 12.90 \\
Total & 11.99 & 12.89 & 12.44 \\
\hline
\end{tabular}

Subsistence differences. The data indicate that between the two samples, the Mississippian sample has higher scores, on average, of skeletal robusticity. Additionally, both samples indicate a slight right-hand bias in robusticity which may be linked to handedness, although none of the other stress indicators indicate that handedness is an important stress factor in any of the samples (Table 16, Table 17).

Finally, males in the Archaic sample have higher robusticity scores than females where as males from the Mississippian were less robust than females. This is an interesting difference suggesting a shift in workload for males and females. 


\section{CHAPTER VI}

\section{DISCUSSION}

The results in the previous chapter provide a number of conclusions regarding mechanical stress in Pre-Columbian upper west-central Tennessee. Geographical and temporal differences in stress expression were apparent. Conclusions are limited in scope because of sample bias both in absolute number of cases within each site as well as the very few individuals who preserved more than one bone (acromion process, clavicle, proximal humerus). Complete rotator cuff osteobiographies were rare and did not contribute to the subsistence based study attempted here. The use of a singular Mississippian site in the study sample skews differences towards site-specific musculoskeletal change. However, extremely poor preservation precluded the use of the few other samples from this geographic area and time period. Nevertheless, site, and subsistence based trends are evident.

The prevalence of stress related musculoskeletal change was observed to be relatively ubiquitous within all samples. However, the locations of degeneration and the demography of those afflicted by degenerative change differ from site to site. Sex data was evaluated at each site to determine if there was intra-site differences observed. 


\section{Intra-site Differences}

Eva. Compared to the other sites within this investigation, Eva had a very high rate of young interments relative to middle age burials. No advanced age individuals were recovered. It is rare for individuals within this sample to have severe entheseal change. In all cases, EC expresses bilaterally suggesting that the mechanical stress endured involved behaviors using both arms. There were no remarkable instances of EC of the supraspinatus. Females had a higher rate of enthesopathies in the subscapularis (rotates the humerus medially and is important in cross-body movements) but this was most likely because the male sample was small. The subscapularis is the most powerful muscle of the rotator cuff and hypertrophy of the insertions suggests females were engaged in behavior that tended toward medial (cross-body) rotation of the shoulder.

Eva had the highest overall rate of EC at the infraspinatus insertion of all of the samples (58.8 percent). In the same vein, all males had rugose teres minor insertions (I or F level rugosity). The infraspinatus, along with the teres minor, is responsible for the external rotation and extension of the arm. This suggests that individuals at the Eva site, particularly males, were engaged in behaviors that involved the arms being positioned behind the back.

To continue the previous theme, Eva was the only Archaic site to exhibit near statistical significance (90 percent confidence level) in dimorphic expression of teres minor rugosity $(\mathrm{p}=0.0822)$. As noted above, the teres minor muscle, paired with the infraspinatus, is responsible for the external rotation and extension of the arm. This may be indicative of inherent sexual division of labor or sampling error. In this instance, the 
latter seems to be the more likely explanation as the male sample recovered from Eva was extraordinarily small (4 males).

Degenerative joint disease at the AC joint was rare in Eva. It was apparent to occur at relatively the same rate in right and left arms which coincides with the EC data. Males had higher rates of DJD in the acromial facet than females did, but nothing appeared significant. As males had rugose (I or F) teres minors and higher rates of reactive change, a common denominator in causative behaviors may be present.

There was a high level of bias of young burials within the sample. There were issues with the age scale utilized in this study. The wide range in age-at-death groups may have skewed the data so that individuals that may normally be aged in a more advanced were placed within the younger cohort. However, the patterns exhibited at Eva may indeed reflect the young age-at-death.

In addition to methodological issues, the age bias could reflect frailty within the Eva sample. The osteological paradox (Wood et al., 1992) states that individuals within a community vary in frailty and those who succumb to disease may not display as such on the skeleton. This might suggest that the young did not simply reflect fewer years of labor, but the les capable (frail) demographic.

Cherry. The Cherry sample included a similar age distribution as Eva with a high rate of young individuals in comparison to the middle age cohort. And again, there were no advanced age individuals. As with Eva, all indicators of mechanical stress expressed bilaterally suggesting that all intensive labor involved the use of both arms. The expression of enthesopathies within this sample may have been biased due to small sample size. Female right humeri did not express any enthesopathy for the subscapularis. 
Although this result is most likely the consequence of small sample size, it may also be indicative that females did not engage in behaviors that required cross-body movements of the humerus.

Although enthesopathies of the supraspinatus are universally rare within the Archaic, this was the only insertion in the Cherry sample where none were observed. None of the left male supraspinatus insertions had enthesopathies. The supraspinatus is responsible for arm abduction at the shoulder, and the low rates of pathological EC at this insertion indicate that few people were engaged in behaviors that required lifting the arm away from the body, at least to the degree where it would cause tissue damage.

There were low rates EC at the infraspinatus insertions in the sample; the Cherry sample even had the lowest rate of insertional rugosity (I or F) at the teres minor insertion. Additionally, there were no differences in teres minor rugosity by sex or side. This suggests that individuals in the sample did not heavily engage in behaviors that required the extension and external rotation of the arm.

Furthermore, there was very low rates of DJD observed at Cherry. None was seen on the clavicular facet and low occurrence was witnessed at the acromial facet. The overall low occurrence of degeneration within Cherry seems to indicate that the people within the sample were not subject to high rates of mechanical stress.

Kays Landing. Similar to the Cherry sample, Kays Landing had a much higher rate of middle age individuals than any of the other age cohorts. Additionally, it is the only sample from the temporal period that had any advanced-age individuals.

Perhaps the larger older age cohort reflects longer individual work histories and may partially explain why Kays Landing was the only sample to display statistical 
significance in EC by sex $(\mathrm{p}=0.0029)$. Males expressed higher rates of pathologies of the infraspinatus than females suggesting that they were engaging in behaviors where the upper limb is rotated away from and/or behind the body than females. Additionally, males had higher rates of enthesopathies than females in the subscapularis (internal rotation), although this was not quite statistically significant. Again, injury to the supraspinatus (arm abduction) was rare throughout the Archaic and was barely represented (in only two females) within the sample.

The sex differences in rates of the enthesopathies are dissimilar to what was observed at the other Middle and Late Archaic sites may suggest a geographic or site based variation in male and female behavior. Geographic variation was suggested because Kays Landing is located further north along the Tennessee River than its contemporaries utilized in this study. It has also been assigned to a slightly later Archaic phase than the other two Archaic sites which may reflect a unique subsistence/settlement pattern.

The postures associated with these differences indicate that males were engaging in intensive behaviors involving the subscapularis (lifting) and the infraspinatus (rotation away from and behind the body).

In addition to the higher rates of EC in males, Kays Landing had the highest rate of reactive change at the $\mathrm{AC}$ joint of all the sites. Individuals at Kays Landing had higher occurrences of reactive change of the acromial articular facet. No sex differences in degeneration were statistically observed, but females did not have the change on the left at the clavicular facet. When compared to the other Archaic sites. It has a significantly higher occurrence of DJD. This again makes Kays Landing an outlier in the Middle and 
Late Archaic Sample. This may reflect the age at death distribution or suggest the individuals within the Kays Landing sample engaged in particular heavy lifting and/or postures that placed high stress upon the joint similar to the pressure exerted by, for example, a cross-shoulder tumpline.

Thompson Village. Thompson Village sample generally displayed more sex-based modifications than any of the Middle and Late Archaic sites. Thompson village expressed near statistical significance in sex-based entheseal damage to the supraspinatus ( $\mathrm{p}=0.0583$ ) and subscapularis $(\mathrm{p}=0.0720)$. In both cases, males expressed higher rates of insertional damage than females. This suggests that males were engaged in heavier cross-body arm movements as well as arm elevation in comparison to females. This information of implied greater work load is an interesting adjunct to consistent research that indicates a decline in overall health after the adoption of agriculture in the Americas (Bridges, 1989; Cook, 1979; Lambert, 2009; Larson, 1995; Lukacs, 2008; Powell, 1988, Schoeninger, 2009). However, sampling error may have contributed to the statistical results due to inconsistent sample recovery.

The infraspinatus EC observed was observed at similar rates to that in the Archaic. Yet, all males and most females had rugose (I and F) teres minor insertions indicating a much higher mechanical stress level than that observed than any of the other sites in the study. This seemingly conflicting data may suggest that although the individuals within the Thompson Village sample were engaged in long-term heavy muscle use which led to high teres minor rugosity, the behaviors that they were engaged in did not lead to higher rates of entheseal trauma. 
The DJD data from Thompson Village suggest that there were no sex differences in the expression of rotator cuff degeneration. Any apparent side differences can be attributed to sampling error as left hand data preserved at higher rates than right side data.

\section{Patterns of Rotator Cuff Disease}

This study of mechanical stress, identified clinically as aspects of rotator cuff disease, examined two primary facets of osteological change entheseal change as an indicator of soft-tissue stress, and degenerative joint disease which is often the result of tissue damage.

\section{Entheseal Change at the Rotator Cuff}

The investigation of entheseal change within the western Tennessee sample indicates that there are generally no intra-site biases in insertional degeneration, these include bilateral expression of enthesopathies and sexual bias in osteological modification.

There is no indication of hand-biased entheseal change. All sites, at all insertions, expressed non-statistically significant results. This suggests that the majority of behaviors which would induce RCD were bilateral or had equal chance of affecting the left and right arms. Hand dominance, it appears, was not a factor in behaviors that would affect rotator cuff degeneration.

The data have suggested that there are site based differences of pathological EC. The Eva and Cherry sites, which are located in close proximity to one another display similar rates of pathological change to all entheseal insertions and neither express any sex or side based differences. Kays Landing seems to be an outlier site from the Middle and Late Archaic sites as sex based differences were observed in pathological changes to the 
infraspinatus. Women expressed hypertrophy (i.e. no serious damage) to the region whereas half of the male humeri expressed pathological level changes.

\section{Degenerative Joint Disease of the Acromioclavicular Joint}

No intra-site differences in reactive change were apparent within any of the sample sites. This indicates that there were few differences in bilateral expression of degenerative joint disease in either the clavicular or acromial facets. Additionally, no sex based differences in degeneration were observed within any of the samples.

Interestingly, a high rate of young individuals at the Eva site had joint remodeling. DJD is seen as a progressive pathology with skeletal change beginning around middle age and fully expressing at advanced age. The high rate of DJD in the young cohort indicates heavy stress at a young age. This may be partially explained by the high rate of young individuals within the sample, but the wide-ranging expression of DJD within the cohort is not fully explained by this reasoning.

The data suggest that there are few inter-site based differences in the expression this of DJD between Eva, Kays Landing and Thompson Village. All three sites express similar rates of DJD at the clavicular facet. Cherry is an outlier in that none of the sample exhibited reactive change to that joint surface. This may be indicative of different behaviors or different cultural behaviors relative to mechanical stress. This could negate the use of a cross-body tumpline for burden bearing or perhaps rule out activities requiring heavily loaded arm abduction (which is reflected in low rates of supraspinatus enthesopathies). This is a particularly interesting finding because a majority of the sample fell within the middle age cohort. In contrast, Eva had a high occurrence of young individuals, many of which exhibited degenerative modifications. 
All of the sites exhibit DJD at the acromial facet. No evidence has been found by this author that indicates why there is differential degeneration between the acromial facet and the clavicular facet. It seems that the differences between the two facets represent normal variation in reactive change to the $\mathrm{AC}$ joint.

What is interesting is that Kays Landing had the highest rate of degeneration of all the sites. High occurrence of reactive change may reflect the middle age bias within the sample as well as the presence of advanced age individuals. As the site had the lowest rate of enthesopathies to the supraspinatus, the reactive change to the acromioclavicular joint may indicate high levels of trauma placed directly on the joint (as with a cross-body tumpline). This again is different to what was observed in the other Middle and Late Archaic samples, making Kays Landing a behavioral outlier.

\section{Skeletal Robusticity}

Not much can be said with the limited analysis conducted on skeletal robusticity. As noted in the Chapter V, both males and females presented similar robusticity scores all centering around the site average of 11.47. Similarly, males and females at Thompson village exhibited similarly robust scores around the site average of 12.44. Females did overall exhibit slightly higher robusticity scores in the right arm, but the difference was not significant. Additionally, many individuals who fell low on the robusticity index were not sexed, so vulnerability within the sample could not be assessed other than to say that there were some weak individuals at the site.

\section{Subsistence-based Differences in Mechanical Stress}

Site based differences seem to disappear when data sets are collapsed into subsistence and settlement based temporal periods. This is seen when Kays Landing was 
combined with Eva and Cherry to create the "Archaic" temporal category. The data overall conform what was observed at Eva and Cherry suggesting that that was the general trend represented in the Archaic sample. Regretfully, Thompson Village was the only Mississippian site represented in the sample, as the other agriculturalist samples from the period yielded insufficient data. Thus temporal comparisons may be biased to reflect idiosyncrasies within the Thompson Village sample and not the entirety of the Mississippian period in upper west-central Tennessee.

\section{Entheseal Change at the Rotator Cuff}

Analysis within each subsistence strategy indicates that there were no sex-based differences of pathological entheseal change within either the hunter-gatherer Archaic sample or the agricultural Mississippian sample. Also, all degeneration was observed to manifest bilaterally. This again indicates no hand favoring in either subsistence based sample. These changes include insert degeneration and entheseal rugosity. There were no sex or side differences identified within the Archaic sample.

As seen previously, near statistical significance was observed in the Mississippian sample at both the Supraspinatus and Subscapularis where it was not in the Archaic. Again, this may reflect site-specific degeneration at Thompson Village or may represent standard Mississippian degenerative change.

The near statistical significant sex difference found within the supraspinatus data $(\mathrm{p}=0.0720)$ within the Mississippian sample was investigated and revealed that there was a side and sex related bias within the sample. It was found that males have higher rates of subscapularis enthesopathies in the right arm than females. This may suggest sampling bias, or more likely sexually dimorphic behaviors within the sample which has been 
found consistently within other Mississippian samples (Bridges, 1989; Buikstra and Milner, 1991; Larsen, 1995; Lucacs, 2008; Powell, 1988).

Along this vein, near statistically significant results were found when comparing supraspinatus enthesopathies between the sexes within the Mississippian sample. As with right subscapularis EC, males exhibited higher rates of modification than females. Increased damage at the subscapularis indicates heavy use or trauma induced by crossbody rotation, extension, and adduction (downward movement) of the shoulder. Damage to the supraspinatus indicates excessive or traumatic arm abduction. Other indications of heavy use in the sample include probable cases of os acromiale and side asymmetry. There are, however, are no indications of humeral impingement (Bigliani and Levine, 1997; Frost and Anderson, 1997: Miles, 1996, 1999, 2000; Roberts et al., 2007).

Unilateral damage would be more indicative of hunting activities (bow hunting, spear, etc.), but as damage is bilateral these are not likely causes of skeletal trauma. Damage to the subscapularis and supraspinatus may have a number of causes the most likely are linked to burden bearing and subsistence activities. It may be suggested that damage to these regions, along with the bilateral expression of reactive changes to the acromioclavicular joint, may indicate increased canoe or kayak paddling (Hawkey and Merbs, 1995; Kennedy, 1989; Merbs, 1983; Molnar, 2006).

Analysis comparing temporal periods indicate there were no differences in enthesopathies that were identified between subsistence strategies; however, there was a difference in the expression of rugose teres minor entheses between subsistence strategies $(\mathrm{p}=0.0017)$. Interestingly, no temporal differences were evident in the left side data where there is a statistical difference in the right hand data. This could be an indication of 
differential use in right arms (possibly indicating handedness). There were no statistical differences between time periods in the male sample indicating that males persist at the same level of upper limb stress between temporal periods. Females, on the other hand seem to see an increase in stress during the Mississippian period.

Differences in entheseal rugosity but not in enthesopathies indicate that high muscle use was employed. However, the stress to the structure did not surpass the load that the bone-soft tissue connection could endure. Higher rates of entheseal rugosity and, pathological EC at the subscapularis (with no difference in the occurrence of enthesopathy at the supraspinatus) in the agricultural sample indicate heavier overall muscle use than that observed in the hunter-gatherer sample.

The only time the hunter-gatherer sample had a higher rate of enthesopathy was in injury to the infraspinatus. This may indicate that archaic peoples engaged in behaviors that required the external rotation and extension of the humerus (putting the arm behind the back) after the setting of entheses around puberty. This is suggested because there were lower rates of entheseal rugosity at the teres minor, but high rates of pathological $\mathrm{EC}$ at the infraspinatus. As these muscles work together in all behaviors, an association to osteological change at these points must be made.

\section{Degenerative Joint Disease of the Acromioclavicular Joint}

When all of the site data for the Archaic sample is combined, no sex or side biases observed in reactive change on the clavicular facet of the acromion process. Damage at the acromioclavicular joint is traditionally associated with subacromial impingement syndrome, burden bearing (e.g. weightlifting) and heavy shoulder use (Bigliani and Levine, 1997; Mall et al., 2013; Roberts et al., 2007). The postural behaviors most likely 
to affect this joint would be the repetitive abduction of the arm with heavy loading and prolonged trauma directly upon the clavicle. One of the associated behaviors may the use of a tumpline or strap across the shoulder which would place direct pressure on the clavicle.

Within the Mississippian sample, there were no sex or side biases observed in the degenerative change to the clavicular facet of the acromion process which would be indicative of sexually dimorphic behaviors or unilateral loading of the joint. As with the Archaic, a near statistically significant bias was found within the sample. However, this bias was observed in side and not sex. Yet, further analyses of the data suggest that there is a sex bias within the side bias. Males were found to express reactive change bilaterally where as females did not. Females were found to have higher rates of modification in the left clavicle. This may suggest that females are straining their left sides more than the right in the Mississippian, however, equally likely, is sampling bias.

There was a difference in the expression of DJD to the clavicular facet between subsistence strategies. This is similar to what was observed in the rates of teres minor rugosity between temporal samples. This is consistent between the sexes where males from both time periods expressed near statistical differences and females had statistically significant differences between time periods. This indicates higher stress from the Archaic to the Mississippian.

There is a significant temporal disparity in the expression of joint degeneration at the clavicular facet of the acromion process $(\mathrm{p}=0.0397)$. This difference becomes more significant when side is accounted for. Interestingly, this difference, when further examined, was only apparent in the left hand data. This difference was most likely due to 
sampling error as the left side sample was more substantial than that available for the right side. This is different than what was observed for the degeneration of the acromial facet of the clavicle. Should the cause of this degeneration have been the use of crossshoulder tumplines, it stands to reason that the Mississippian sample employed them to either transport heavier loads, or utilizing them at higher rates than that observed in the Archaic sample. This may be consistent with the increased labor associated with sedentary agriculturalist cultures.

There were no significant differences in DJD at the clavicular facet observed between subsistence strategies. Yet there were differences in the expression of degeneration at the acromial facet. It could be proposed that this is linked with the application of force to the clavicles associated with carrying heavy loads in both hands (Kennedy, 1989). Differential reactive change at either articulation represents typical variation in joint wear.

Less than half of the acromial articular facets examined from the Archaic sample did not display reactive change. Within the hunter-gatherer sample, these changes appeared bilaterally. A near statistically significant difference in acromial facet DJD was observed between the sexes which were not viewed in any individual sample $(\mathrm{p}=0.0753)$. Additional analysis of these data indicates that the differences were observed in the right clavicles but not the left. In this case, male right Males were observed to have a higher rate of joint erosion at the clavicle than females. This may be indicative of sexually dimorphic behaviors where males experienced higher stress to their clavicles, possibly due to carrying heavier loads than females utilizing cross-shoulder tumplines. 
Over half of the acromial facets observed in the Mississippian sample had reactive change. No statistically significant side or sex data were observed in this sample. There was a near statistically significant difference in side expression $(\mathrm{p}=0.0805)$. When this side difference was examined by sex, a difference was found within the female sample. This could be the result of sampling error, or perhaps it is indicative on increased stress being placed on female left clavicles. As this pattern was not observed in the Clavicular articular facet of the acromion it may be construed that these differences were due to sample recovery.

When examined by sex, statistical data suggested a very nearly statistical temporal difference between males of the Archaic and Mississippian. Males have higher rates of DJD of the acromial facet in the Mississippian than in the Archaic. No temporal differences were observed between the females of either temporal period. This may suggest that some of the behaviors in males have changed. As mentioned previously, degeneration at either facet of the $\mathrm{AC}$ joint seems to represents normal variation the reactive change to the joint. Thus, the near temporal difference observed in the acromial articular facet and the significant differences in the clavicular articular facet indicate an overall difference in degeneration at the $\mathrm{AC}$ joint.

Differences in DJD between subsistence strategies indicate that in upper westcentral Tennessee agriculturalists had higher rates of reactive change than huntergatherers. It may be the case that peoples from the Archaic did not need to engage in heavy burden bearing activities because resources in the region were plentiful. Food and other supplies were gathered as-needed and thus caused less mechanical strain while they were collected. Additionally, burden bearing activities may have been more variable 
within seasons because people were not restricted to the seasonality of crop planting and harvesting. Higher rates of reactive change in the Mississippian sample may therefore be the result of more standardized burden-bearing practices and/or increased burden bearing (carrying heavier loads) associated with agricultural practices.

\section{Skeletal Robusticity}

Skeletal robusticity was observed to increase with the transition to agriculture. Skeletal robusticity increased for both sexes, but more significantly for females than males. The increase in robusticity is consistent with the increase in rugosity of the teres minor entheses and the higher levels of DJD at the clavicular facet of the acromial process.

Mississippian male data of the subset of individuals with lower robusticity is inverse to the damage seen at subscapularis and supraspinatus. It could be suggested that this sort of damage is reflective of the development of small muscle insertion sites (Hawkey and Merbs, 1995; Jurmain et al., 2012; Nolte and Wilczak, 2013). Lower mechanical stress in youth may have led to the development small enthesis formation. An increase in manual labor with age may have triggered muscle growth that the skeletal system attempted to, but ultimately failed to support.

Although there was an apparent pattern of injury within the small Mississippian males, there was not overwhelming evidence of sexual divisions of labor within any of the samples or between subsistence patterns. It was hypothesized that if there were any dimorphic behaviors they would have been evident within the Mississippian sample. These differences were not observed in the Tennessee sample which may indicate similar stress levels between the sexes. 


\section{CHAPTER VII}

\section{CONCLUSIONS}

This study has provided insight into mechanical stress in the Middle and Late Archaic and the Mississippian from a specific geographic area with arguably the same ecological context. Hopefully this study has contributed to the growing body of literature gathered about mechanical stress in prehistory. This thesis had two objectives, the first was to determine the presence of rotator cuff disease (RCD) in North American Prehistory and the second was to examine the subsistence base differences in mechanical stress markers.

As today, RCD seems to be ubiquitous in Pre-Columbian Tennessee. The presence of enthesopathies (as a proxy for indicating soft-tissue over use and/or damage) and DJD (e.g. subacromial impingement, acromioclavicular joint damage) are indicative of the presence of RCD. These pathologies signify heavy shoulder use within the upper west-central Tennessee region regardless of subsistence or settlement strategy. Although there were no indications of severe subacromial impingement on the humeral head within the sample, degeneration at the acromioclavicular joint indicates a high likelihood that this pathology (which is also closely associated with clinical RCD) was present within all living populations (Bigliani and Levine, 1997; Frost and Anderson, 1997; Mall et al., 2013; Roberts et al., 2007). 
In this investigation of mechanical stress in a specific context of the Tennessee River valley, it is evident that the majority of observable stress indicators expressed bilaterally and equally between the sexes in both subsistence strategies. In all cases where there was a sex difference, males expressed higher rates of skeletal change than females. This suggests that overall males were subject to higher rates of stress.

When there was a subsistence strategy based difference, the Mississippian period always had higher rates of RCD than the Archaic. This is most likely the result of intensive agricultural practices with manual labor that was either more repetitive or required more effort than the physical demands of hunter-gatherers.

This study is by no meant the definitive study on RCD in Pre-Columbian upper west-central Tennessee. Further research on the corollaries of shoulder pathologies (e.g., deltoid tuberosity, elbow EC) must be undertaken to create further understanding of mechanical stress endured by humans. This investigation functions as a launching point for further research on upper-limb mechanical stress within the greater Tennessee River Valley, and will hopefully contribute to the understanding of stress endured in PreColumbian North America. 


\section{REFERENCES}

Ackland DC, Pandy MG. 2009. Lines of action and stabilizing potential of the shoulder musculature. Journal of Anatomy 215:184-197. DOI:10.1111/j.14697580.2009.01090.x

Alves-Cardoso F, Henderson CY. 2010. Enthesopathy formation in the humerus: data from known age-at death and known occupation skeletal collections. American Journal of Physical Anthropology141: 550-560. DOI:10.1002/ajpa.21171

Alves-Cardoso F, Henderson CY. 2012.The Categ2orization of Occupation in Identifies Skeletal Collection: A Source of Bias? International Journal of Osteology 23:186-196. DOI: 10.1002/oa.2285.

Andary JL. 2002. The vascular Anatomy of the Glenohumeral capsule and ligaments: An anatomic study. Journal of bone and joint surgery 84-A(12):2258-2265.

Anderson DG. 2004. Archaic mound and the archaeology of southeastern tribal societies. In Signs of Power: The Rise of Cultural Complexity in the Southeast, Gibson JL and Carr PJ (eds.). University of Alabama Press: Tuscaloosa; 270-299.

Armelagos GJ, Goodman AH, Jacobs KH. 1991. The origins of agriculture: Population growth during a period of declining health. Population and Environment 13(1):922.

Auerbach BM, Raxter MH. 2008. Patterns of clavicular bilateral asymmetry in relation to the variation among humans. Journal of Human Evolution 54:663-674.

Baastrup CL. 1933. On the spinous processes of the lumbar vertebrae and the soft tissue between them and on pathological changes in the region. Acta Radiologica 14:524

Bass, Q R. II 1985. Sociopolitical and Economic aspects of the Mississippian Occupation in the Lower Tennessee River Valley. Manuscript on File.

Bass, WM, 1987. Human Osteology: A laboratory and field manual, Trimble MK (ed.). Missouri Archaeological Society Inc., Columbia.

Beahm EL. 2013. Mississippian polities in the Middle Cumberland region of Tennessee. Dissertation. Athens: University of Georgia.

Benjamin M, McGonagle D. 2001. The anatomical basis for disease localization in seronegative spondyloarthopathy at entheses and related sites. Journal of Anatomy 199:503-526.

Benjamin M, Toumi H, Ralphs JR, Bydder G, Best TM, Milz S. 2006. Where tendons and ligaments meet bone: Attachment sites ('entheses') in relation to exercise and/or mechanical load. Journal of Anatomy 208:471-490.

Benjamin M, Toumi H, Suzuki D, Hayashi K, McGonagle D. 2009. Evidence for a distinctive pattern of bone formation in entheseophytes. Annals of the Rheumatic Disease 68(6):1003-1010. DOI: 10.1136/ard.2008.091074.

Bense, JA. Archaeology of the Southeastern United States: Paleoindian to World War I. Academic Press: New York. 
Benson, RT, McDonnell, SM, Rees JL, Carr AJ, Hulley PA. 2010. Tendinopathy and

Tears of the Rotator Cuff are Associated with Hypoxia and Apoptosis. Journal of

Bone and Joint Surgery 92(3):448-453

Bigliani LU, Levine WN. 1997. Subacromial Impingement Syndrome. The Journal of Bone and Joint Surgery 79(12):1854-1868.

Blakely RL. 1980. Sociocultural Implications of Pathology Between the Village Area and

Mound C Skeletal Remains from Etowah, Georgia. In Skeletal Biology of Aboriginal

Populations in the Southeastern United States, Willey P and Smith FH (eds.)

Miscellaneous Paper 5. Tennessee Anthropological Association, Knoxville; 28-38.

Blakely RL. 1995. Social Organization at Etowah: A Reconsideration of

Paleodemographic and Paleonutritional Evidence. Southeastern Archaeology

14(1):46-59.

Blakely RL, Beck LA. 1981. Trace Elements, Nutritional Status, and Social Stratification

at Etowah Georgia. Annals of the Academy of Science 376:417-431.

Boulle EL. 2001. Evolution of two human skeletal markers of the squatting position: A diachronic study from antiquity to the modern age. American Journal of Physical Anthropology 115:50-56.

Boyd D. 1996. Skeletal correlates of human behavior in the Americas. Journal of Archaeological Method and Theory 3(3):189-251. DOI:10.2307/20177348

Boyd CC Jr., Boyd DC. 1989. A Comparison of Tennessee Archaic and Mississippian Maximum Femoral Lengths and Midshaft Diameters: Subsistence Change and Postcranial Variability. Southeastern Archaeology 8(2):107-116.

Boyd CC Jr., Boyd DC. 1991. A Multidimensional Investigation of Biocultural Relationships among Three Late Prehistoric Societies in Tennessee. American Antiquity 56(1):75-88.

Bowen WR. 1975. Late Archaic subsistence and settlement in the western Tennessee Valley. M.A. Thesis. Knoxville: University of Tennessee.

Bowen WR. 1977. A reevaluation of Late Archaic subsistence and settlement patterns in the western Tennessee Valley. Tennessee Anthropologist 2:101-120.

Bridges PS. 1985. Changes in Long Bone Structure with the Transition to Agriculture: Implications for Prehistoric Activities. Ph.D. Dissertation, University of Michigan, Ann Arbor.

Bridges PS. 1989. Changes in Activities with the Shift to Agriculture in Southeastern United States. Current Anthropology 30:385-394.

Bridges PS, Blitz JH, Solano M. 2000. Changes in Long Bone Diaphyseal Strength with Horticultural Intensification in West-Central Illinois. American Journal of Physical Anthropology 112:217- 23..

Brailsford JF. 1929. Deformities of the lumbosacral regions of the spine. British Journal of Surgery 16: 562-627. DOI: 10.1002/bjs.1800166405

Brooks ST, Suchey JM. 1990. Skeletal age determination based on the os pubis: A comparison of the Ascadi Nemeskeri and Suchey Brooks Methods. Human Evolution 5:227-238. DOI: 10.1007/BF02437238

Brown JA. 1985a. The Mississippian period. Ancient art of the American Woodland Indians. Edited by Brose DS, Brown JA and Penny DW. Harry N. Abrams: New York; 93-145. 
Brown, JA. 1985b. Prehistoric hunter-gatherers: the emergence of cultural complexity. TD Price and JA brown eds. Academic Press: New York.

Buikstra JE, Milner GR.1991. Isotopic and Archaeological Interpretations of Diet in the Central Mississippi River Valley. Journal of Archaeological Science 18:319-329.

Bunker T. 2002. Rotator Cuff Disease. Current Orthropaedics 16:223-233. Doi:10.1006/cuor.2002.0257

Chamay A, Tschantz P. 1972. Mechanical influence in bone remodeling. Experimental research on Wolff's law. Journal of Biomechanics 5 (2): 173-180. DOI: 10.1016/0021-9290(72)90053-X

Charles DK, Buikstra JE. 1983. Archaic Mortuary Sites in the Central Mississippi Drainage: Distribution, Structure and Behavioral Implications. In Archaic Hunters and Gatherers in the American Midwest. Philips JL and Brown JA (eds.) Academic Press : New York; 117-144.

Cohen MN, Armelagos GJ (Eds.). 1984. Paleopathology at the Origins of Agriculture. Academic Press of Florida, Gainesville.

Cook DC. 1979. Subsistence Base and Health in Prehistoric Illinois Valley: Evidence from the Human Skeleton. Medical Anthropology 3:109-124.

Cobb CR, Butler BM. 2002. The Vacant Quarter revisited: Late Mississippian abandonment of the lower Ohio Valley. American Antiquity 67(4):625-641.

Curtis, AS, Burbank KM, Tierney JJ, Scheller AD, Curran AR. 2006. The insertional footprint of the rotator cuff: An anatomic Study. Arthroscopy: The Journal of Arthroscopic and Related Surgery 22(6): 603-609.

Davis CB. Schuler KA, Danforth ME, Herndon KE. 2013. Pattern of Interobserver Error in the Scoring of Entheseal Changes. International Journal of Osteoarchaeology 23:147-151. DOI:10.1002/oa.2277

Dowd JT. 2008 The Stone-Box Burials of Middle Tennessee. Tennessee Archaeology 3(2): 163-180.

Dutour, O. 1986. Enthesopathies (Lesions of Muscular Insertions) as indicators of the Activities of Neolithic Saharan populations. American Journal of Physical Anthropology 71:221-224.

Dugas JR, Campbell DA, Warren RF, Robie BH, Millett PJ. 2002. Anatomy and dimensions of rotator cuff insertions. Journal of shoulder and Elbow surgery 11(5):498-503. DOI:10.1067/mse.2002.126208

Edelson JG. 1996. Patterns of Degenerative Change in the Acromioclavicular Joint. Journal of Bone and Joint Surgery 78B (2): 242-243.

Eshed V, Gopher A, Galili E, Hershkovitz I. 2004. Musculoskeletal Stress Markers in Natufian Hunter-Gatherers and Neolithic Farmers in the Levant: The Upper Limb. American Journal of Physical Anthropology 123:303-315.

Eshed V, Gopher A, Pinhasi R, Hershkovitz I. 2010. Paleopathology and Origin of Agriculture in the Levant. American Journal of Physical Anthropology 143:121133.

Emerson TE Lewis RB. 1999. Cahokia and the hinterlands middle Mississippian cultures of the Midwest. University of Illinois Press: Champagne.

Emerson TE, McElrath DL, Fortier A (eds.). 2009. Archaic Societies: Diversity and Complexity Across the Midcontinent. SUNY Press: Albany. 
Ferguson. 1972. The Middle Cumberland Culture No. 3 Vanderbilt University.

Vanderbilt University: Nashville.

Flatow EL, Soslowsky, LJ, Ticker JB, Pawluk RJ, Helper, Mark J, Mow VC, Bigliani

LU. 1994. Excursion of the rotator cuff under the acromion. Patterns of subacromial contact. American Journal of Sports Medicine 22:779-788.

Foster A, Buckley H, Tayles N. 2012 Using enthesis robusticity to infer activity in the past: A review. Journal of Archaeological Method and Theory (2013): 1-23.

Fowler ML. 1997. The Cahokia atlas: A historical atlas of Cahokia Archaeology No. 2. University of Illinois Press: Champagne.

Frost P, Anderson H. 1999. Shoulder impingement in relation to shoulder intensive work. In Occupational and Environmental Medicine 56(7):494-498. DOI: $10.2307 / 27731157$

Franklin SB. Late-Pleistocene and Holocene vegetation history of land between the lakes, Kentucky and Tennessee. Trans. Kentucky Academy of Science 55:6-19.

Goodman AH. 1993. On the Interpretation of Health from Skeletal Remains. Current Anthropology 34(3):281-288. DOI: 10.2307/2743669

Goodman AH, Armelagos G. 1988. Childhood Stress and Decreased Longevity in a Prehistoric Population. American Anthropologist 9(4): 936-944.

Hawkey DE, Merbs CF. 1995. Activity-induced musculoskeletal stress markers (MSM) and subsistence strategy changes among ancient Hudson Bay Eskimos.

International Journal of Osteoarchaeology 5: 324-338.

DOI: 10.1002/oa.1390050403

Hawley MF, and Dye DH. 2011. George A. Lidberg Jr. and Depression-Era Archaeology. Southeastern Archaeology 30(2):399-412.

Hazlett J. 1964. Kissing spines. Journal of Bone and Joint Surgery 46: 1368-1369.

Hegemon, M. 2003 Setting Theoretical Egos Aside: Issues and Theory in North American Archaeology. American Antiquity 68(2):213-243.

Henderson CY. 2012 Technical note: Quantifying size and shape of entheses. Anthropological Science, 121017. DOI: 10.1537/ase.121017

Henderson CY. 2013a. Do diseases cause entheseal changes at fibrous entheses? International Journal of Paleopathology 3:64-6. DOI:1 0.1016/j.ijpp.2013.03.007

Henderson CY. 2013b. Subsistence strategy changes: The evidence of entheseal changes. HOMO Journal of Comparative Human Biology 64(6):491-508.

Henderson CY, Alves Cardoso F. 2013.Special Issue Entheseal Change and Occupation: Technical and Theoretical Advances and their Applications (Preface). International Journal of Osteoarchaeology 23:127-134. DOI: 10.1002/oa.2287

Henderson CY, Craps DD, Caffell AC, Millard AR, Gowland R. 2013. Occupational Mobility in 19th century rural England: The interpretation of Entheseal Changes. International Journal of Osteoarchaeology 23:197-210. DOI:10.1002/oa.2286

Henderson CY, Mariotti V, Pany-Kucera D, Perréard-Lopreno G, Villotte S, Wilczak C. 2010. Scoring entheseal changes: Proposal of a new standardised method for fibrocartilagenous entheses. [Online]. Poster presented at the 18th European Meeting of the Paleopathology Association, Vienna, Austria 23rd-26th of August 2010. Available from: https://www.uc.pt/en/cia/msm/Vienna2010.pdf.

Henderson CY, Mariotti V, Pany-Kucera D, Perréard-Lopreno G, Villotte S, Wilczak C. 2013a. Recording specific entheseal changes of fibrocartilagenous entheses: 
Initial tests using the Coimbra Method. International Journal of Osteoarchaeology 23: 152-162. DOI:10.1002/oa.2287.

Higgins KF. 1982. Ledbetter Landing Site: A Study of Late Archaic Mortuary Patterning. M.A. Thesis. Knoxville: University of Tennessee.

Jefferies RW, Thompson VD, Milner GR. 2005. Archaic Hunter-Gatherer Landscape Use in West-Central Kentucky. Journal of Field Archaeology 30(1):3-23.

Jolley RL. 1983. Mississippian Adaptations to the Middle Cumberland Drainage of Central Tennessee. Midcontinental Journal of Archaeology 8(1):73-90.

Jurmain, RD. 1999. Stories from the Skeleton: Behavioral Reconstruction. Gordon and Breach: Amsterdam.

Jurmain RD, Villotte S. 2010. Terminology-entheses in medical literature: a brief review. In Workshop in Musculoskeletal Stress Markers (MSM): Limitations and Achievements in the Reconstruction of Past Activity Patterns. http://www.uc.pt/en/cia.msm/MSM_terminology435 Accessed by February 5, 2014.

Jurmain RD., Aves-Cardoso F, Henderson C, Villotte S. 2012. Bioarchaeology's Holy Grail: The reconstruction of activity. A Companion to Paleopathology. Grauer, A (ed.). Blackwell Publishing Ltd: Oxford; 531-552.

Kannus P, Haapasao H, Sankelo M. Sievänen H, Pasanen M, Heinonen A, Oja P, Vuori I. 1995. Effect of starting age of physical activity on bone mass in the dominant arm of tennis and squash players. Annals of Internal medicine 123:27-31.

Kackia S, Villotte S, Knüsel CJ. 2011. Baastrup's sign (kissing spines): A neglected condition in paleopathology. International Journal of Paleopathology 1(2): 104110.

Kennedy KAR. 1989. Skeletal markers of occupational stress. In Reconstruction of Life from the Skeleton, İşcan M, Kennedy K (eds). Alan R. Liss: New York; 129-160.

Klippel WE, Morey DF. 1986. Contextual and Nutritional Analysis of Freshwater Gastropods from Middle Archaic Deposits at the Hayes Site, Middle Tennessee. American Antiquity 51(4):799-813.

Knüsel C. 2000. Bone adaptation and its relationship to physical activity in the past. In Human Osteology in Archaeology and Forensic Science, Cox M, Mays S (eds). Greenwich Medical Media Ltd: London; 381-401.

Konigsburg LW, Hens SM, Jantz LM, Jungers WL. 1998. Stature estimation and calibration: Bayesian and maximum likelihood perspectives in physical anthropology. Yearbook of Physical Anthropology 41: 65-92.

Kostick EL. 1963. Facets and imprints on the upper and lower extremities of femora from a Western Nigerian population. Journal of Anatomy 97:393-402.

Kuemin Drews, NJ. 2000. A Bioarchaeological Perspective of Mississippian Period Warfare in West-Central Tennessee. M.A. Thesis, DeKalb: Northern Illinois University.

Lambert PM. 2009. Health versus fitness: Competing themes in the origins and spread of agriculture? Current Anthropology 50:603-608.

Larsen CS. 1995. Biological Changes in Human Populations with Agriculture. Annual Review of Anthropology 24:185-213.

Larsen CS. 1997. Bioarchaeology: Interpreting Behavior from the Human Skeleton. Cambridge University Press, Cambridge. 
Larsen CS. 2000. Skeletons in Our Closet: Revealing our Past through Bioarchaeology. Princeton University Press, New Jersey.

Larsen CS. 2002 Bioarchaeology: The Lives and Lifestyles of Past People. Journal of Archaeological Research 10(2): 119-166.

Lewis TMN, Lewis MD. 1947. The Archaic Horizon in Western Tennessee. No. 2 Division of University Extension, University of Tennessee.

Lewis TMN, Lewis MD. 1959. The Archaic Culture in the Middle south. American Antiquity 25(2):161-183.

Lewis TMN, Lewis M. 1961. Eva: An Archaic Site. The University of Tennessee Press, Knoxville.

Lukacs JR. 2008. Fertility and Agriculture Accentuate Sex Differences in Dental Caries Rates. Current Anthropology 49(5): 901-914.

Lyon EA. 1996. A New Deal for Southeastern Archaeology. University of Alabama Press: Tuscaloosa.

Magennis AL. 1977. Middle and Late Archaic Mortuary Patterning: An Example from the Western Tennessee Valley. M.A. Thesis. Knoxville: University of Tennessee.

Mall NA, Foley E, Chalmers PN, Cole BJ, Romeo AA, Bach BR. 2013. Degenerative Joint Disease of the Acromioclavicular Joint. American Journal of Sports Medicine 47: 2684-2692. DOI:10.1177/0363546513485359

Mariotti V, Faccini F, Belcastro MG. 2007. The study of entheses: Proposal of a standardised scoring method for twenty-three entheses of the postcranial skeleton. Collegium antropologicum 31(1):291-313.

Marquardt WH. 2010. Shell Mounds in the Southeast: Middens, Monuments, Temple Mounds, Rings, or Works? American Antiquity 75(3):551-570.

Marquardt WH, Watson PJ. 1983. The Shell Mound Archaic of Western Kentucky. In Archaic Hunters and Gatherers in the American Midwest. JL Philips and JA Brown (eds.). Academic Press: Orlando; 323-339.

McClain, ML. 2013. Activity-related variation in pathologies of the patella among Native American Groups. M.A. Thesis. San Marcos: Texas State University-San Marcos.

McDonald JH. 2009. Handbook of Biological Statistics (2nd ed.). Sparky House Publishing: Baltimore.

Merbs CF. 1983. Patterns of Activity Induced Pathology in a Canadian Inuit Population. National Museums of Canada: Ottawa.

Milella M, Belcastro MG, Zollikofer CPE, Mariotti V. 2012. The effect of age, sex, and physical activity on entheseal morphology in a contemporary Italian skeletal collection. American Journal of Physical Anthropology 148: 379-388. DOI: 10.002/ajpa.22060.

Minagawa H, Itoi E, Konno N, Kido T, Sano A, Urayama M, Sato K. 1998. Humeral attachment of the supraspinatus and infraspinatus tendons: An anatomic Study. The Journal of Arthroscopic and Related Surgery 14(3):302-306.

Miles AEW 1994. Non-union of the epiphysis of the acromion of ca. 1700. International Journal of Osteoarchaeology 4:149-163. DOI: 10.1002/oa.1390040207

Miles, AEW. 1996. Humeral impingement on the acromion in a Scottish island population of c. 1600 AD. International Journal of Osteoarchaeology 6:529-288. DOI: 10.1002/(SICI)1099-1212(199606)6:3<259::AID-OA270>3.0.CO;2-5 
Miles, AEW. 1999. Observations on the undersurface of the skeletalized human acromion in two populations. International Journal of Osteoarchaeology 9: 83-101.

DOI: 10.1002/(SICI)1099-1212(199903/04)9:2<131::AID-OA462>3.0.CO;2-P

Miles, AEW. 2000. Developing stages of subacromial humeral- impingement facets in the skeletal remains of two human populations. International Journal of Osteoarchaeology 10: 161-176. DOI: 10.1002/10991212(200005/06)10:3<161:AID-OA516>3.0.CO;2-G

Molnar P. 2006. Tracing prehistoric activities: Musculoskeletal stress marker analysis of a Stone-Age population the Island of Gotland in the Baltic Sea. American Journal of Physical Anthropology 129:12-23.

Molnar P, Ahlsrom TP, Leden I. 2011. Osteoarthritis and activity-An analysis of the relationship between eburnation, musculoskeletal stress markers (MSM) and age in two Neolithic hunter-gatherer populations from Gotland, Sweden. International Journal of Osteoarchaeology 21: 283-291.

Morse DF. 1969. The Robinson site and Shell Mound Archaic culture in the Middle South. Dissertation. University of Michigan.

Mummert A, Esche E, Robinson J,. Armelagos GJ. 2011. Stature and Robusticity During the Agricultural Transition: Evidence from the Bioarchaeological Record. Economic and Human Biology 9: 284-301

Myszka A, Piontek J. 2011. Shape and size of the body vs. musculoskeletal stress markers. Anrthropologischer Anzeiger 68(2): 139-152. DOI: 1 0.1127/00035548/2011/0047

Nance JD. 1987. Research in the Lower Tennessee-Cumberland-Ohio Region. Southeastern Archaeology 6(2):93-100.

Niinimäki S. 2011. What do muscle marker ruggedness scored actually tell us? International Journal of Osteoarchaeology 21: 292-299. DOI: 10.1002/oa.1134

Niinimäki S. 2012. The relationship between musculoskeletal stress markers and biomechanical properties of the humeral diaphysis. American Journal of Physical Anthropology 147(4): 618-628. DOI: 10.1002/ajpa.22023

Niinimäki S, Södering S, Junno J-A, Finnilä M, Niskanen M. Cortical bone thickness can adapt locally to muscular loading with changing with age. HOMO Journal of Comparative Human Biology 64:474-490.

Northover JR, Lunn P, Clark DI, Phillipson CM. 2007. Risk factors for the development of rotator cuff disease. International Journal of Shoulder Surgery 1(3):82-86.

O'Rourke N, Hatcher L, Stepanski EJ. 2005. A Step-by-Step Approach to Using SAS for Univariate and Multivariate Statistics. Second Edition. SAS Institute Inc, Cary.

Oygucu IH, Kurt MA, Ikiz I, Erem T, Davies DC. 1998. Squatting Facets on the neck of the talus and extensions of the trochlear surface of the talus in the Late Byzantine males. Journal of Anatomy 192(2): 287-291.

Pauketat TR. 2005. The History of the Mississippians. In North American Archaeology Pauketat TR and Loren DD (eds.). Blackwell Publishing Ltd.: London.

Peacock E. 2000. Assessing Biases in Archaeological Shell Assemblages. Journal of Field Archaeology 27(2): 183-196.

Peacock E, Carr PJ. Price, SE, Underwood JR, Kingery WJ, Lilly M. 2010. Confirmation of an Archaic Period Mound in Southwest Mississippi. Southeastern Archaeology 29(2): 355-368. 
Pearson OM. 2000. Activity, Climate, and Postcranial Robusticity: Implications for Modern Human Origins and Scenarios of Adaptive Change. Current Anthropology

41(4):569-607. DOI: 0011-3204/2000/4104-0004\$3.00

Phillips JL, Brown JA. eds. 2009. Archaic hunters and gatherers in the American Midwest. Academic Press, New York.

Powell ML. 1988. Status and Health in Prehistory: A Case Study of the Moundville

Chiefdom. Smithsonian Institution Press: Washington, DC .

Price TD. 1985.Late Archaic subsistence in the Midwestern United States. Journal of Human Evolution 14(5):449-459.

Pritchard EE, Alhman TM. (Editors). 2009. TVA Archaeology: Seventy-five Years of Prehistoric Site Research. University of Tennessee Press: Knoxville.

Rani A, Mishra SR, Chopra J, Rani A, Manik P, Kumar N, Dewan RK. 2009. Coracoclavicular and costoclavicular joints at a common juncture: A rare phenomenon. International Journal of Morphology 27(4):1089-1092.

Roberts AM, Peters PJ, Brown KR. 2007. New Light on Old Shoulders:

Paleopathological Patterns of Arthropathy and Enthesopathy in the Shoulder Complex. Journal of Anatomy 211: 485-492. DOI: 10.1111/j.14697580.2007.00789.x

Roberts C, Manchester K. 2007. The Archaeology of Disease. Cornell University Press: Ithaca.

Rogers J. 2000. The Paleopathology of Joint Disease. In Human Osteology in Archaeology and Forensic Science. Cox, Margaret and Simon Mays eds. Pp. 163182. London: Greenwich Medical Media Ltd.

Ruff CB. 2000. Body size, body shape, and long bone strength in modern humans. Journal of Human Evolution 38(2):269-290.

Ruff CB, Hays WC. 1983. Cross-Sectional geometry of Pecos Pueblo femora and tibiaeA biomechanical investigation: I. Method and general patterns of variation. American Journal of Physical Anthropology 60(3):359-381.

Ruff CB, Holt BM, Niskanen M, Saldék V, Berner M, Garofalo E, Garvin HM, Hora M, Maijanen H, Niinimäki S, Salo K, Schuplerová E, Tompkins D. 2012. Stature and body mass estimation from skeletal remains in the European Holocene. American Journal of Physical Anthropology 148:601-617.

Ruff CB, Holt BM, Trinkaus E. 2006.Who's afraid of the big bad Wolff?: "Wolff's Law" and bone functional adaptation. American Journal of Physical anthropology 129(4):484-498. DOI:10.1002/1jpa.20371

Ruff CB, Trinkaus E, Walker A, Larson CS. 1993. Postcranial robusticity in Homo. I: Temporal trends and mechanical interpretation. American Journal of Physical Anthropology 9(1):125-136. DOI: 10.1002/ajpa.1330910103

Sammarco VJ. 2000. Os Acromiale: Frequency, anatomy and clinical implications. Journal of Bone and Joint Surgery 82-A(3):394-400.

Sassman, KE. 2004. Complex hunter-gatherers in evolution and history: a North American perspective. Journal of Archaeological Research 12(3):227-280.

Schoeninger MJ. 2009. Stable Isotope Evidence for the Adoption of Maize Agriculture. Current Anthropology 50(5):633-640.

Schoeninger MJ, Peebles CS. 1981. Effect of Mollusk Eating on Human Bone Strontium Levels. Journal of Archaeological Science 8:391-397. 
Schoeninger MJ, Sattenspiel L, Schurr MR. 2000. Transition at Moundville: A Question of Collapse. In Bioarchaeological Studies of Life in the Age of Agriculture: A View from the Southeast, Lambert PM (ed.). University of Alabama Press:

Tuscaloosa; 63-77.

Schwartz, JH. 1995. Skeleton Keys: An introduction to human skeletal morphology, development, and analysis. Oxford University Press: New York.

Smith MO. 2006. Treponemal Disease in the Middle Archaic to Early Woodland Periods of the Western Tennessee River Valley. American Journal of Physical Anthropology 131:205-217.

Steadman DW. 1998.The Population Shuffle in the Central Illinois Valley: A diachronic model of Mississippian biocultural interactions. World Archaeology 30(2):306326.

Stenlund D, Goldie I, Hagberg M, Hogstedt C, Marions O. 1992. Radiographic osteoarthritis in the acromioclavicular joint resulting from manual work or exposure to vibration. British Journal of Industrial Medicine 49:588-593.

Stirland AJ. 1996. Patterns of trauma in a unique medieval parish cemetery. International Journal of Osteoarchaeology 6: 92-100. DOI: 10.1002

Stirland AJ, Waldron T. 1997. Evidence for activity related markers in the vertebrae of the crew of the Mary Rose. Journal of Archaeological Science 24: 329-335.

Stock, J.T. 2006 Hunter-Gatherer Postcranial Robusticity Relative to Patterns of Mobility, Climatic Adaptation and Selection for Tissue Economy. American Journal of Physical anthropology 131: 194-204. DOI: 10.1002/ajpa.20398

Stock JT, Shaw CN. 2007 Which Measures of Diaphyseal Robusticity are Robust? A Comparison of External Methods of Quantifying Strength of Long Bone Diaphyses to Cross-Sectional Geometric Properties. American Journal of Physical Anthropology 134:412-423. DOI: 10.1002/ajpa.20686

Thomas C. 1894.Report on the Mound Exploration of the Bureau of Ethnology. Twelfth Annual Report of the Bureau of Ethnology to the Secretary of the Smithsonian Institute, 1890-1891. Smithsonian Institute: Washington; 17-742.

Trinkaus E. 1975. Squatting among the Neanderthals: A Problem in the behavioral interpretation of skeletal morphology. Journal of archaeological science 2:327351.

Via AG, De Cupis M, Spoliti M, Oliva F. 2013. Clinical and Biological Aspects of Rotator Cuff Tears. Muscles, Ligaments and Tendons Journal 3(2):70-79.

Villotte S, Castex D, Couallier V, Dutor O, Knüsel CJ, Henry-Gambier D. 2010. Enthesopathies as occupational stress markers: Evidence from the upper limb. American Journal of Physical Anthropology 142: 224-234. DOI: 10.1002/ajpa.21217

Villotte S, Knüsel CJ. 2012. Understanding Entheseal Changes: Definition and Life Course Changes. International Journal of Osteoarchaeology 23:135-146.

Waldron HA. 1991. Prevalence and distribution of osteoarthritis in a population from Georgian and Early Victorian London. Annals of Rheumatic Diseases 50:301-307.

Waldron T. 1995. Changes in the distribution of osteoarthritis over historical time. International Journal of Osteoarchaeology 5:385-389.

Waldron T. 2012. Joint Disease. In A Companion to Paleopathology. Grauer A (ed.). Blackwell Publishing Ltd: Oxford; 513-530. 
Weiss E. 2004. Understanding muscle markers: lower limbs. American Journal of Physical Anthropology 125: 232-238. DOI: 10.1002/ajpa.10397

Weiss E. 2007. Muscle markers revisited: activity pattern reconstruction with controls in a Central California Amerind population. American Journal of Physical Anthropology 133: 931-940. DOI:10.1002/ajpa.20607

Wescott DJ, Cunningham DL. 2006. Temporal changes in Arikara humeral and femoral cross-sectional geometry associated with horticultural intensification. Journal of Archaeological Science 33: 1022-1036.

White TD, Folkens P. 2005. The Human Bone Manual. Elsevier Academic Press: Boston. Wolff J. 1892. Das Gesetz der Transformation der Knochen. A. Hirschwald: Berlin.

Wood JW, Milner GR, Harpening HC, Weiss KM. The Osteological paradox: Problems of inferring prehistoric health from skeletal samples. Current Anthropology 33(4):343-370

Yerkes RW.2005. Bone chemistry, body parts and growth markers: Evaluating Ohio Hopewell and Cahokia Mississippian seasonality, subsistence, ritual and feasting. American Antiquity 70(2):241-265. DOI:10.2307'400035703

Zumwalt A, Ruff C, Wilczak C. 2000. Primate muscle insertions: what does size tell you? American Journal of Physical Anthropology 30: 331 (abstract). 
APPENDIX A

DEMOGRAPHICS FOR ENTHESEAL CHANGE BY SITE 


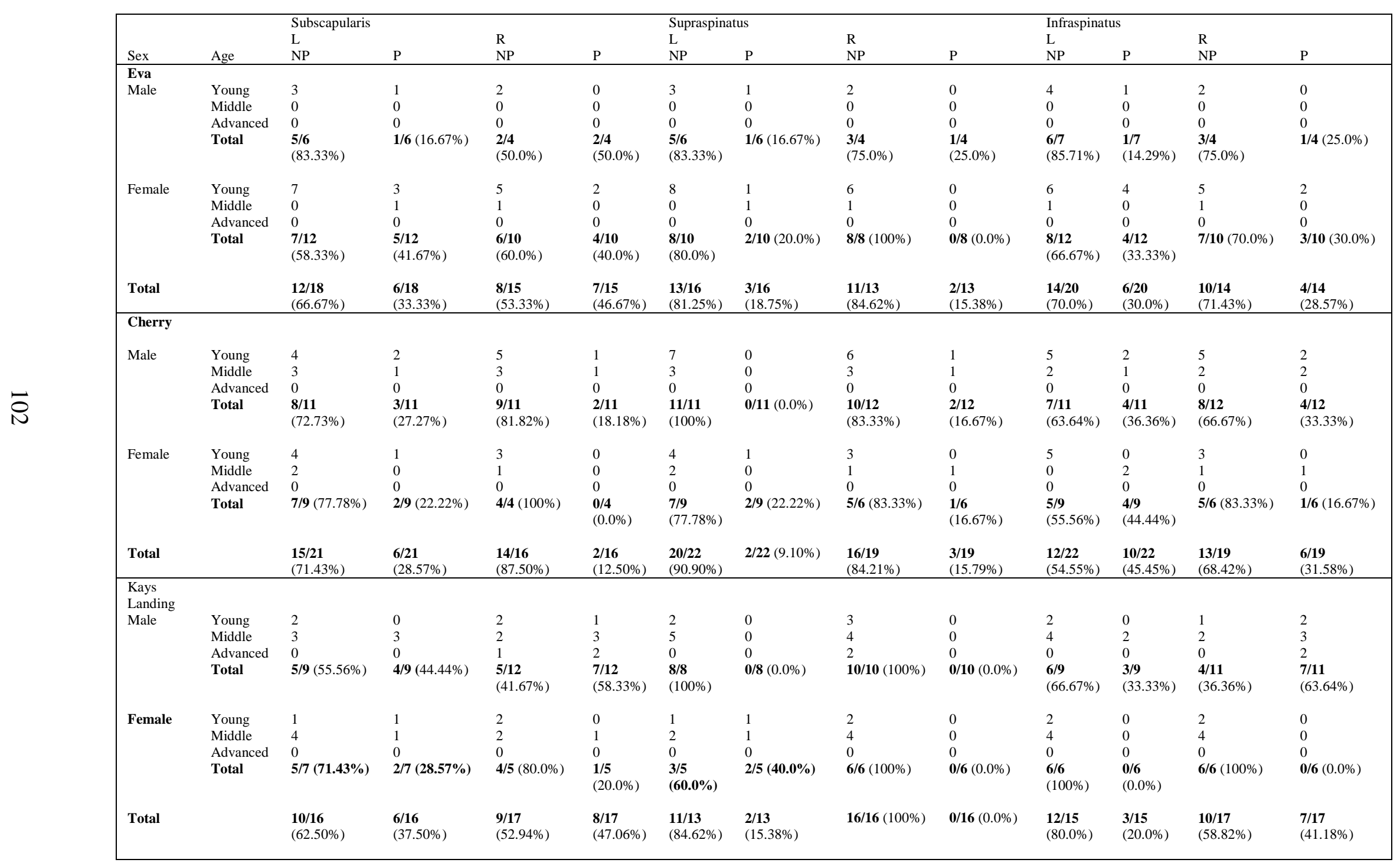




\begin{tabular}{|c|c|c|c|c|c|c|c|c|c|c|c|c|c|}
\hline Sex & Age & $\begin{array}{l}\text { Subscapularis } \\
\text { L } \\
\text { NP }\end{array}$ & $\begin{array}{l}\text { Supraspinatus } \\
\mathrm{R} \\
\mathrm{P} \\
\end{array}$ & $\begin{array}{l}\text { Infraspinatus } \\
\text { L } \\
\text { NP } \\
\end{array}$ & Sex & Age & $\begin{array}{l}\text { Subscapularis } \\
\text { L } \\
\text { NP } \\
\end{array}$ & $\begin{array}{l}\text { Supraspinatus } \\
\mathrm{R} \\
\mathrm{P} \\
\end{array}$ & $\begin{array}{l}\text { Infraspinatus } \\
\mathrm{L} \\
\mathrm{NP} \\
\end{array}$ & Sex & Age & $\begin{array}{l}\text { Subscapularis } \\
\text { L } \\
\text { NP }\end{array}$ & $\begin{array}{l}\text { Supraspinatus } \\
\mathrm{R} \\
\mathrm{P} \\
\end{array}$ \\
\hline \multicolumn{14}{|l|}{ Thompson } \\
\hline Male & Young & 2 & 2 & 1 & 1 & 3 & 0 & 3 & 0 & 3 & 0 & 2 & 0 \\
\hline & Middle & 4 & 2 & 1 & 4 & 4 & 1 & 3 & 0 & 4 & 1 & 2 & 1 \\
\hline & Advanced & 0 & 0 & 0 & 0 & 0 & 0 & 0 & 0 & 0 & 0 & 0 & 0 \\
\hline & Total & $\begin{array}{l}\mathbf{8 / 1 3} \\
(61.54 \%)\end{array}$ & $\begin{array}{l}\mathbf{5 / 1 3} \\
(38.46 \%)\end{array}$ & $\begin{array}{l}\mathbf{2 / 9} \\
(22.22 \%)\end{array}$ & $\begin{array}{l}7 / 9 \\
(77.78 \%)\end{array}$ & $\begin{array}{l}7 / 10 \\
(70.0 \%)\end{array}$ & $\mathbf{3 / 1 0}(30.0 \%)$ & $6 / 7(85.71 \%)$ & $\begin{array}{l}\mathbf{1} / 7 \\
(14.29 \%)\end{array}$ & $\begin{array}{l}\mathbf{1 0 / 1 1} \\
(90.91 \%)\end{array}$ & $\begin{array}{l}\mathbf{1 / 1 1} \\
(9.09 \%)\end{array}$ & $\mathbf{2 / 6}(33.33 \%)$ & $\mathbf{4 / 6}(66.67 \%)$ \\
\hline Female & Young & 1 & 0 & 2 & 1 & 2 & 0 & 2 & 1 & 1 & 1 & 2 & 1 \\
\hline & Middle & 7 & 3 & 8 & 4 & 8 & 0 & 10 & 1 & 3 & 4 & 8 & 4 \\
\hline & Advanced & 0 & 0 & 0 & 0 & 0 & 0 & 0 & 0 & 0 & 0 & 0 & 0 \\
\hline & Total & $\begin{array}{l}\mathbf{1 5 / 2 1} \\
(71.43 \%)\end{array}$ & $\begin{array}{l}\mathbf{6} / 21 \\
(28.57 \%)\end{array}$ & $\begin{array}{l}\mathbf{1 6 / 2 5} \\
(64.0 \%)\end{array}$ & $\begin{array}{l}\mathbf{9} / 25 \\
(36.0 \%)\end{array}$ & $\begin{array}{l}\mathbf{1 7 / 1 7} \\
(100 \%)\end{array}$ & $\mathbf{0} / \mathbf{1 7}(0.0 \%)$ & $\begin{array}{l}\mathbf{2 1 / 2 3} \\
(91.30 \%)\end{array}$ & $\begin{array}{l}\mathbf{2 / 2 3} \\
(8.70 \%)\end{array}$ & $\begin{array}{l}\mathbf{1 3 / 1 9} \\
(68.42 \%)\end{array}$ & $\begin{array}{l}\mathbf{6 / 1 9} \\
(31.58 \%)\end{array}$ & $\begin{array}{l}\mathbf{1 6 / 2 4} \\
(66.67 \%)\end{array}$ & $\begin{array}{l}\mathbf{8 / 2 4} \\
(33.33 \%)\end{array}$ \\
\hline Total & & $\begin{array}{l}\mathbf{2 5 / 3 8} \\
65.79 \%)\end{array}$ & $\begin{array}{l}\mathbf{1 3 / 3 8} \\
(34.21 \%)\end{array}$ & $\begin{array}{l}\mathbf{1 9 / 3 8} \\
(50.0 \%)\end{array}$ & $\begin{array}{l}\mathbf{1 9 / 3 8} \\
(50.0 \%)\end{array}$ & $\begin{array}{l}\mathbf{2 6 / 3 0} \\
(86.67 \%)\end{array}$ & $\begin{array}{l}\mathbf{4 / 3 0} \\
(13.33 \%)\end{array}$ & $\begin{array}{l}\mathbf{3 1 / 3 5} \\
(88.57 \%)\end{array}$ & $\begin{array}{l}\mathbf{4 / 3 5} \\
(11.43 \%)\end{array}$ & $\begin{array}{l}\mathbf{2 5 / 3 3} \\
(75.76 \%)\end{array}$ & $\begin{array}{l}\mathbf{8 / 3 3} \\
(24.24 \%)\end{array}$ & $\begin{array}{l}\mathbf{2 1 / 3 4} \\
(61.76 \%)\end{array}$ & $\begin{array}{l}\mathbf{1 3 / 3 4} \\
(38.24 \%)\end{array}$ \\
\hline
\end{tabular}


APPENDIX B

DEMOGRAPHICS FOR ENTHESEAL CHANGE BY PERIOD 


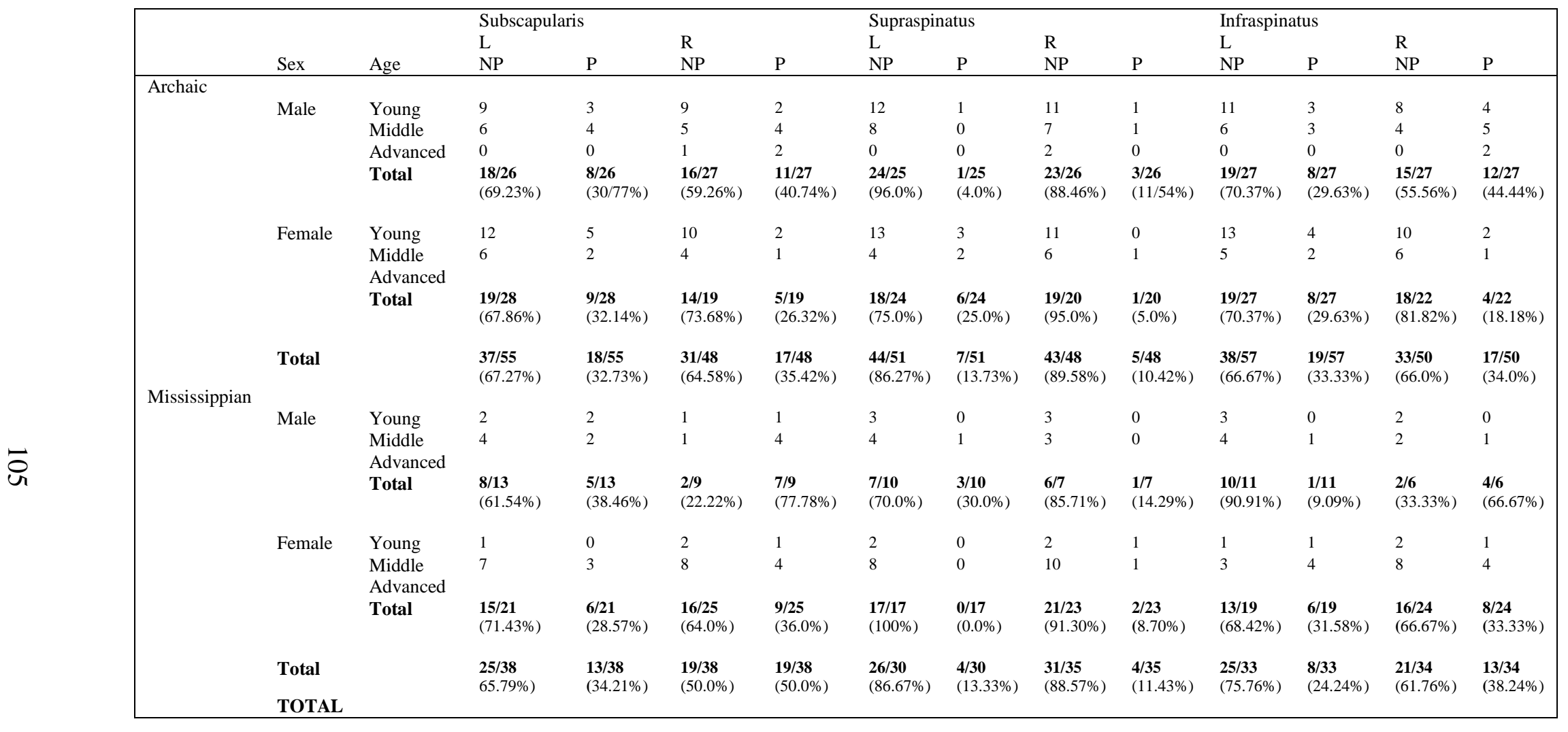

